WASHINGTON PHASE II FISH DIVERSION SCREEN EVALUATIONS IN THE YAKIMA RIVER BASIN, 1999

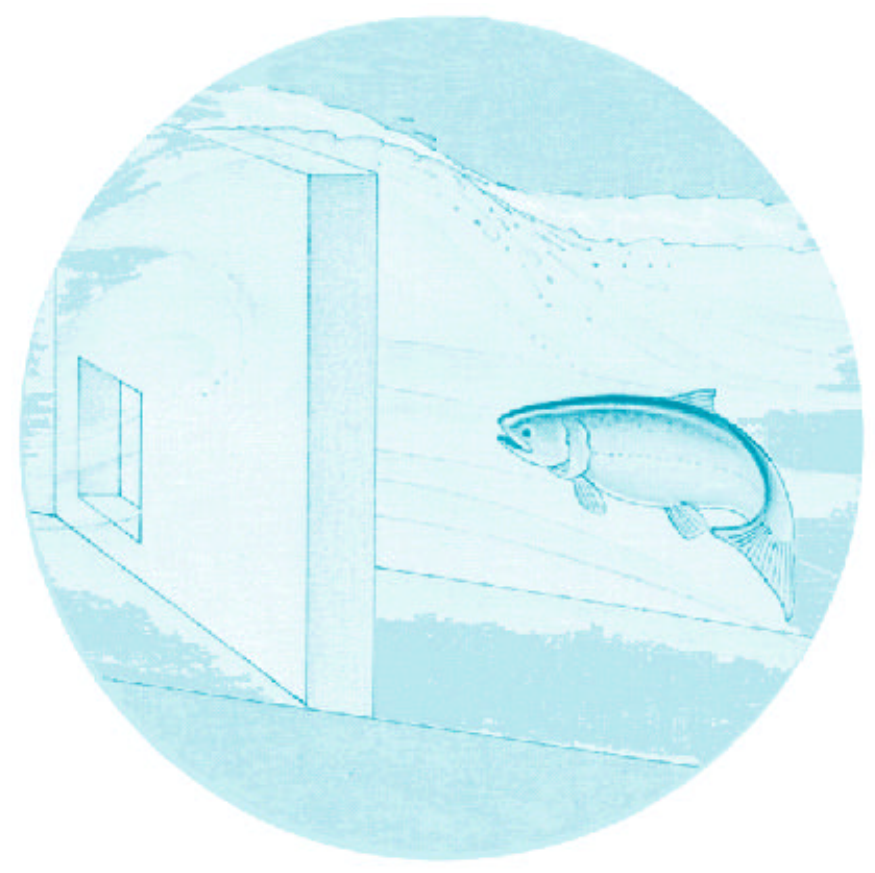

DOE/BP-00000652-4 
This report was funded by the Bonneville Power Administration (BPA), U.S. Department of Energy, as part of BPA's program to protect, mitigate, and enhance fish and wildlife affected by the development and operation of hydroelectric facilities on the Columbia River and its tributaries. The views of this report are the author's and do not necessarily represent the views of BPA.

This document should be cited as follows:

Blanton, S.L., G.A. McMichael, D.A. Neitzel - Pacific Northwest National Laboratory, Washington Phase II Fish

Diversion Screen Evaluations in the Yakima River Basin, 1999, Report to Bonneville Power Administration, Contract

No. 00000652, Project No. 198611800, 57 electronic pages (BPA Report DOE/BP-00000652-4)

This report and other BPA Fish and Wildlife Publications are available on the Internet at:

\section{http://www.efw.bpa.gov/cgi-bin/efw/FW/publications.cgi}

For other information on electronic documents or other printed media, contact or write to:

Bonneville Power Administration

Environment, Fish and Wildlife Division

P.O. Box 3621

905 N.E. 11th Avenue

Portland, OR 97208-3621

Please include title, author, and DOE/BP number in the request. 


\title{
Washington Phase II Fish Diversion Screen Evaluations in the Yakima River Basin, 1999
}

\author{
Prepared by: \\ S.L. Blanton \\ G.A. McMichael \\ D.A. Neitzel \\ Pacific Northwest National Laboratory \\ Richland, Washington
}

\author{
Prepared for: \\ U.S. Department of Energy \\ Bonneville Power Administration \\ Environment Fish and Wildlife \\ P.O. Box 3621 \\ Portland, Oregon 97208-3621 \\ Project Number 1986-118-00 \\ Task Order DE-AT79-9430373BPA \\ Contract Number 00000652
}

April 2000 
[left blank with purpose] 


\section{Summary}

Pacific Northwest National Laboratory (PNNL) evaluated 20 Phase II screen sites in the Yakima River Basin as part of a multi-year study for the Bonneville Power Administration (BPA) on the effectiveness of fish screening devices. The sites were examined to determine if they were being effectively operated and maintained to provide fish a safe, efficient return to the Yakima River. Data were collected to determine if velocities in front of the screens and in the bypass met current National Marine Fisheries Service (NMFS) criteria to promote safe and timely fish bypass and whether bypass outfall conditions allowed fish to safely return to the river.

In general, water velocity conditions at the screen sites met fish passage criteria set forth by the NMFS. Although velocities often fluctuated from one sampling location to the next, average sweep velocities typically exceeded approach velocities and increased toward the bypass. Mean approach velocities were below the NMFS criteria of $\leq 0.4$ feet per second (fps) at most sites (Table 1). Based on our observations in 1999, we believe that most facilities were efficiently protecting juvenile fish from entrainment, impingement, or migration delay.

Most screens were properly sealed to prevent fish entrainment and injury, although potential problems were identified at several screen sites. Six sites (one fewer than the seven sites identified in 1998) had loose or damaged seals that might have allowed fish to be entrained (Table 1). Other sites still had spaces larger than 3/32 in. where small fish could possibly pass into the irrigation canal.

Submergence levels at the drum screen sites $(\mathrm{N}=12)$ were outside of established criteria (between 65 and $85 \%$ submerged) in $39 \%$ of the site evaluations. Over half of the drum screen facilities were always within the established criteria for drum submergence (Table 1). Water depths at the outfall pipe were acceptable at all sites in 1999 (Table 1). Screens were generally well maintained. Automated cleaning brushes generally functioned properly, chains and other moving parts were well greased, and inoperative and algae-covered drum screens were repaired and cleaned, typically within 1 month of notification (unless the severity of the problem required removal of the screens, in which case they were repaired following the irrigation season), by the Washington Department of Fish and Wildlife's Screen Shop staff. Removal of sediment build-up and accumulated leafy and woody debris are areas where improvement was seen in 1999. In 1998, 58\% of the sites evaluated had excessive silt or debris problems, while in 1999 , only $30 \%$ of the sites had these problems. 
Table 1. Summary of problem areas identified at Yakima River Basin Phase II screen sites in 1997 (circle), 1998 (diamond) and 1999 (square). The different symbols are intended to make it easier to distinguish between the different years.

\begin{tabular}{|c|c|c|c|c|c|c|c|c|c|c|c|c|c|c|c|c|c|c|c|}
\hline \multirow[b]{2}{*}{$\begin{array}{l}\text { Screen } \\
\text { Type }\end{array}$} & \multirow[b]{2}{*}{$\begin{array}{l}\text { Screen } \\
\text { Site }\end{array}$} & \multicolumn{3}{|c|}{ 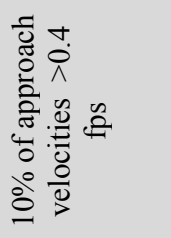 } & \multicolumn{3}{|c|}{ 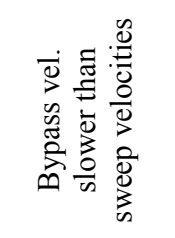 } & \multicolumn{3}{|c|}{ 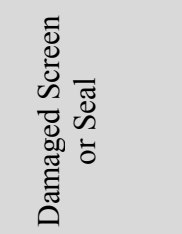 } & \multicolumn{3}{|c|}{ 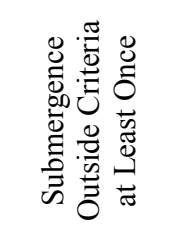 } & \multicolumn{3}{|c|}{ 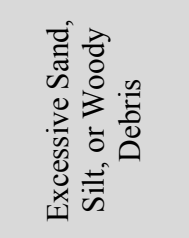 } & \multicolumn{3}{|c|}{ 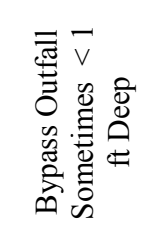 } \\
\hline & & $\hat{\check{\alpha}}$ & $\stackrel{\infty}{2}$ & ลे & aे & $\stackrel{\infty}{\circ}$ & ڤे & $\hat{\sigma}$ & $\stackrel{\infty}{2}$ & ڤे & $\hat{\sigma}$ & $\begin{array}{l}\infty \\
\curvearrowright\end{array}$ & ลे & $\hat{\sigma}$ & $\stackrel{\infty}{\circ}$ & ڤे & $\hat{a}$ & $\stackrel{\infty}{2}$ & よे \\
\hline \multirow[t]{12}{*}{$\begin{array}{l}\text { Drum } \\
\text { screens }\end{array}$} & $\begin{array}{l}\text { Bachelor } \\
\text { Hatton }\end{array}$ & $\bullet$ & $\diamond$ & & $\bullet$ & 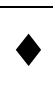 & & $\bullet$ & $\checkmark$ & घ & & $\diamond$ & $\mathbf{\square}$ & $\bullet$ & $\bullet$ & & & & \\
\hline & Clark & & & & & & & & & & $\bullet$ & $\diamond$ & & & 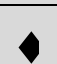 & & • & & \\
\hline & Congdon & • & & & & $\diamond$ & & $\bullet$ & & & $\bullet$ & & a & • & & & & & \\
\hline & $\begin{array}{l}\text { Kelly } \\
\text { Lowry }\end{array}$ & & & & & & & & $\checkmark$ & & $\bullet$ & & & $\bullet$ & & 口 & & & \\
\hline & Lindsey & & 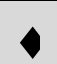 & & & & & & $\checkmark$ & च & $\bullet$ & $\diamond$ & & - & & & - & & \\
\hline & Lower WIP & & & & & & 口 & & & & $\bullet$ & & $\mathbf{\square}$ & $\bullet$ & 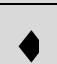 & च & & & \\
\hline & $\begin{array}{l}\text { Naches } \\
\text { Cowiche }\end{array}$ & & & घ & & & & & & & $\bullet$ & & & & $\bullet$ & & & & \\
\hline & $\begin{array}{l}\text { New } \\
\text { Cascade }\end{array}$ & & & & & & & - & & घ & & & $\mathbf{\square}$ & & & & & & \\
\hline & $\begin{array}{l}\text { Snipes } \\
\text { Allen }\end{array}$ & & & & & & & • & & & $\bullet$ & & घ & & & & & & \\
\hline & Taylor & & & & & & & - & & & $\bullet$ & $\bullet$ & & $\bullet$ & 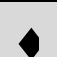 & & & & \\
\hline & $\begin{array}{l}\text { Toppenish } \\
\text { Pump }\end{array}$ & - & $\checkmark$ & 口 & & & & $\bullet$ & $\checkmark$ & च & & & & • & $\bullet$ & Ш & & & \\
\hline & WIP Upper & • & & & $\bullet$ & 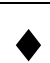 & & $\bullet$ & & घ & & $\diamond$ & & • & 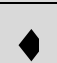 & 口 & $\bullet$ & & \\
\hline \multirow{7}{*}{$\begin{array}{l}\text { Vertical } \\
\text { plate } \\
\text { screens }\end{array}$} & Bull & $\bullet$ & & $\square$ & & & & & & & $\bullet$ & $\diamond$ & & & & & & & \\
\hline & $\begin{array}{l}\text { Ellensburg } \\
\text { Mill }\end{array}$ & & & $\square$ & & 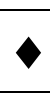 & $\boldsymbol{\square}$ & $\bullet$ & & घ & & & & & $\bullet$ & 口 & & & \\
\hline & Fruitvale & $\bullet$ & & & & & & & & & $\bullet$ & $\diamond$ & $\mathbf{\square}$ & & $\diamond$ & & $\bullet$ & & \\
\hline & $\begin{array}{l}\text { Naches } \\
\text { Selah }\end{array}$ & & & घ & & & & - & $\checkmark$ & 口 & & & & & $\bullet$ & & & $\diamond$ & \\
\hline & Union Gap & & & Ш & • & & $\boldsymbol{\square}$ & & & $\mathbf{\square}$ & & & & & & & & & \\
\hline & $\begin{array}{l}\text { Yakima } \\
\text { Tieton }\end{array}$ & $\bullet$ & & & & & & & $\checkmark$ & & & & & & & & & & \\
\hline & Younger & & & & & & & & & & & & & & & & & & \\
\hline $\begin{array}{l}\text { Vertical } \\
\text { traveling } \\
\text { screen }\end{array}$ & Gleed & & & घ & & & & - & $\checkmark$ & & & & & $\bullet$ & $\bullet$ & E & & & \\
\hline
\end{tabular}


Continued periodic, regular screen evaluations will increase the effectiveness of screen operation and maintenance practices by confirming the effectiveness (or ineffectiveness) of screen operating procedures at individual sites. Where procedures are being followed and problems still occur, evaluation results will suggest means to better protect fish at screening facilities. There has been a progressive improvement in the design, construction, maintenance, and effectiveness of these Phase II fish screen facilities during the past several years, in part, as a result of regular screen evaluations and the rapid feedback of information necessary to improve operations of these important fish protection devices. 


\section{Contents}

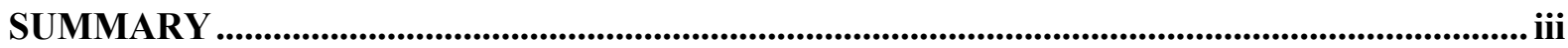

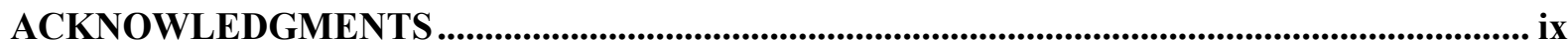

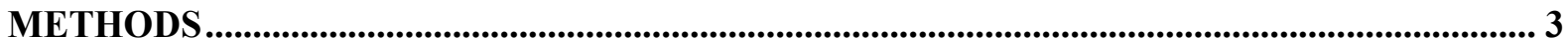

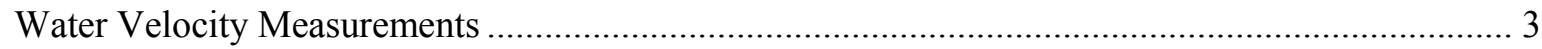

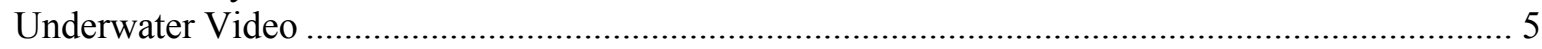

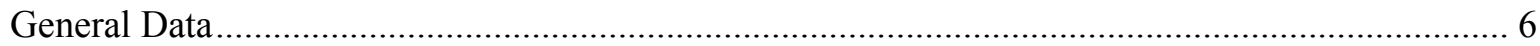

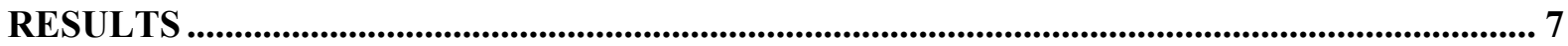

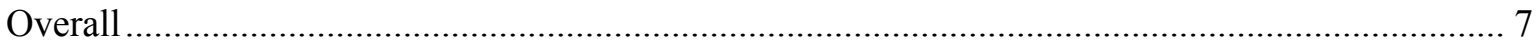

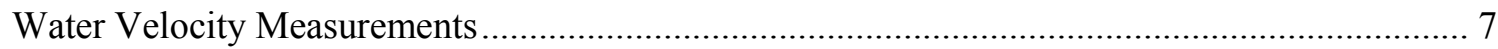

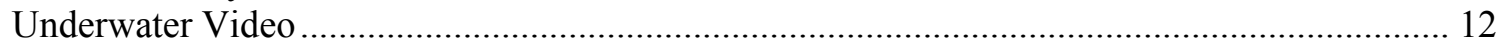

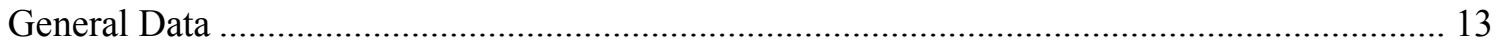

Screen Submergence Levels ............................................................................ 13

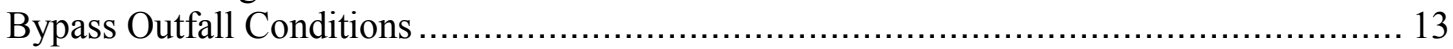

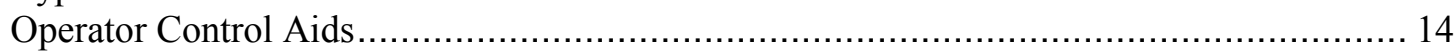

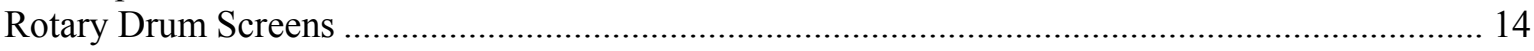

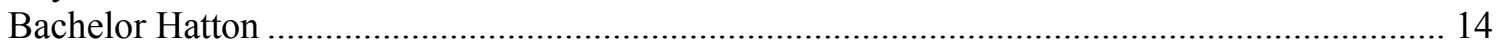

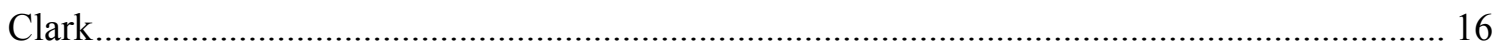

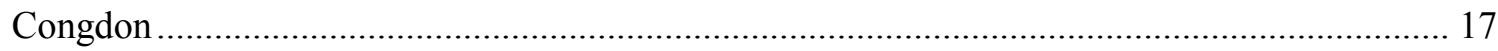

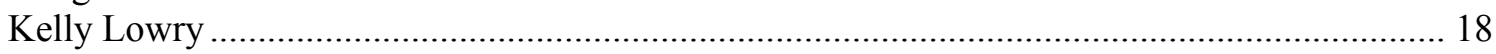

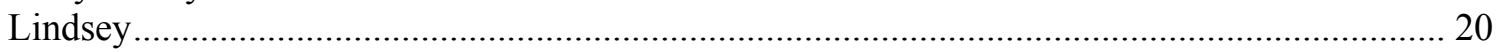

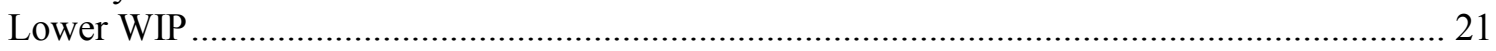

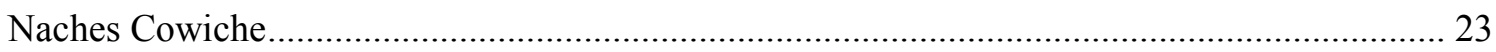

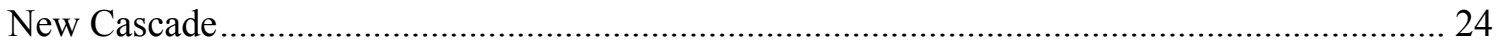

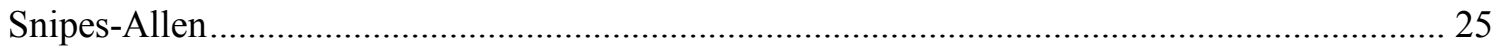

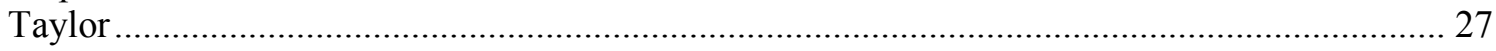

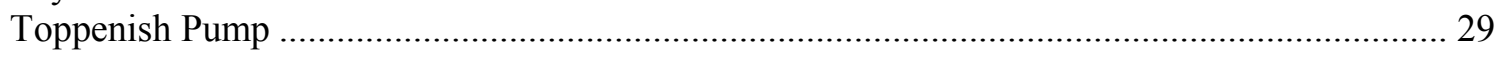

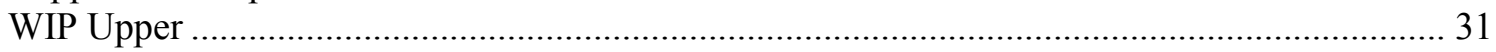

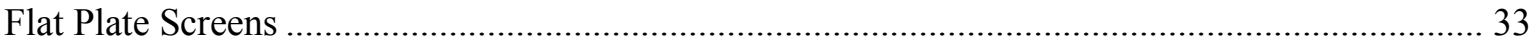

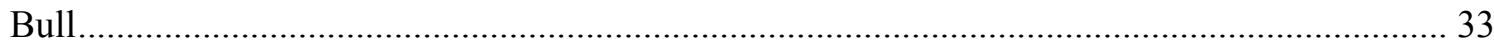

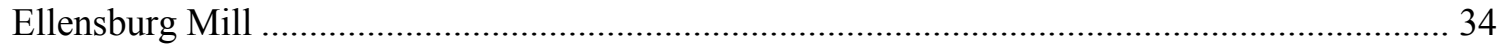

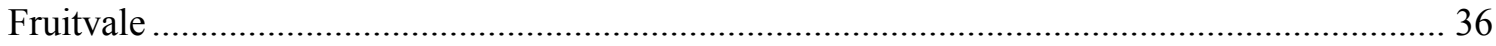

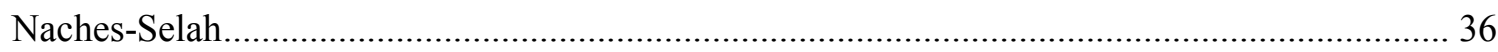

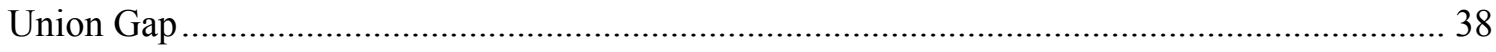

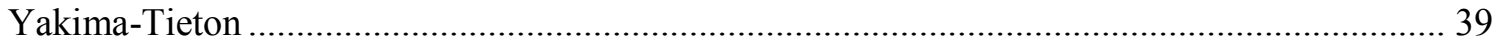

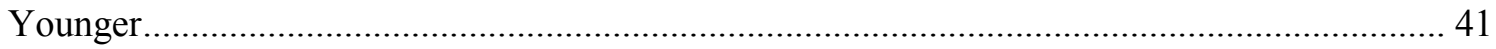

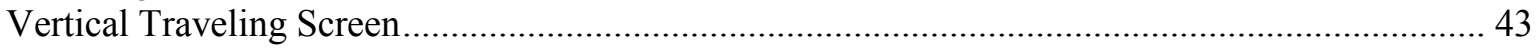

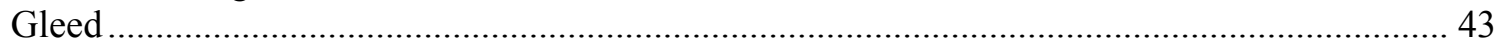

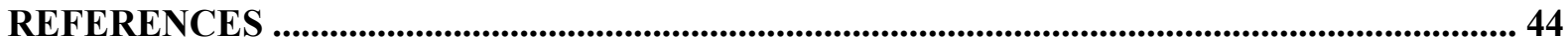




\section{Figures}

Figure 1. Yakima River Basin phase II screening facilities.

Figure 2. Percentage of measurements at Yakima Basin Phase II screen sites that met or did not meet NMFS approach velocity criteria of $\leq 0.4 \mathrm{fps}$ in 1999 . Zero/negative flows were generally created by eddies in front of the screens.

Figure 3. Mean approach, sweep, and bypass velocities (fps) at Phase II fish screen facilities in the Yakima Basin in 1999.

Figure 4. Water velocities and sediment depths at Bachelor Hatton, 5/12/99................................ 15

Figure 5. Water velocities and sediment depths at Bachelor Hatton, 7/7/99 ................................. 15

Figure 6. Gap in bottom seal of screen number 2 at Bachelor Hatton, 5/12/99.............................. 16

Figure 7. Water velocities and sediment depths at Congdon, 5/13/99 ............................................. 17

Figure 8. Water velocities and sediment depths at Congdon, 7/14/99 ......................................... 18

Figure 9. Water velocities and sediment depths at Kelly Lowry, 5/14/99 ....................................... 19

Figure 10. Water velocities and sediment depths at Kelly Lowry, 7/20/99...................................... 19

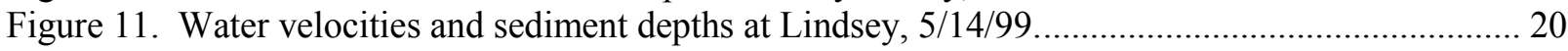

Figure 12. Water velocities and sediment depths at Lindsey, 7/20/99 .......................................... 21

Figure 13. Water velocities and sediment depths at Lower WIP on 5/12/99................................... 22

Figure 14. Water velocities and sediment depths at Lower WIP on 8/4/99.................................... 22

Figure 15. Water velocities and sediment depths at Naches Cowiche, 5/13/99............................... 23

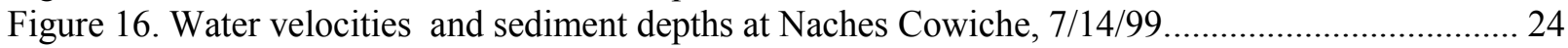

Figure 17. Water velocities and sediment depths at New Cascade, 7/22/99 ...................................... 25

Figure 18. Water velocities and sediment depths at Snipes Allen, 5/14/99 ...................................... 26

Figure 19. Water velocities and sediment depths at Snipes Allen, 8/4/99 ........................................ 27

Figure 20. Water velocities and sediment depths at Taylor, 5/19/99............................................ 28

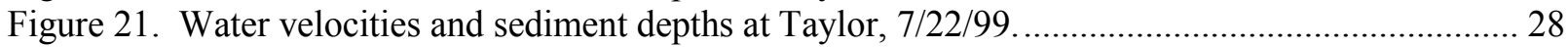

Figure 22. Water velocities and sediment depths at Toppenish Pump, 5/19/99. .............................. 29

Figure 23. Water velocities and sediment depths at Toppenish Pump, 7/22/99 ............................... 30

Figure 24. Trash rack at Toppenish Pump site, note separation of metal grate and concrete................. 31

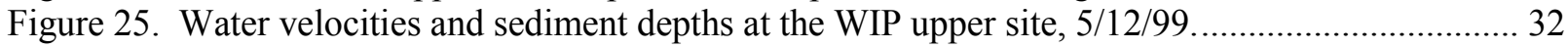

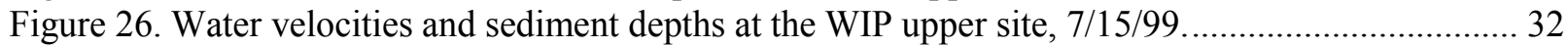

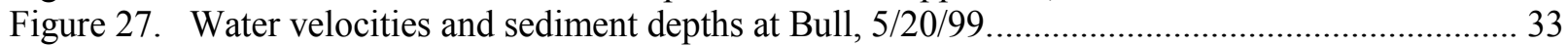

Figure 28. Water velocities and sediment depths at Bull, 7/23/99 ............................................... 34

Figure 29. Water velocities and sediment depths at Ellensburg Mill, 5/19/99. .................................. 35

Figure 30. Water velocities and sediment depths at Ellensburg Mill, 7/23/99 .................................. 35

Figure 31. Water velocities and sediment depths at Naches Selah, 5/17/99 ................................... 37

Figure 32. Water velocities and sediment depths at Naches Selah, 8/4/99 ..................................... 37

Figure 33. Water velocities and sediment depths at Union Gap, 5/13/99 _......................................... 38

Figure 34. Water velocities and sediment depths at Union Gap, 7/14/99........................................ 39

Figure 35. Water velocities and sediment depths at Yakima Tieton, 5/17/99.................................... 40

Figure 36. Water velocities and sediment depths at Yakima Tieton, 7/21/99..................................... 40

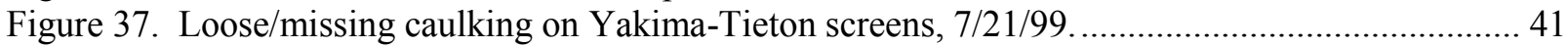

Figure 38. Water velocities and sediment depths at Younger, 5/20/99 .......................................... 42

Figure 39. Water velocities and sediment depths at Younger, 7/23/99 ............................................ 42

Figure 40. Water velocities and sediment depths at Gleed, 7/20/99 ............................................. 43 


\section{Tables}

Table 1. Summary of problem areas identified at Yakima River Basin Phase II screen sites in 1997, 1998 and 1999.

iv

Table 2. Percent of approach velocity measurements that exceeded the NMFS criteria of 0.4 fps by screen site in 1997, 1998, and 1999.

Table 3. Mean sweep and approach velocities ( \pm standard deviation) at Phase II fish screen facilities in the Yakima Basin in 1999. ......................................................................... 11 


\section{Acknowledgments}

The successful completion of this project depended on the involvement and cooperation of many people. Ken Barnhart, Bonneville Power Administration (BPA), directed the project. John Easterbrooks, Washington Department of Fish and Wildlife (WDFW), provided valuable background information on the sites and also comments on the operation and maintenance of individual sites. Mickie Chamness and Scott Abernethy, Pacific Northwest National Laboratory (PNNL), and student Rachel Prince assisted during field evaluations and/or data interpretation. 


\section{Introduction}

Over the years, irrigation has played an important role in the development of the middle Columbia River Basin. Water has been diverted from western rivers since the mid-1850's to irrigate crops. During the 1920's, some of these diversions were equipped with fish protection devices, but it wasn't until the Mitchell Act of 1938 provided funding to protect fish that screening irrigation diversions and evaluating their effectiveness truly got underway (Bryant and Parkhurst 1950) .

In more recent history, the Bonneville Power Administration (BPA) and the Northwest Power Planning Council (Council) expanded screening efforts to protect and enhance fish populations. The Council's Columbia River Fish and Wildlife Program (Program) lists fish protection through effective screening of irrigation diversions as an essential element in their plan to restore declining steelhead (Oncorhynchus mykiss) and salmon runs (NPPC 1984, 1987, 1994).

Research on the effectiveness of fish screening devices initiated changes in design and operating procedures of screening facilities over the years. For example, maximum allowable screen size openings decreased as protecting fish at their earliest developmental stages became a national concern. Such new requirements for fish protection are developed by the National Marine Fisheries Service (NMFS) and adopted by individual state agencies. Changes in the regulations require that older, less-efficient screening facilities be updated or replaced. Through a regional Conservation and Electric Power Plan implemented under the Pacific Northwest Electric Power Planning and Conservation Act, the BPA and the Bureau of Reclamation (BoR) funded construction of and improvements to fish passage and protection facilities at irrigation diversions in the Yakima River Basin. Construction and enhancements of the Phase II screens are part of this plan. In addition, BPA has established a monitoring and evaluation program to ensure that new and updated screening facilities meet current fish protection standards.

Pacific Northwest National Laboratory (PNNL) staff have conducted a number of fish screen evaluations in the Yakima Basin since 1985. Initially, staff monitored Phase I screening facilities to determine whether fish that entered irrigation canals were diverted back to the river safely (Neitzel et al. 1985, 1986, 1988, 1990a, and 1990b). Additional studies examined water velocities in front of the screens to determine whether NMFS criteria were being met (Abernethy et al. 1990). Two studies conducted at PNNL's Aquatic Laboratory in Richland, Washington, used modular drum screens constructed by the Washington Department of Fish and Wildlife (WDFW) to determine fish survival through submerged orifices and the relative effectiveness of two screen configurations at bypassing fish (Abernethy et al. 1996, Neitzel et al. 1997). The 
methods developed while conducting these studies were incorporated into Phase II screen site surveys conducted in 1997 and 1998 (Blanton et al. 1998, 1999).

In 1997, 19 Phase II sites were evaluated. Those evaluations addressed three main questions:

1. Are screens designed, operated, and maintained to meet NMFS criteria standards over a wide range of conditions?

2. Do velocities/flows meet NMFS criteria?

3. Are screens effective at protecting fish from injury and from unnecessary migration delay?

Surveys were conducted at the same 19 Phase II sites in 1998 to evaluate operations and maintenance of the screens over time and changing water conditions. In 1999, a total of 20 sites were evaluated; the same 19 sites that were sampled in 1997 and 1998, as well as one additional new site (Younger) in 1999. This report presents the results of the 1999 surveys. 


\section{Methods}

Twenty operating screen sites in the Yakima, Naches, and Tieton river basins were evaluated between May 12 and August 4, 1999 (Figure 1). All of the 20 sites were visited twice during 1999. The two rounds of evaluations were conducted during May and late July/early August 1999. Three types of data were collected. These included water velocity measurements, underwater video, and general data (i.e., screen submergence, bypass conditions, fish presence, operator aids), as described below.

\section{Water Velocity Measurements}

\section{Equipment}

Water velocities in front of the screens and in the bypass were measured with a MarshMcBirney Model $511^{\circledR}$ electromagnetic water current meter. The meter used a bi-directional probe that allowed measurement of flows in two directions (approach and sweep) simultaneously. Output was read visually from a panel gage. The probe was securely mounted to a horizontal metal arm that extended approximately 12 in. from a vertical pole. The length of the horizontal arm and its position on the vertical pole were adjustable. The probe support assembly was positioned at least 12 in. downstream or outside the probe's sensors to minimize interference from the vertical pole when taking velocity readings.

\section{Probe Positioning}

Velocity measurements were taken in front of all screens. The vertical pole was placed close to the front of the screen, but was never in contact with the screen face. The bottom of the pole rested on the concrete forebay floor (usually on the raised sill), but the pole was not allowed to come in contact with metal (e.g., walking platform, gantry, or girder) to reduce the likelihood of electrical interference. The probe was pointed upstream and was positioned within 3 in. of the screen face. Because the screens are constructed at an angle to the canal flow, all measurements were taken with the probe orientation parallel (sweep) and perpendicular (approach) to the screen face, not to canal flow. Measurements were taken across the screen face at 0.2 and 0.8 of the water depth when the forebay depth was $\geq 4 \mathrm{ft}$. Measurements were taken only at 0.6 of the water depth where forebay depth was $<4 \mathrm{ft}$. Velocity measurements were taken at either three or five evenly spaced positions across each screen or panel. 


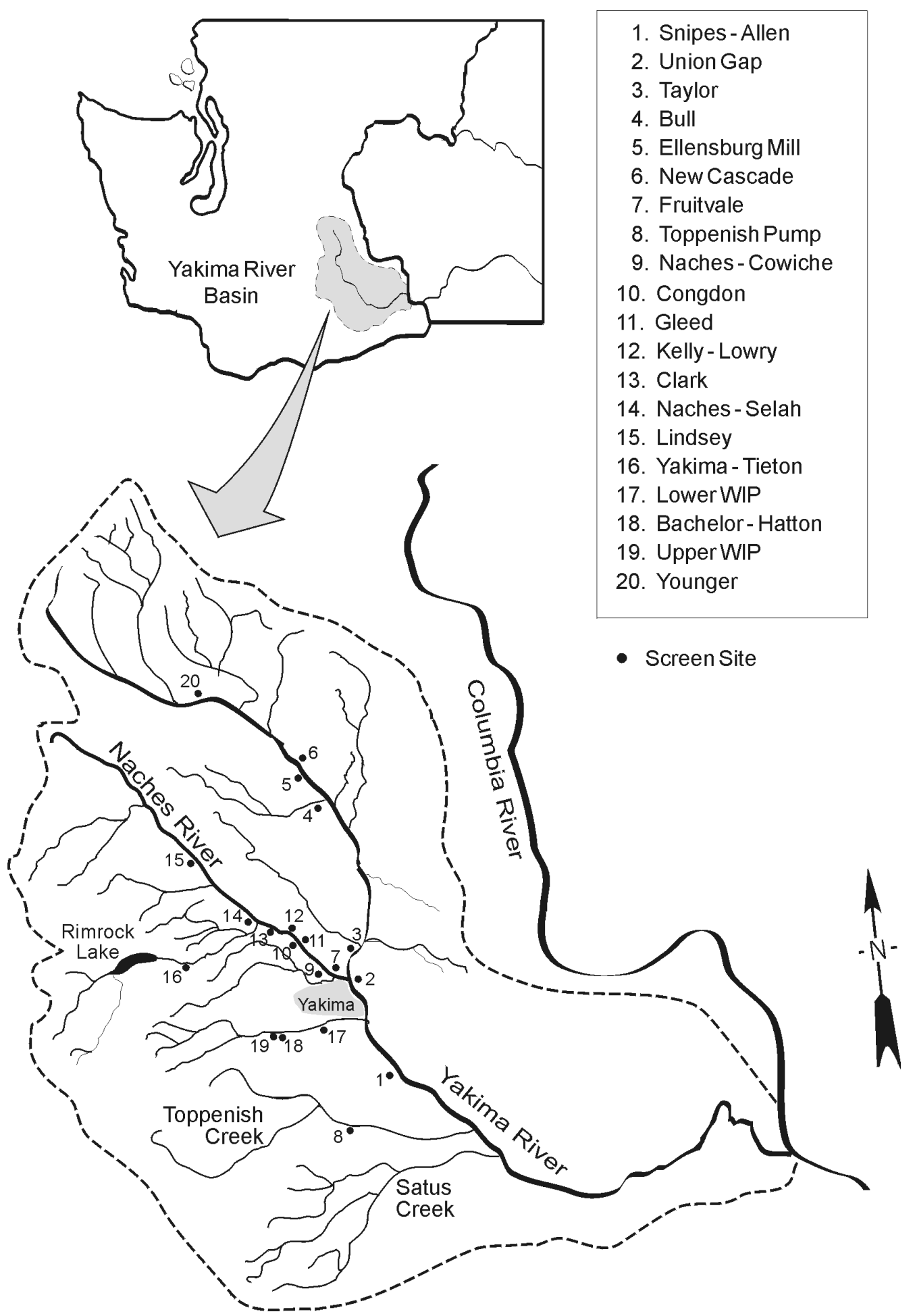

Figure 1. Yakima River Basin phase II screening facilities. 
Velocities were also measured in the bypass. Two measurements were recorded. The first was taken immediately inside the vertical slot bypass entrance at mid-water depth. The second was recorded halfway between the bypass entrance and the overflow weir, again at midwater depth.

\section{$\underline{\text { Data Collection and Analysis }}$}

Flow measurements were taken in front of every screen during both site visits. Power-todrum screens and cleaning brushes were disconnected to decrease the likelihood of electrical interference. Average ( \pm 1 standard deviation) sweep and approach velocities at each site were calculated for each visit.

\section{Underwater Video}

\section{Equipment}

An underwater video system was used to investigate screen seal condition and to monitor debris build-up and fish presence. The system consisted of a high-sensitivity remote camera (Sony, model HVM-352 ${ }^{\circledR}$ ) with a wideangle lens $\left(70^{\circ}\right.$ Sony, model VCL-06HS $\left.{ }^{\circledR}\right)$. The camera was housed in a water-resistant case (Sony, model WPC- $140^{\circledR}$ ) and connected by $66 \mathrm{ft}$ of quadraxial cable to an $8-\mathrm{mm}$

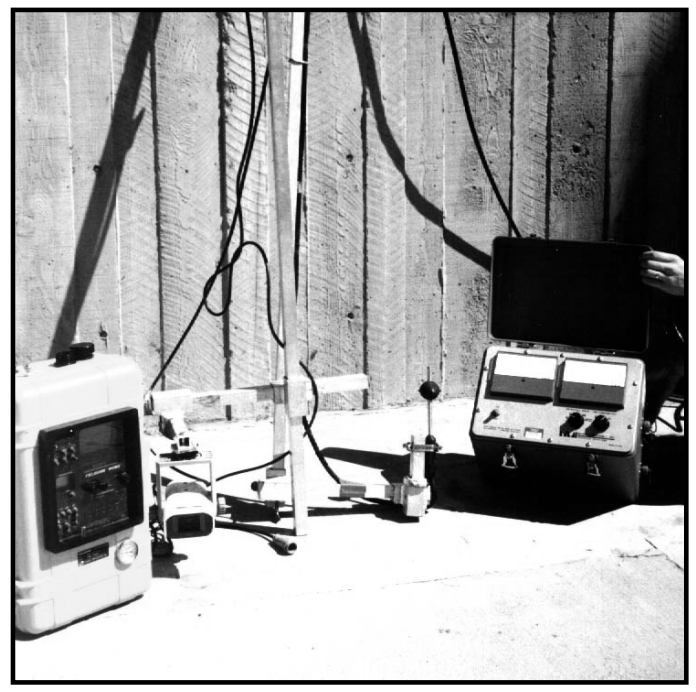
camcorder (Sony, model CCD-FX710 Handycam Hi- $8^{\circledR}$ ) in a weatherproof housing. The case was fitted with external weatherproof controls, a 4-in. black and white monitor, and internal battery power supply for the system. The underwater camera operated at extremely low light levels ( $<1$ lux), so that artificial light sources were not necessary to obtain video images during daylight hours.

\section{Camera Positioning}

The camera was securely mounted under a horizontal metal arm that extended approximately $15 \mathrm{in}$. from a vertical pole. The length of the horizontal arm and its position on the vertical pole was adjustable. The camera was usually angled slightly downward to observe the area between the screen and the bottom seal where there was a potential for gaps to occur. The camera was moved from upstream to downstream, following the side and bottom seal $/$ screen 
interfaces. Flatplate screens had vertical seals between panels that were also observed and recorded on videotape. Where there were signs of excessive debris or of fish presence, images were also recorded showing the forebay area and/or bypass.

\section{Data Collection and Analysis}

Video footage was not recorded on all visits in 1999 because high turbidity ( $>6$ NTU) precluded video analysis during some surveys. Written observations were also made when something of interest was seen (i.e., faulty seals, gaps, fish). The videotapes were later reviewed in detail and images of interest were digitized using Snappy Video Snapshot ${ }^{\circledR}$ Version 3.30 software.

\section{General Data}

Additional data collected during each evaluation included the following:

- general site descriptions and photographs

- screen and seal conditions

- screen submergence levels

- cleaning system operation and the incidence of headloss across the screen face

- bypass flow conditions

- bypass outfall flow conditions

- fish presence

- observations of debris in the forebay or bypass

- presence or absence of operator control aids such as water gages and drum submergence marks on screen frames. 


\section{Results}

This section presents the overall results first, then describes each site in more detail. The site-by-site descriptions are organized into to two groups; rotary drum screens and flat-plate screens.

\section{Overall}

Water velocity measurements, underwater video, and general data collection results for all screen sites are described in this subsection. Most sites were operating in a manner that would be expected to provide for the safe passage of juvenile salmonids.

We generally compared our field measurements to the criteria adopted by the NMFS. The NMFS has defined several conditions concerning velocity that screen operators should try to achieve at all sites (NMFS 1995). These include:

- maintaining a uniform flow distribution over the screen surface to minimize approach velocity

- $\quad$ keeping approach velocities $\leq 0.4$ feet per second (fps)

- achieving sweep velocities that are greater than approach velocities

- effecting a bypass flow greater than or equal to the maximum flow velocity vector resultant upstream of the screens.

In addition, there should be a gradual and efficient acceleration of flow into the bypass entrance to minimize delay by emigrating salmonids.

\section{$\underline{\text { Water Velocity Measurements }}$}

Water velocities at the 20 screen sites evaluated were highly variable, both spatially and temporally. Site-specific information is given following these overall results. Flows were typically not uniform over screen surfaces. Often, there were distinct differences between top and bottom approach velocity values. Where a pattern could be determined, it often showed that approach velocities were higher at the center of drum screens and lower at the ends of the screens. 
There were no obvious patterns to the fluctuations of approach velocity observed at flat plate screens.

Overall, $89 \%$ of all approach velocity measurements met criteria (compared to $86 \%$ in 1997 and 93\% in 1998). However, approach velocities were always within criteria at only 9 of 18 screen sites screen sites evaluated (Table 2 , Figure 2). Areas of screen (i.e., top, bottom, upstream, downstream) that exceeded these criteria were dependent on factors at the individual sites.

Sites such as Toppenish Pump, where greater than $10 \%$ of the approach velocities measured exceed criteria, indicate potential problems that may be the result of flow imbalance, poorly sized screens, or over-use by the irrigator.

Averaging velocities for each screen site presented a clearer picture of the flows at these sites (Table 3; Figure 3). Considering only averages, sweep velocity was typically greater than approach velocity. All ratios were $\geq 1.5$, except at Bachelor Hatton and Gleed. Sweep velocities at these sites were negative due to large eddies created by high flows. Mean top sweep velocities were generally greater than mean bottom sweep velocities. Mean top and bottom approach velocities were more evenly mixed.

The four largest approach-to-sweep ratios occurred at flat plate screen sites. In general, flow patterns in front of flat plate screens were less variable than those in front of drum screens. In addition, sweep and approach velocities were more discrete at flat plate screens.

The ratio of sweep velocities to approach velocities at the flat plate screens was generally greater than at drum screens. This characteristic also retained approach velocities $<0.4 \mathrm{fps}$. This condition is likely to minimize the time it takes for fish to reach the bypass.

Five sites had average bypass velocities less than their average sweep velocities. Bypass flows were usually faster than the average flow past the screens (Figure 3). 
Table 2. Percent of approach velocity measurements that exceeded the NMFS criteria of $0.4 \mathrm{fps}$ by screen site in 1997, 1998, and 1999.

\begin{tabular}{|c|c|c|c|}
\hline \multirow[b]{2}{*}{ Screen Site } & \multicolumn{3}{|c|}{$\begin{array}{c}\text { Percent of } \\
\text { Approach Velocity } \\
\text { Measurements }>0.4 \mathrm{fps}\end{array}$} \\
\hline & 1997 & 1998 & 1999 \\
\hline Clark & 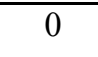 & 0 & $\bar{a}$ \\
\hline Ellensburg Mill & 0 & 0 & 33.3 \\
\hline Union Gap & 2.3 & 5.0 & 22.9 \\
\hline Kelly-Lowry & 3.3 & 0 & 0 \\
\hline Lindsey & 3.3 & 0 & 0 \\
\hline Fruitvale & 12.5 & $\mathrm{a}$ & 0 \\
\hline Gleed & $\mathrm{a}$ & $\mathrm{a}$ & 14.3 \\
\hline Snipes-Allen & 3.3 & 0 & 0 \\
\hline New Cascade & 4.2 & $\mathrm{ND}^{\mathrm{a}}$ & 0 \\
\hline Taylor & 4.2 & 0 & 0 \\
\hline Naches Selah & 5.5 & 2.8 & 27.8 \\
\hline Naches-Cowiche & 6.6 & 0 & 12.5 \\
\hline Lower WIP & 8.3 & $\mathrm{ND}^{\mathrm{b}}$ & 0 \\
\hline Yakima Tieton & 10.5 & 5.2 & 2.1 \\
\hline Bachelor-Hatton & 12.5 & 34.1 & 0 \\
\hline Upper WIP & 17.5 & 9.4 & 2.5 \\
\hline Congdon & 31.1 & 4.4 & 8.3 \\
\hline Bull & 36.1 & 2.9 & 14.7 \\
\hline Toppenish Pump & 43.0 & 60 & 25.4 \\
\hline Younger & $\bar{c}$ & $\mathrm{c}$ & 0 \\
\hline $\begin{array}{l}\text { a No data; electrical interfe } \\
{ }^{b} \text { No data; flooded in May } \\
{ }^{c} \text { Not sampled in } 1997 \text { or } 1\end{array}$ & $\begin{array}{l}\text { velocit } \\
\text { yuly } 1\end{array}$ & uremen & \\
\hline
\end{tabular}




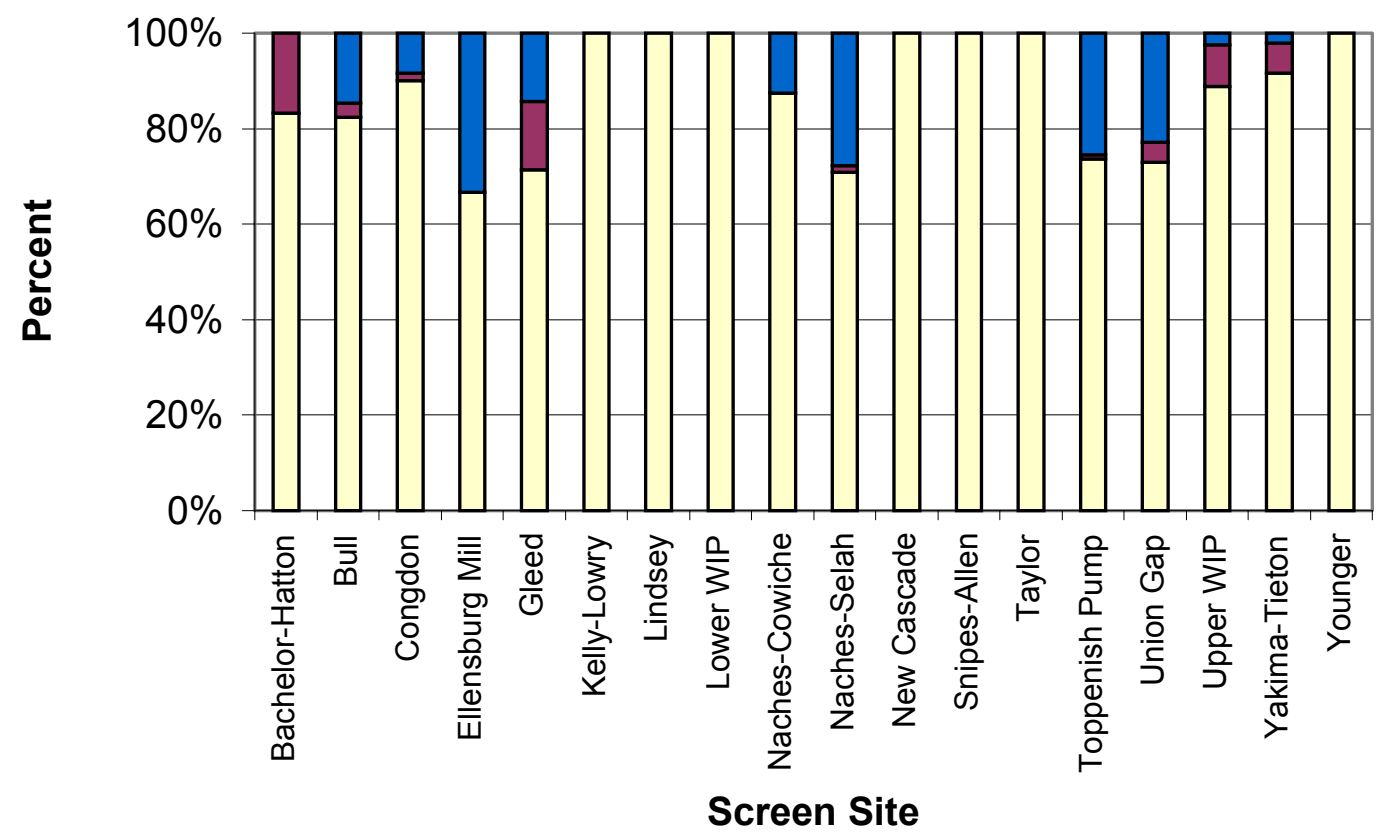

$\square$ met NMFS criteria $\square$ zero or negative $\square>0.4 \mathrm{fps}$

Figure 2. Percentage of measurements at Yakima Basin Phase II screen sites that met or did not meet NMFS approach velocity criteria of $\leq 0.4 \mathrm{fps}$ in 1999 . Zero/negative flows were generally created by eddies in front of the screens. 
Table 3. Mean sweep and approach velocities ( \pm standard deviation) at Phase II fish screen facilities in the Yakima Basin in 1999.

\begin{tabular}{|l|c|c|}
\hline \multicolumn{1}{|c|}{ Site } & $\begin{array}{c}\text { Mean Sweep } \\
\text { Velocity } \pm \text { S.D. }\end{array}$ & $\begin{array}{c}\text { Mean Approach } \\
\text { Velocity } \pm \text { S.D. }\end{array}$ \\
\hline \hline Bachelor-Hatton & $0.59 \pm 0.29$ & $0.14 \pm 0.12$ \\
\hline Bull & $0.66 \pm 0.65$ & $0.29 \pm 0.17$ \\
\hline Clark & ND $^{\text {a }}$ & ND $^{\text {a }}$ \\
\hline Congdon & $0.65 \pm 0.13$ & $0.33 \pm 0.08$ \\
\hline Ellensburg Mill & $0.53 \pm 0.42$ & $0.31 \pm 0.20$ \\
\hline Fruitvale & ND ${ }^{\text {a }}$ & ND \\
\hline Gleed & $0.52 \pm 0.48$ & $0.28 \pm 0.52$ \\
\hline Kelly-Lowry & $0.55 \pm 0.11$ & $0.27 \pm 0.06$ \\
\hline Lindsey & $0.40 \pm 0.12$ & $0.16 \pm 0.06$ \\
\hline Lower WIP & $0.33 \pm 0.12$ & $0.27 \pm 0.07$ \\
\hline Naches-Cowiche & $0.72 \pm 0.17$ & $0.28 \pm 0.12$ \\
\hline Naches-Selah & $1.10 \pm 0.21$ & $0.37 \pm 0.16$ \\
\hline New Cascade & $-0.01 \pm 0.31$ & $0.16 \pm 0.03$ \\
\hline Snipes-Allen & $0.22 \pm 0.14$ & $0.17 \pm 0.05$ \\
\hline Taylor & $0.25 \pm 0.12$ & $0.09 \pm 0.02$ \\
\hline Toppenish Pump & $0.77 \pm 0.35$ & $0.31 \pm 0.19$ \\
\hline Union Gap & $1.37 \pm 0.23$ & $0.32 \pm 0.20$ \\
\hline Upper WIP & $0.58 \pm 0.34$ & $0.21 \pm 0.14$ \\
\hline Yakima-Tieton & $1.46 \pm 0.52$ & $0.19 \pm 0.12$ \\
\hline Younger & $0.94 \pm 0.32$ & $0.25 \pm 0.04$ \\
\hline${ }^{a}$ No data; electrical interference prevented velocity measurements. \\
\hline
\end{tabular}




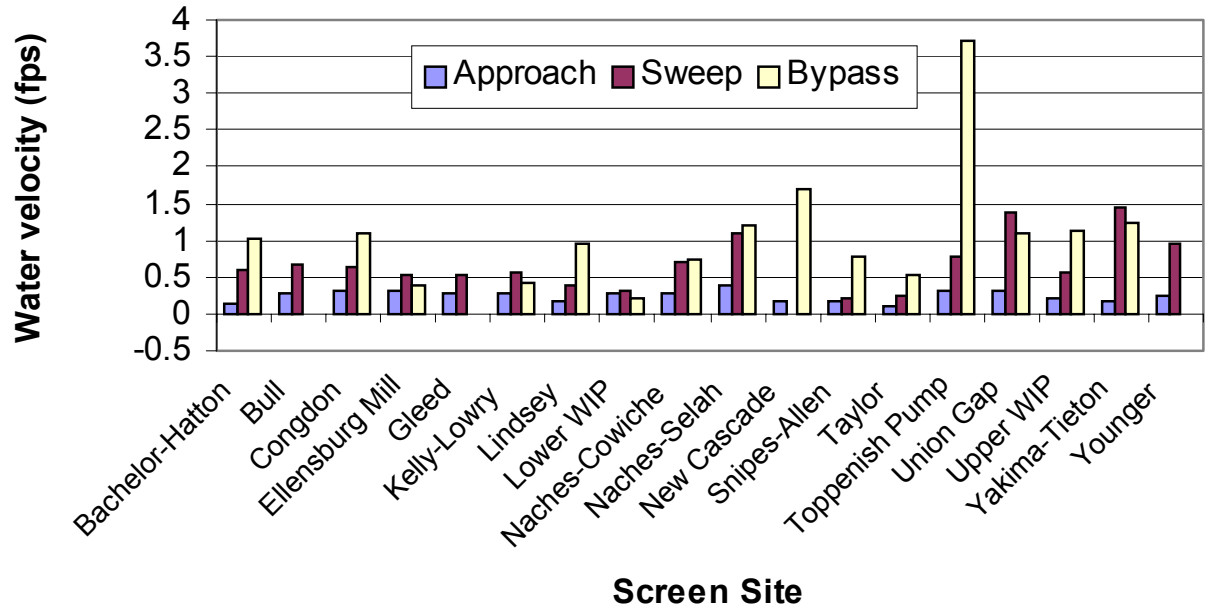

Figure 3. Mean approach, sweep, and bypass velocities (fps) at Phase II fish screen facilities in the Yakima Basin in 1999.

\section{$\underline{\text { Underwater Video }}$}

Underwater video was used to monitor and document sediment and debris accumulation in front of a screen and to provide a permanent record of conditions. This is important because debris can severely decrease seal life, cause drag on screen motors, and provide cover for predator fish species. Most often, it is impossible to see this debris from above the water's surface. Although a pole can be placed in the water to gage the depth of accumulated sediments, one cannot determine exactly the kind of debris present and how it is affecting water flow through or past the screen.

Most of the visible screen seals (approximately 70\%) were in good condition. Bottom frame seals were sometimes buried in sediment and could not be evaluated. All drum screen seals that were classified as in "good condition" were tight against the screen and not cracked or punctured in any way. Many rubber seals were covered in algae, but this was not considered a problem. Flat plate screen sealant was generally in good condition with the exception of some panels showing loose or missing caulking (e.g., Ellensburg Mill). 


\section{General Data}

\section{Screen Submergence Levels}

Canal operating conditions are designed to provide water levels that cover between 65 and $85 \%$ of a drum screen's diameter. At higher water levels, fish may roll over the top of the screen and enter the canal. Lower water levels can prevent the screen from efficiently removing debris from the forebay area.

Percent screen submergence was calculated at every drum screen site $(\mathrm{N}=12)$ for each evaluation. The percent of time that screens met the $65 \%$ to $85 \%$ submergence guidelines was $61.5 \%$ (which was down from $69 \%$ in 1998 ). Levels exceeded $85 \%$ submergence for $38.5 \%$ of our evaluations. High water levels occurred at 4 of 11 drum screen sites (Bachelor-Hatton, Congdon, Lindsey, and New Cascade). Most of these sites experienced high levels for only one evaluation period; however, the Lindsey site exceeded the criteria on both surveys. No screen sites were measured below 65\% submergence in 1999.

Flat plate screen sites do not have the same roll over and debris removal issues to contend with as rotary drum screens. However, should a screen become completely submerged, fish can freely enter the irrigation canals by swimming over the top of the screen. Total screen submergence was observed at the Fruitvale screen. However, there were no reports of overtopping at the Fruitvale site in the operator's log book at the site.

\section{Bypass Outfall Conditions}

The NMFS established a number of guidelines and criteria concerning bypass conduit design and outfall conditions (NMFS 1995). These criteria state that, "for diversions $25 \mathrm{cfs}$ and greater, the required pipe diameter shall be greater than or equal to $24 \mathrm{in}$. $(61 \mathrm{~cm})$ and that the minimum depth of open-channel flow in the bypass conduit shall be greater than or equal to 9 in. $(23 \mathrm{~cm})$, unless otherwise approved by the NMFS." Pipe diameter criteria exist primarily to minimize debris clogging and sediment deposition and to facilitate cleaning. For screens with a diversion flow less than 25 cubic feet per second (cfs), the requirements are a 10-in. diameter pipe and a minimum allowable water depth in the pipe of 1.8 in. $(4.6 \mathrm{~cm})$.

All screens with bypasses that were evaluated, with the exception of Clark, Lindsey, and Lower WIP, are designed and built for diversion flows $\geq 25 \mathrm{cfs}$. However, many sites had bypass pipes with diameters much smaller than the NMFS criteria. Most sites appeared to meet the minimum requirements for in-pipe water depth, although it was impossible to be certain when the outfall was submerged. 


\section{Operator Control Aids}

Although not required, visual operator control aids are extremely useful for maintenance and operations personnel periodically inspecting sites. They compliment the operating criteria and help "flag" operational or procedural problems. Operator aids include marks indicating submergence level on drum screen frames; water depth or elevation gages in the forebay, aftbay, and irrigation canal; and marks indicating how far headgate, bypass weir, or canal intakes are open. Providing highly visible indicators of screen system operation as it relates to NMFS criteria or of proper water diversion to the canal can save time and reduce incidences of operator error that may result in fish impingement, entrainment, or stranding at a site.

Most sites were equipped with gages measuring elevation or water depth, although gages were not always present both in front of and behind the screens. Drum screen submergence marks were present at most sites, but were difficult to read late in the season due to algae growth. We recommend regular cleaning of these marks to facilitate operator adjustments and evaluation.

\section{Rotary Drum Screens}

\section{$\underline{\text { Bachelor Hatton }}$}

The Bachelor Hatton site was evaluated 5/12/99 and 7/15/99. The major hydraulic problems that were observed at this site in 1998 were not present in 1999. Approach velocities were always within the NMFS criteria for the first time in the 3 years this site has been evaluated (Figure 4 and Figure 5). Sediment deposits in the forebay were up to 15 in. deep during the May 12 evaluation, and were about half that on the July 7 evaluation.

A gap was observed in the rubber seal under screen 2 on May 12 (Figure 6). 
Bachelor-Hatton - May 12, 1999

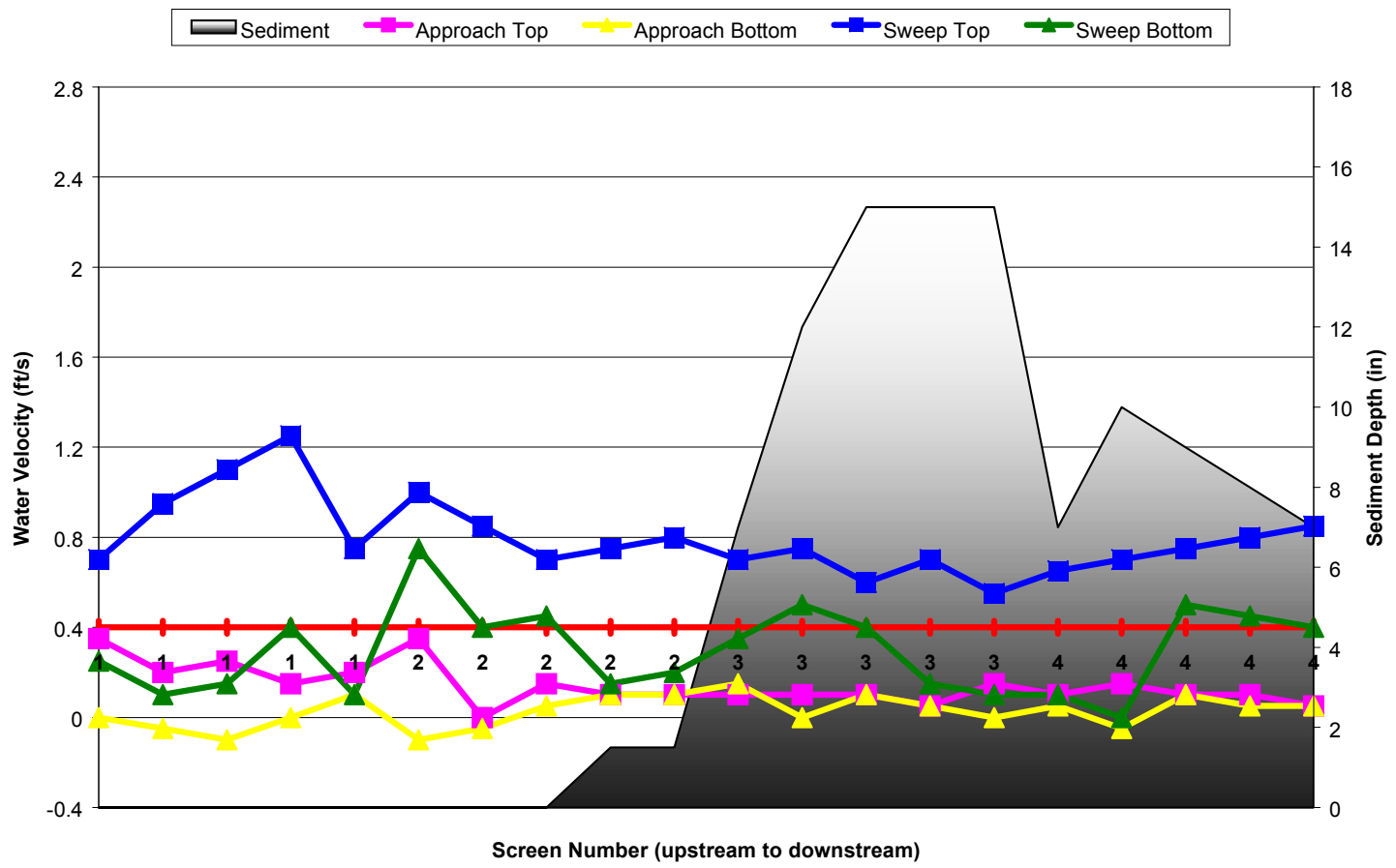

Figure 4. Water velocities and sediment depths at Bachelor Hatton, 5/12/99.

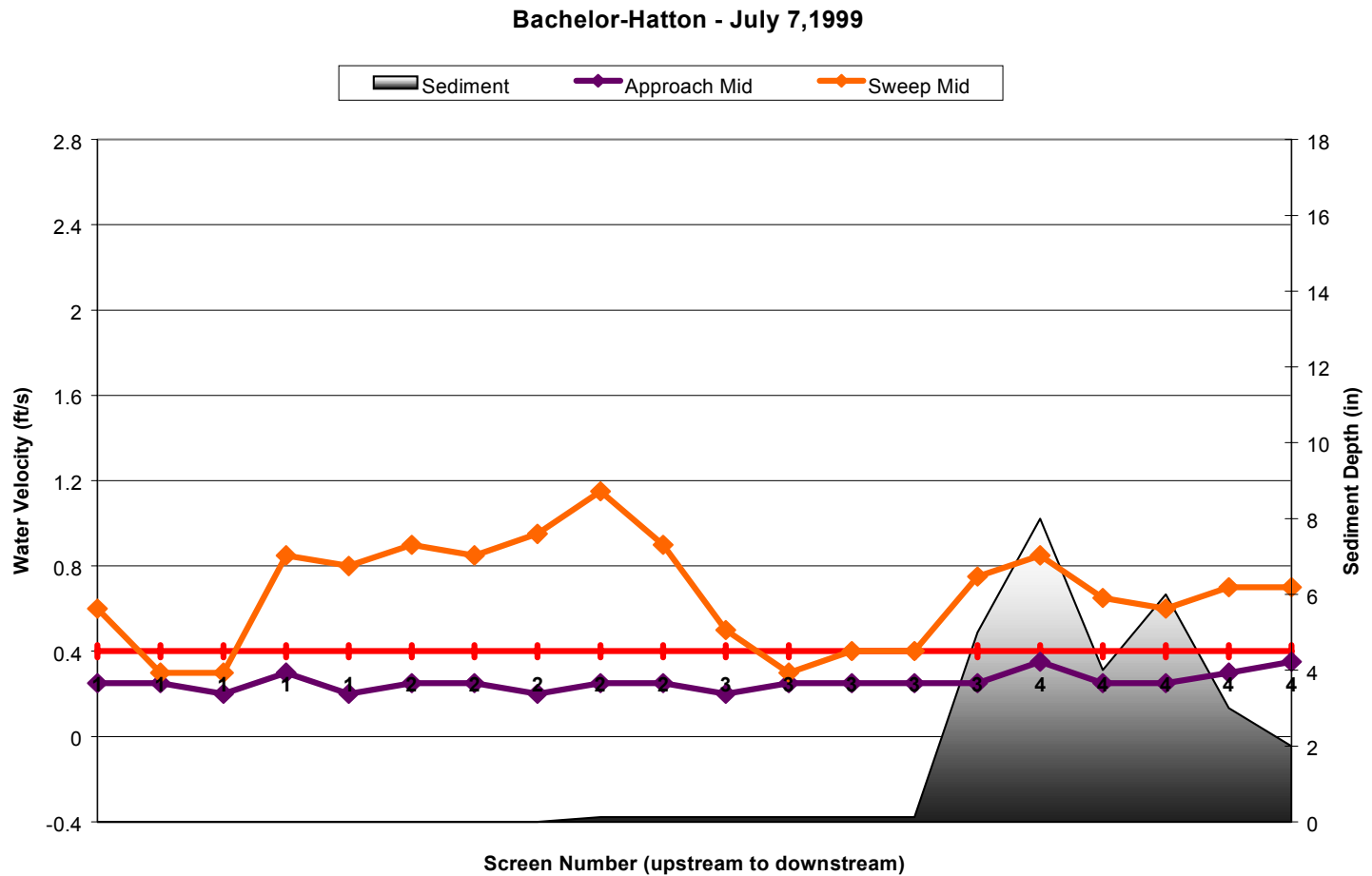

Figure 5. Water velocities and sediment depths at Bachelor Hatton, 7/7/99. 


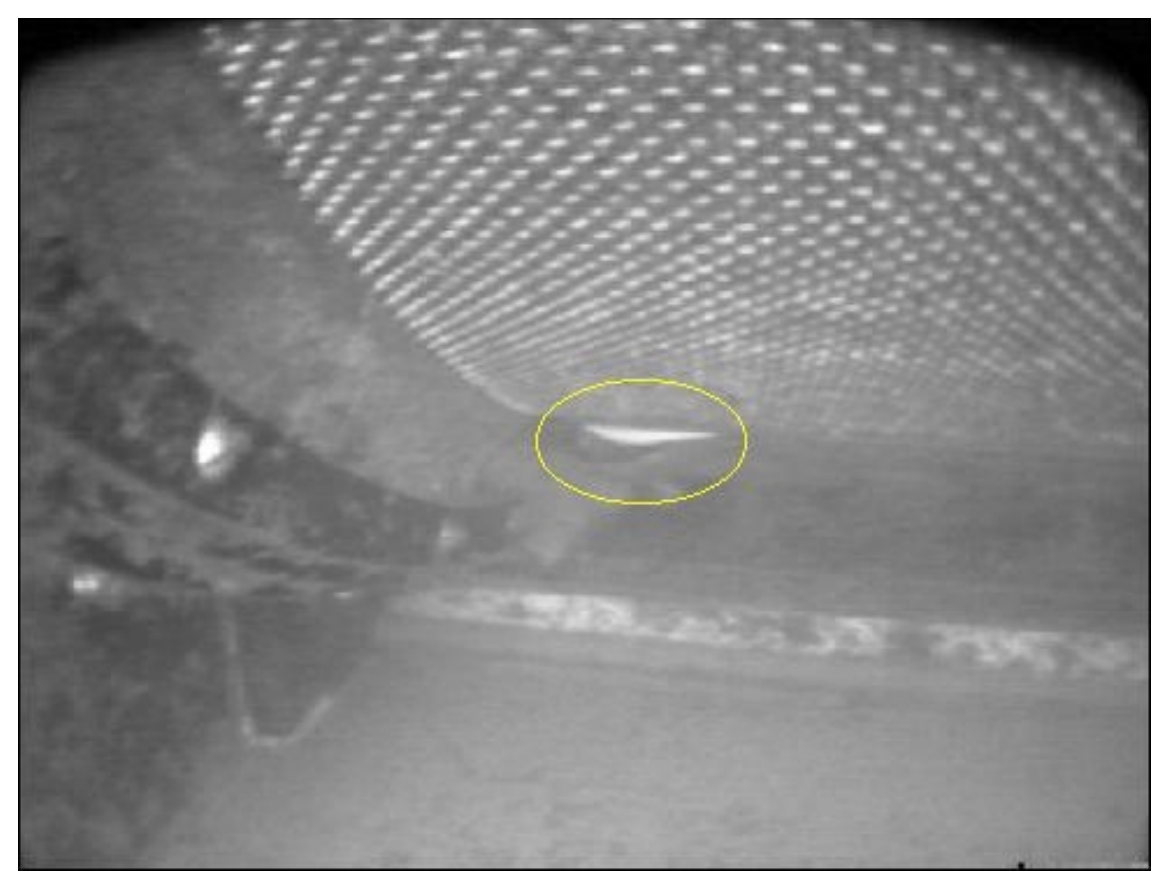

Figure 6. Gap in bottom seal of screen number 2 at Bachelor Hatton, 5/12/99.

Water flowed over the bypass weir during both evaluations. Bypass outfall conditions were good for fish passage in both May and July. Mean bypass velocities exceeded sweep velocities at this site. Screen submergence was approximately $91 \%$ on May 12 and $86.5 \%$ on July 7, 1999, both slightly above the NMFS criteria for drum screens (65 to 85\%).

Regarding operator control aids, there were no submergence marks painted on the screen frames or gages provided for measuring weir depth. One staff gage was present in the aftbay to track water levels.

\section{$\underline{\text { Clark }}$}

Clark was evaluated 5/14/99 and 7/20/99. The bypass was in flush mode on 5/14/99, and velocities were very low. Marks showing percent submergence were painted on the screen frame at the 70,80 , and $90 \%$ levels. Unfortunately, the lower markings were obscured with algae growth over the course of the season so that only the $90 \%$ mark was legible in July.

Electrical interference prevented velocity measurements on both surveys in 1999. Screen submergence was measured at 78 and $84.7 \%$ in May and July, respectively. The screen and the seals were in good condition, with the exception of some possible small gaping along the bottom 
observed on the underwater video taken during the July evaluation. The single drum screen rotated very slowly. Conditions at the outfall pipe were always good at the Clark site when water was being bypassed. The site did not appear to collect a lot of debris. A few twigs and some reeds and trash buildup were noted at the headgate and trash rack.

\section{Congdon}

The Congdon screen site was evaluated 5/13/99 and 7/14/99. Ninety-two percent of the recorded approach velocities met NMFS criteria at the Congdon site. The remaining $8 \%$ of the recorded velocities were $>0.4$ fps. In general, sweep velocities were greater than approach velocities and increased near the bypass (Figure 7 and Figure 8). The only places sweep velocities were less than approach velocities or where approach velocities exceeded criteria were in front of Screen 1 (farthest upstream) in July and September.

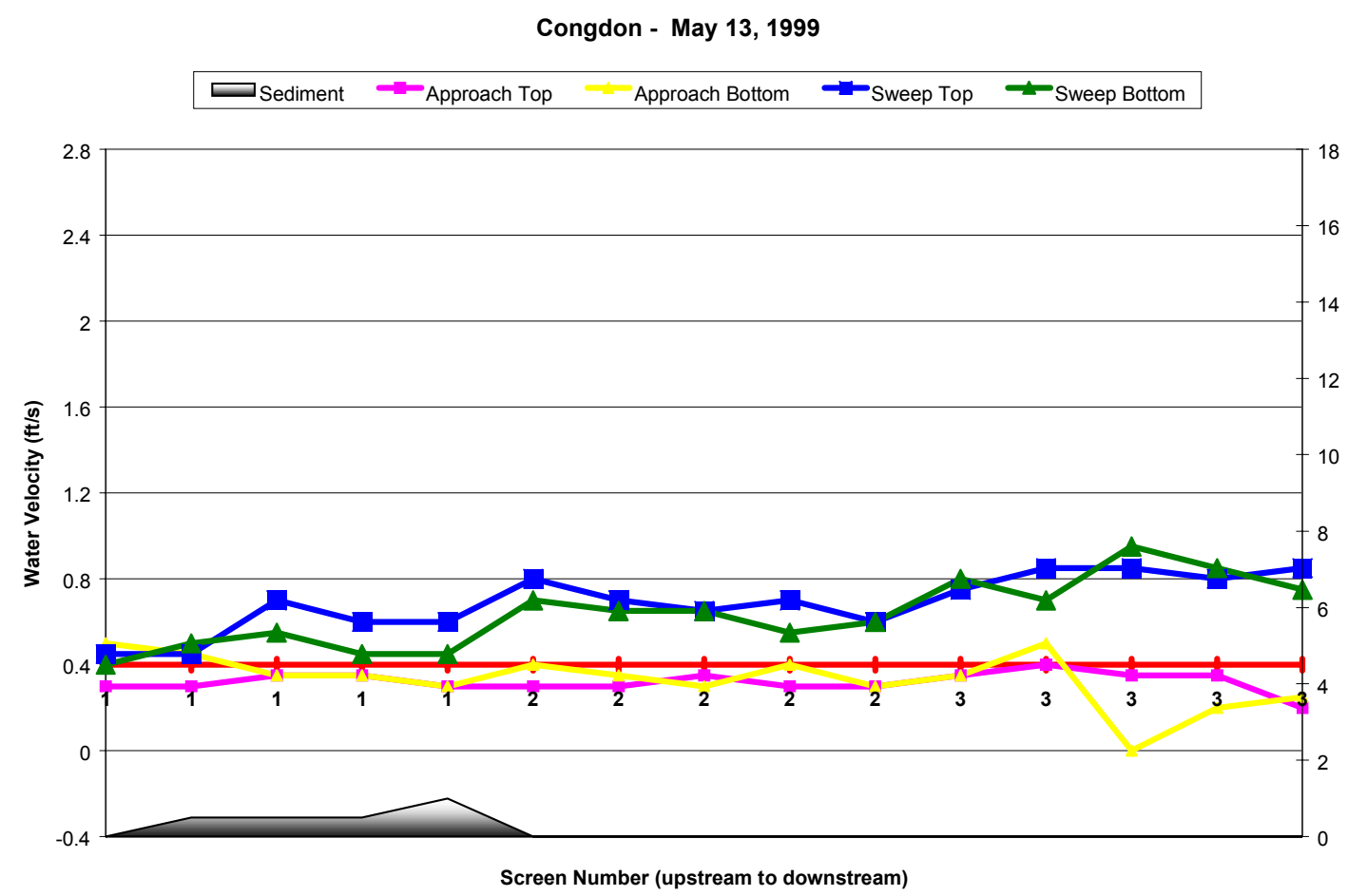

Figure 7. Water velocities and sediment depths at Congdon, 5/13/99. 


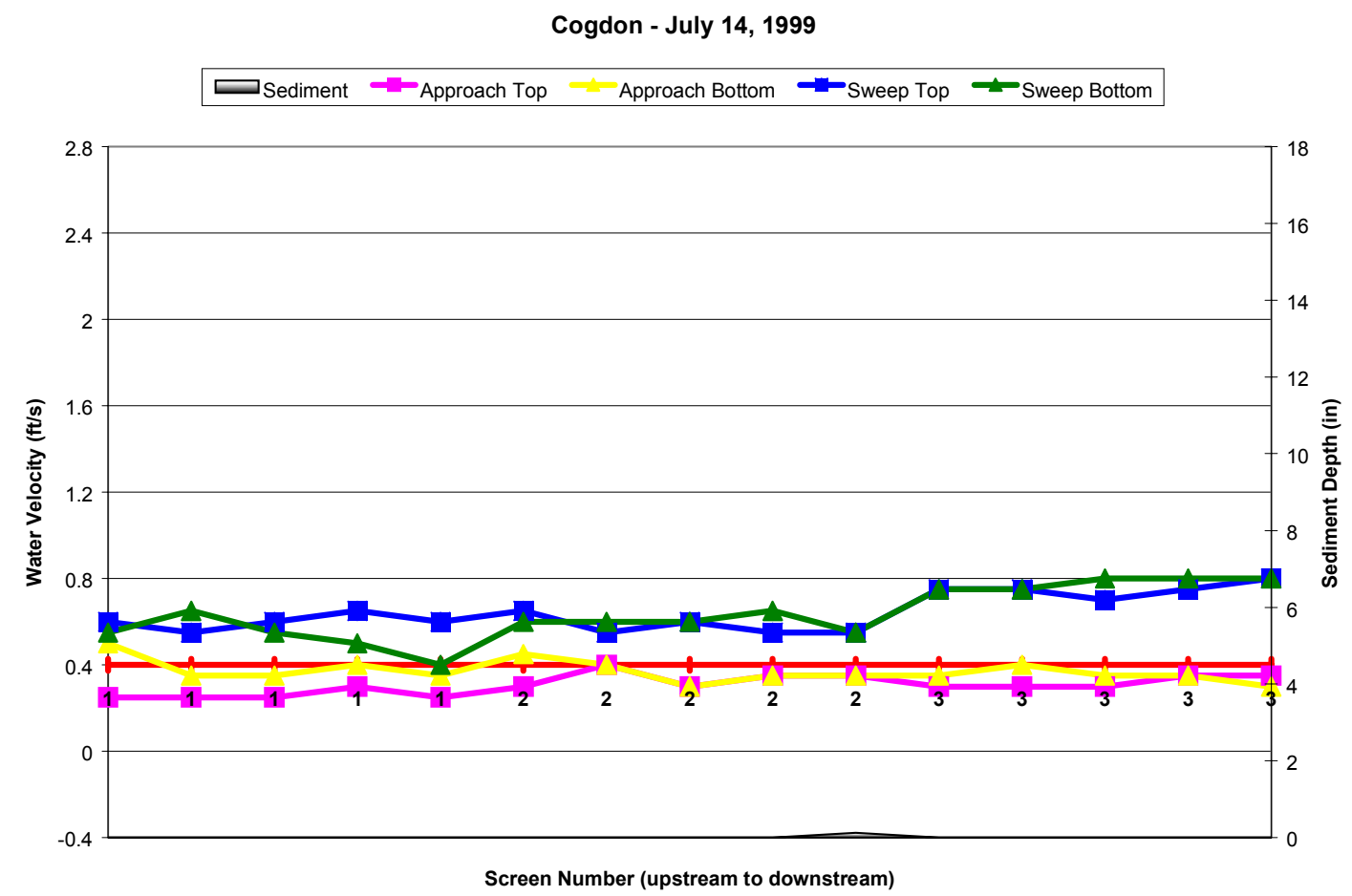

Figure 8. Water velocities and sediment depths at Congdon, 7/14/99.

Bypass velocities averaged higher than sweep velocities at Congdon in 1999. Screen submergence was $88 \%$ during the May survey and was down to $82 \%$ on the date of the July survey. Water always flowed over the bypass weir and ran freely through the outfall pipe, which was always submerged at its terminus. However, the bypass pipe was never completely full of water (evidenced by the bubbles that were observed). The seals were in good condition and screens always turned smoothly. There were no debris or silt problems observed at Congdon in 1999.

\section{Kelly Lowry}

The Kelly Lowry screen site was evaluated 5/14/99 and 7/20/99. All approach velocities recorded at this site met NMFS criteria (Figure 9 and Figure 10). Sweep velocities always exceeded approach velocities, but decreased near the bypass instead of increasing during the July evaluation. There was $1 \mathrm{in}$. of head-loss across the screens in May due to thick algae/diatom growth on the screens. Mean bypass velocities were lower than mean sweep velocities at this site in 1999. Screen submergence levels met NMFS criteria at 81 and $69 \%$. 


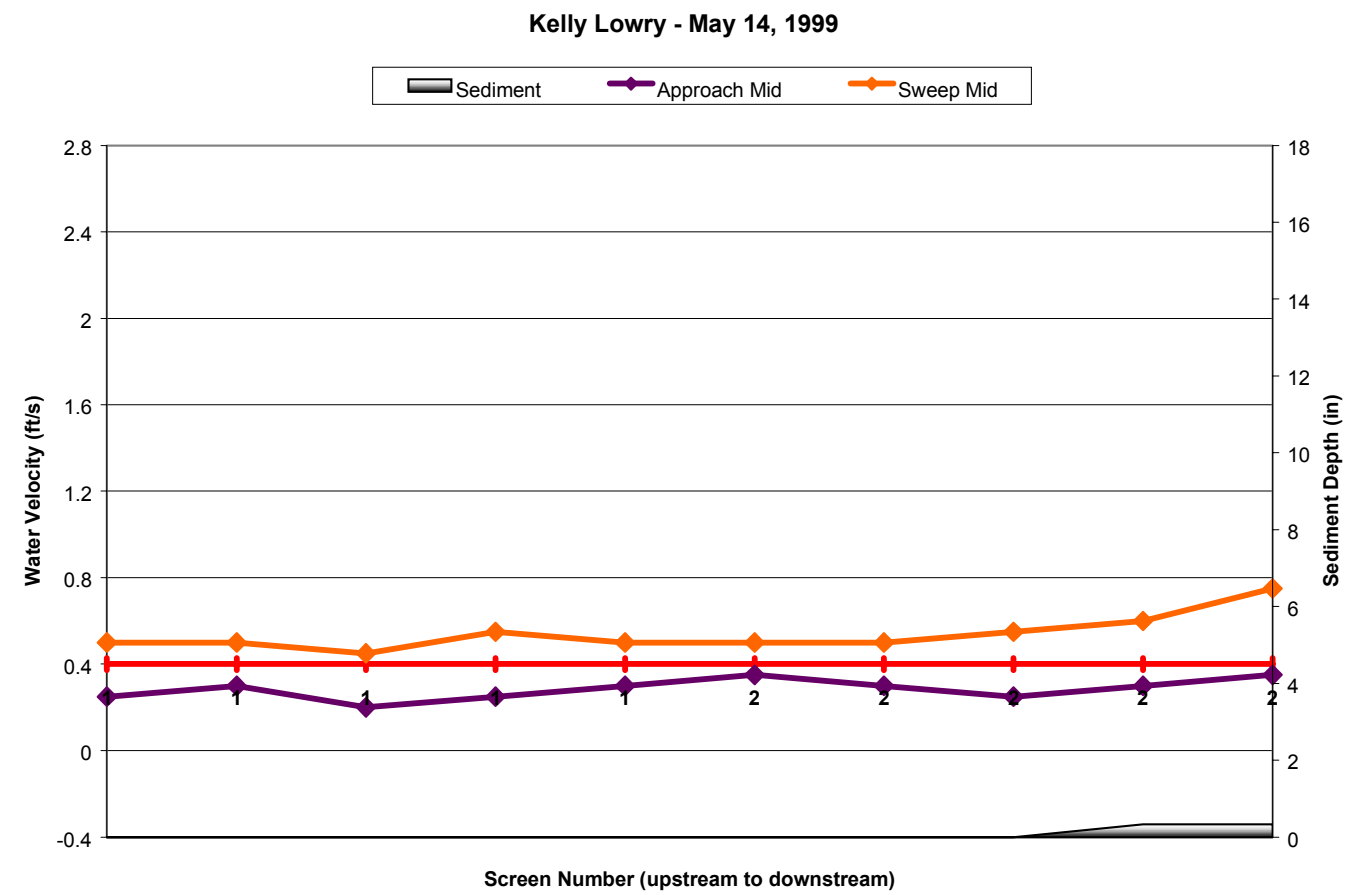

Figure 9. Water velocities and sediment depths at Kelly Lowry, 5/14/99.

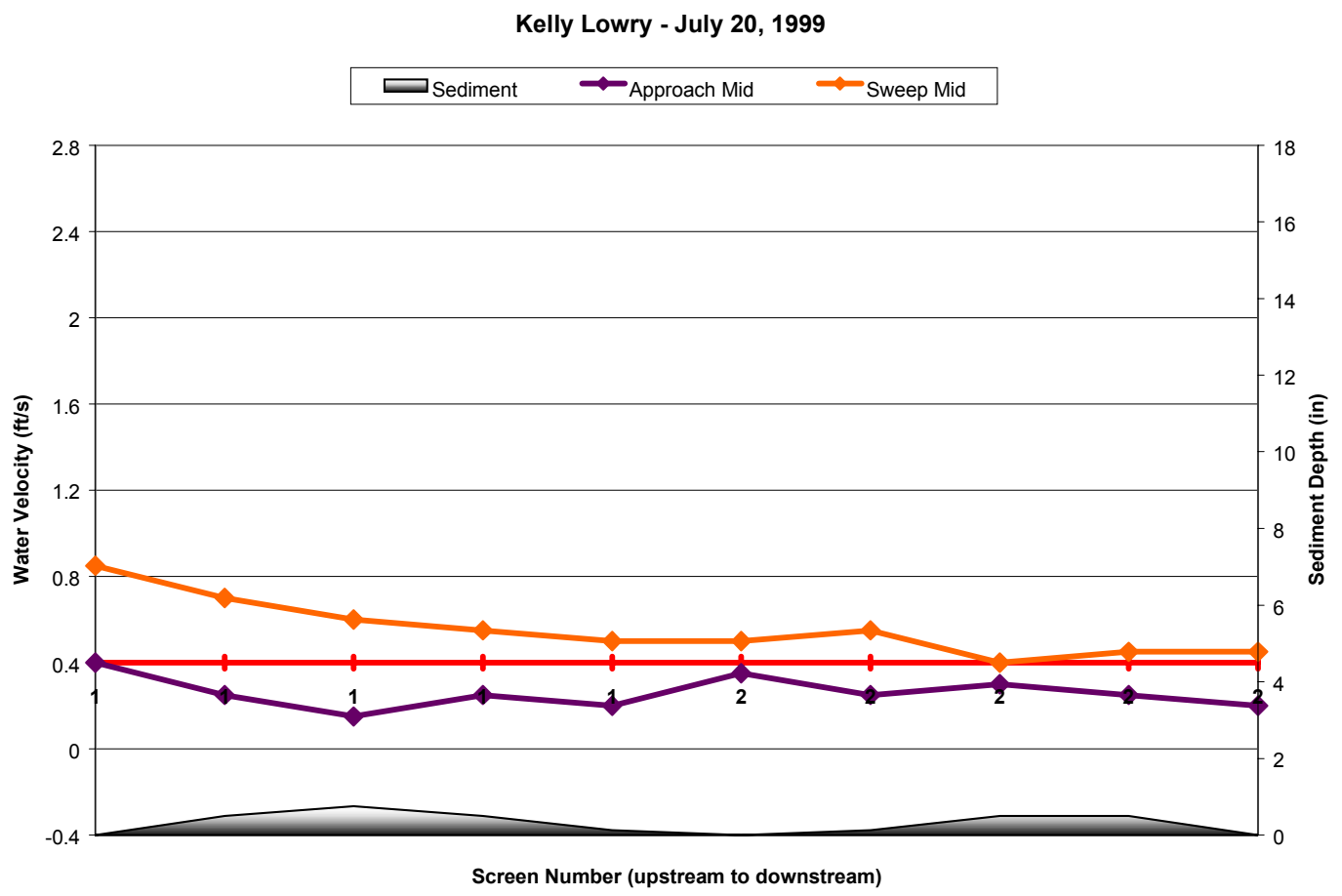

Figure 10. Water velocities and sediment depths at Kelly Lowry, 7/20/99. 
The only concern regarding screen condition was the build-up of algae/diatom growth that resulted in some head-loss in May. The screens were in good shape and the drums turned evenly. The seals were in good condition. Water always ran freely over the bypass weir, and conditions for fish at the outfall site were always good.

The trashrack kept many sticks out of the forebay and did not appear to be cleaned regularly in-season. There were dead crows, garbage, and sticks at the bypass entrance. The trashrack also was holding bottles, cans, and sticks. There was only a minor accumulation of silt on top of the sill in front of both screens throughout the season. WDFW personnel described a difficult relationship with the property owners in which the owners would not allow the WDFW maintenance crews to access the site (B. Werst, WDFW, pers. communication 1/6/00).

\section{Lindsey}

The Lindsey screen site was evaluated 5/14/99 and 7/20/99. All recorded approach velocities at this site met NMFS criteria. Sweep velocities were greater than approach velocities, but did not always increase near the bypass (Figure 11 and Figure 12). Mean bypass velocities exceeded sweep velocities. Screen submergence levels were slightly high at 86 and $89 \%$.

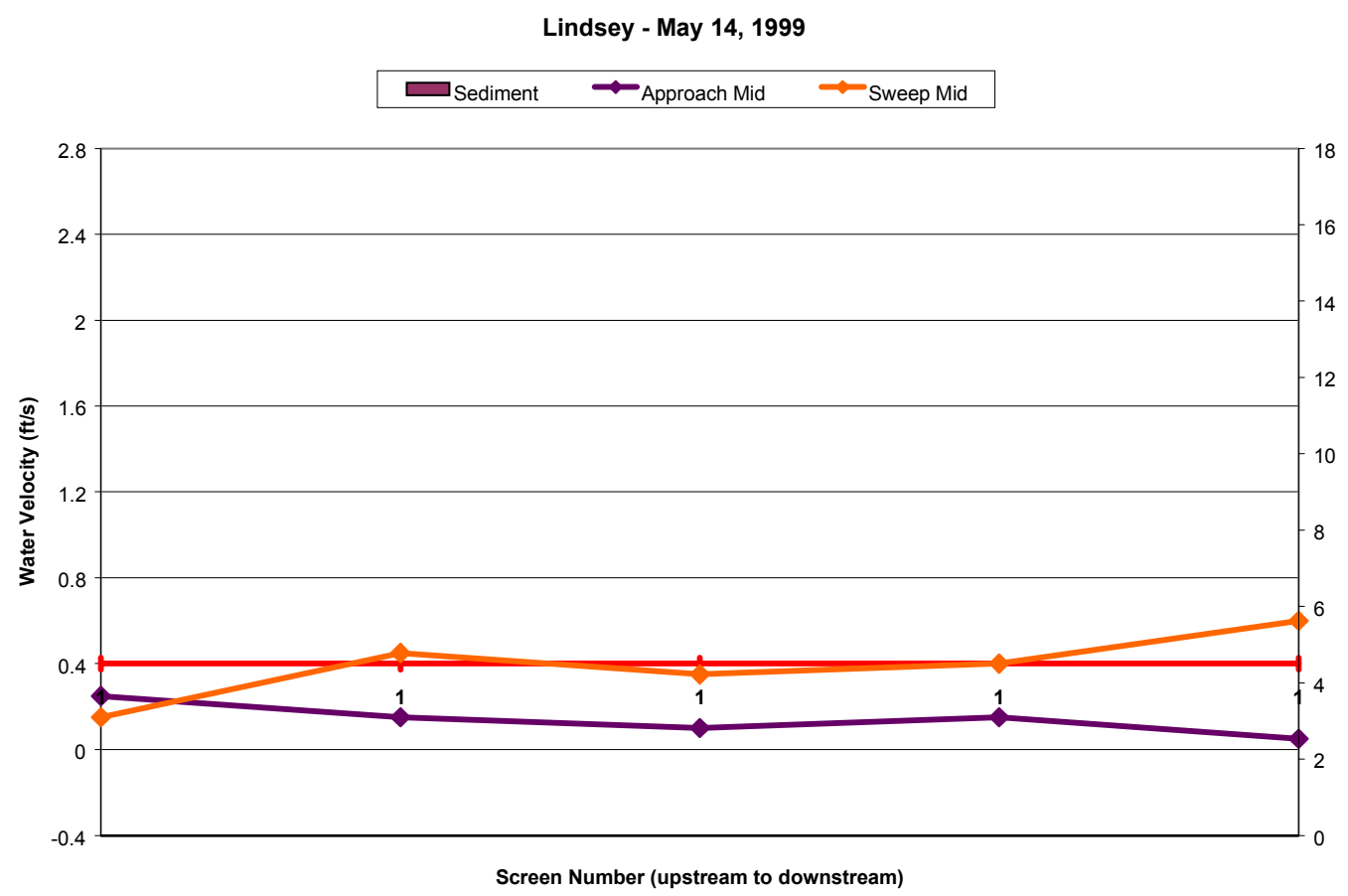

Figure 11. Water velocities and sediment depths at Lindsey, 5/14/99. 


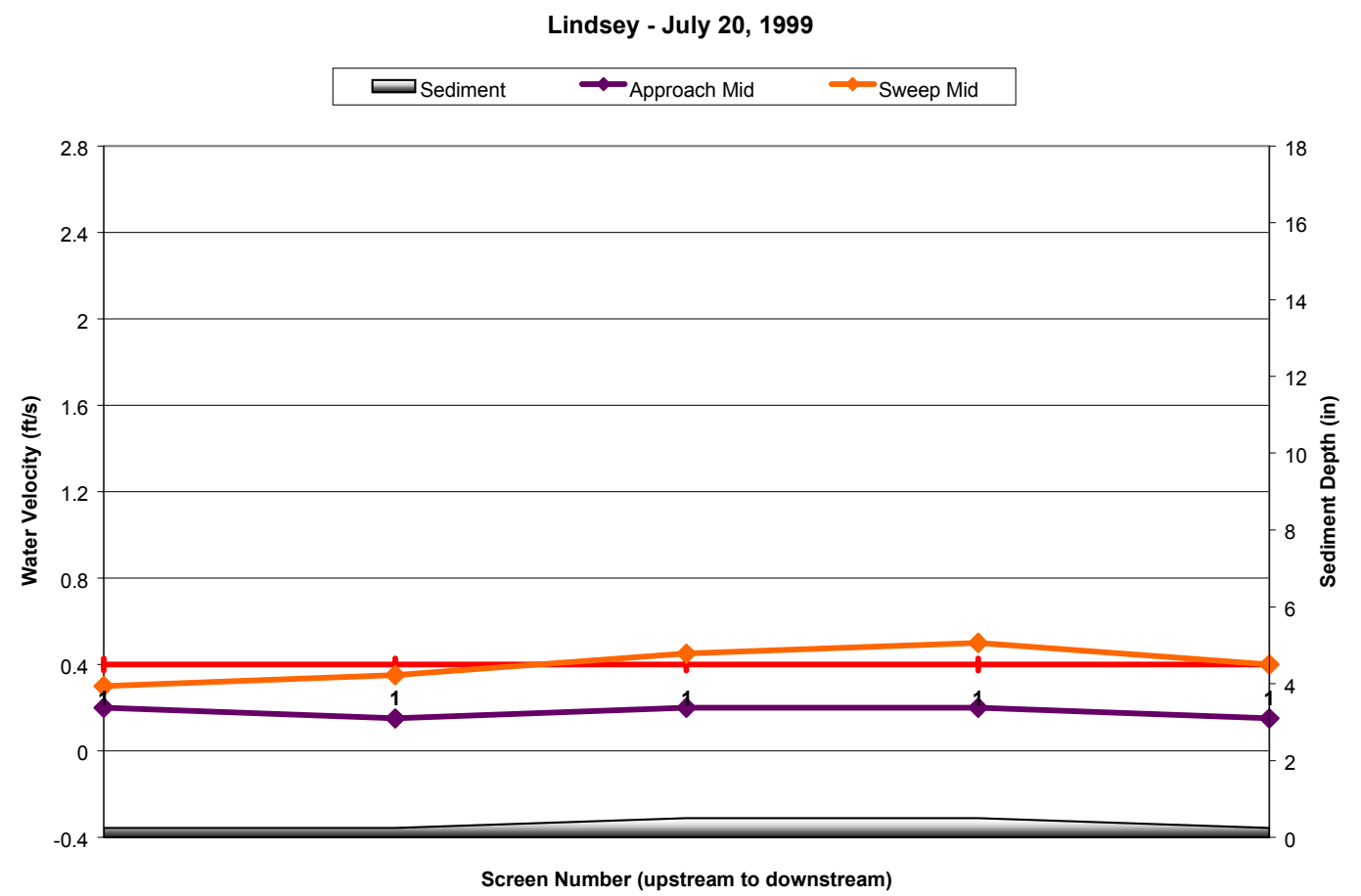

Figure 12. Water velocities and sediment depths at Lindsey, 7/20/99.

The screens and most seals were in good shape. Some white caulking was missing along the bottom in the same place that was identified in 1998. The side seals were in good condition, and the screen always rotated evenly. Water ran freely behind the bypass weir on both surveys. Levels of silt and sand were not excessive. Woody debris was not a problem, though there were some leaves and sticks in the forebay. The bypass was operating effectively and discharged into water over $1 \mathrm{ft}$ deep.

\section{Lower WIP}

Lower WIP was visited 5/12/99 and 8/4/99. All approach velocities met NMFS criteria. Sweep velocities were not consistently greater than approach velocities and did not tend to increase toward the bypass (Figure 13 and Figure 14). The bypass velocity did not exceed the sweep velocity during the August evaluation. A board had been installed in the bypass that reduced velocities (with board in velocity was $0 \mathrm{fps}$, with the board removed, the velocity increased to $0.15 \mathrm{fps})$. 


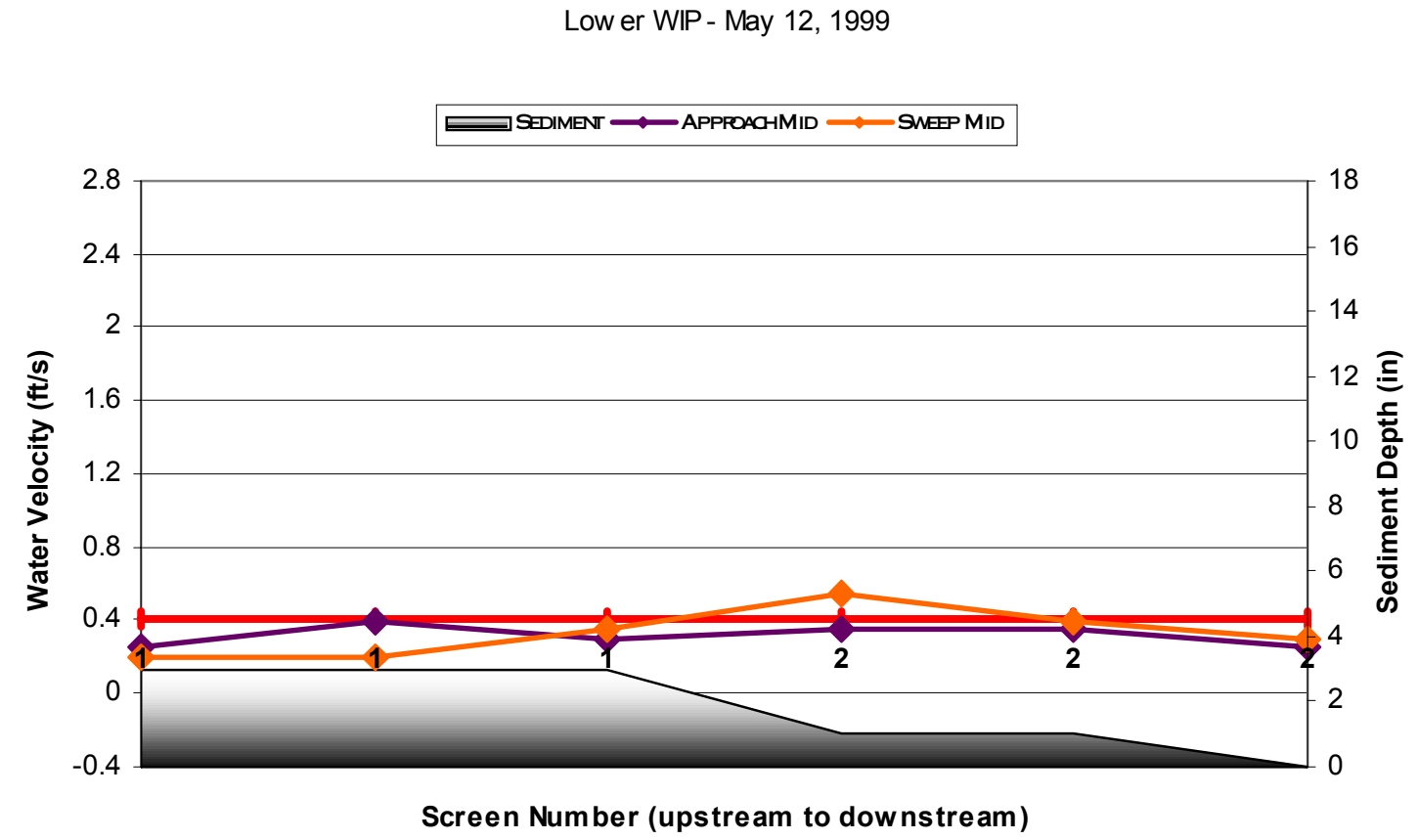

Figure 13. Water velocities and sediment depths at Lower WIP, 5/12/99.

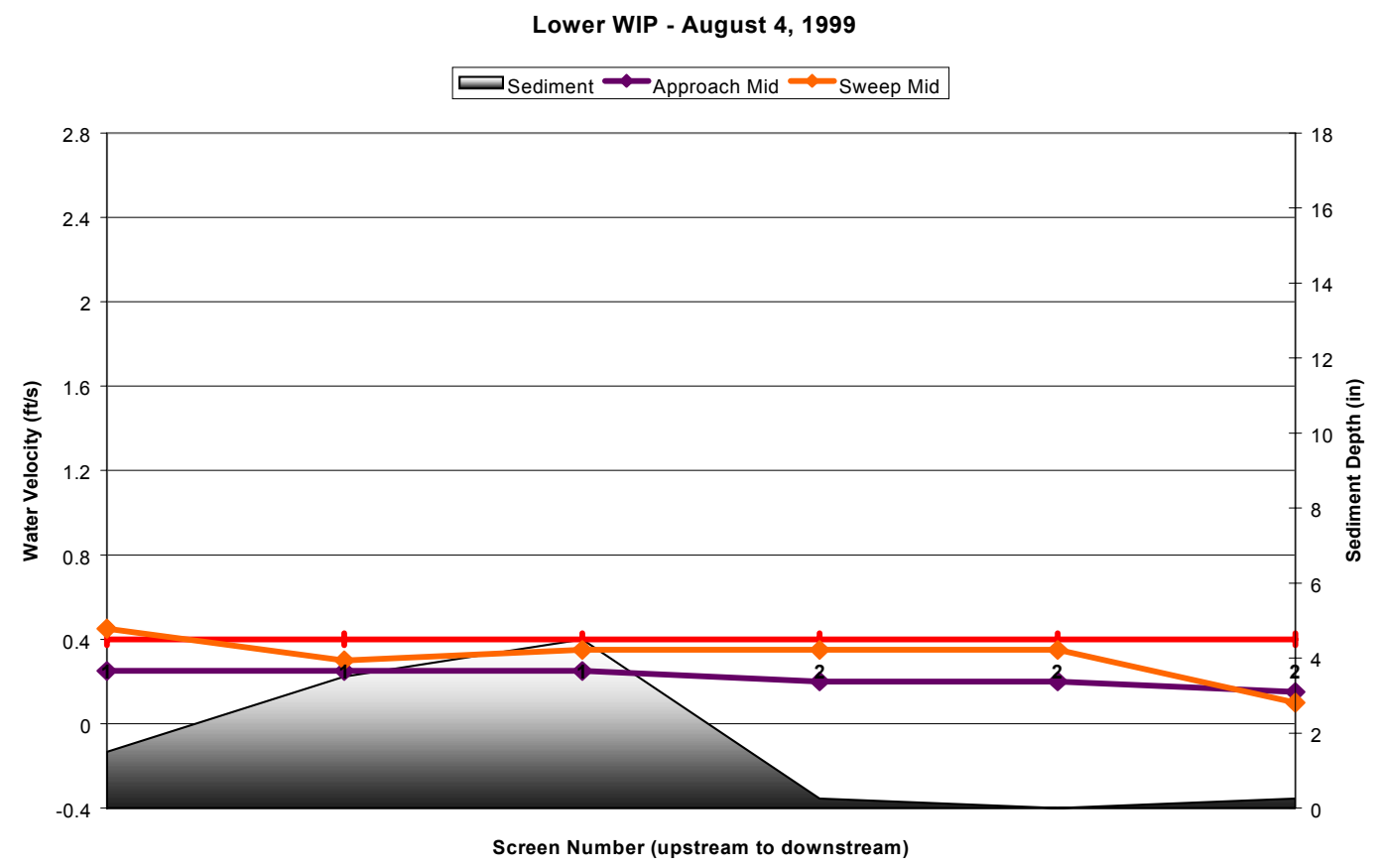

Figure 14. Water velocities and sediment depths at Lower WIP, 8/4/99. 
Screen submergence was relatively low (67\%) in May and very high (96\%) in August. Sediment depth increased to over 4 in. in the forebay in front of the downstream end of screen 1 by August. The screen seals and screening appeared to be in good condition, and the drums were turning evenly. Water was running over the bypass weir, and the bypass was running smoothly into water over $1 \mathrm{ft}$ deep.

\section{Naches Cowiche}

The Naches Cowiche site was evaluated 5/13/99 and 7/15/98. Over 12\% of the recorded approach velocity values exceeded $0.4 \mathrm{fps}$; up from $0 \%$ in 1998 . The excessive approach velocities were confined to the upstream portion of screen 1 (Figure 15). Sweep velocities were generally greater than their corresponding approach velocities but did not always increase near the bypass. Mean bypass velocities were slightly greater than mean sweep velocities. Screen submergence levels were within the bounds set by NMFS criteria ( 81 and $82 \%$ ).

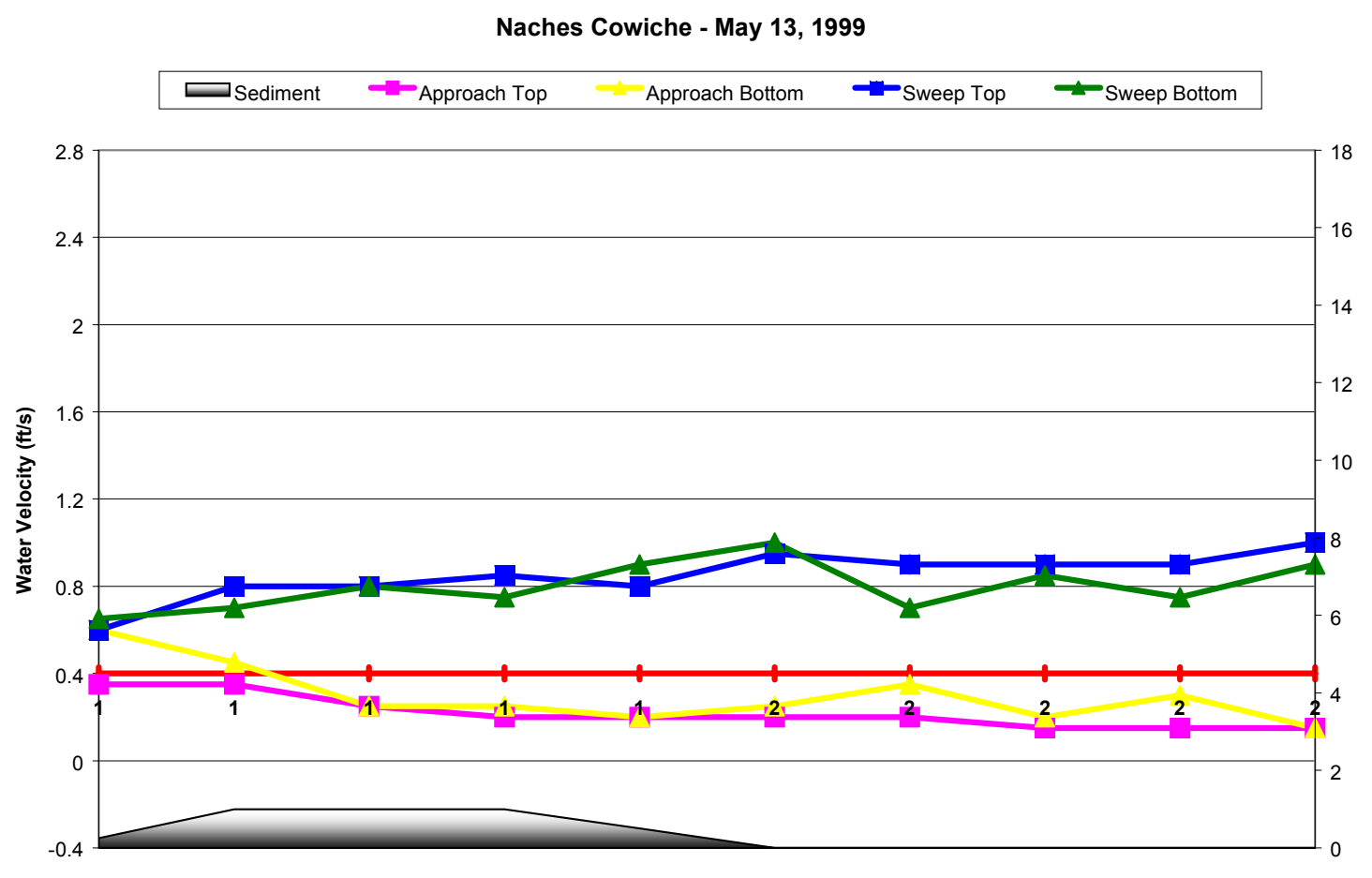

Screen Number (upstream to downstream)

Figure 15. Water velocities and sediment depths at Naches Cowiche, 5/13/99. 


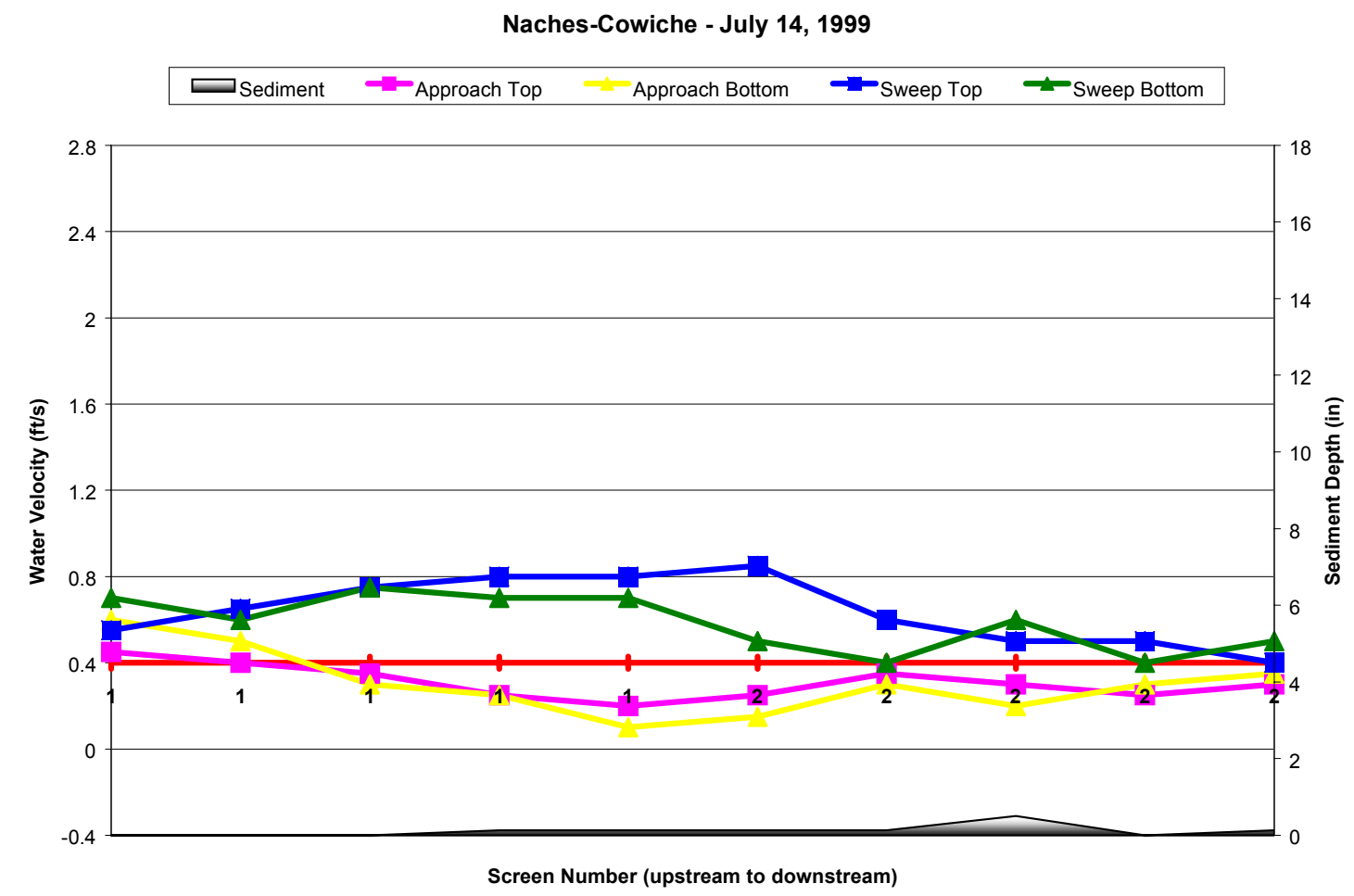

Figure 16. Water velocities and sediment depths at Naches Cowiche, 7/14/99.

Screens and seals were in good condition and drums turned evenly. Water always flowed over the weir. Conditions for fish at the outfall site were always good. In contrast to observations from 1997 and 1998, siltation was a not problem at this site when it was evaluated in 1999.

\section{New Cascade}

The site was evaluated 5/20/99 and 7/22/99. The approach velocities measured at New Cascade in July 1999 were below the $\leq 0.4$ fps NMFS criteria. However, sweep velocities were a problem on that July survey. Sweep velocities were generally lower than approach velocities until the very end of the last drum near the bypass (Figure 17). 


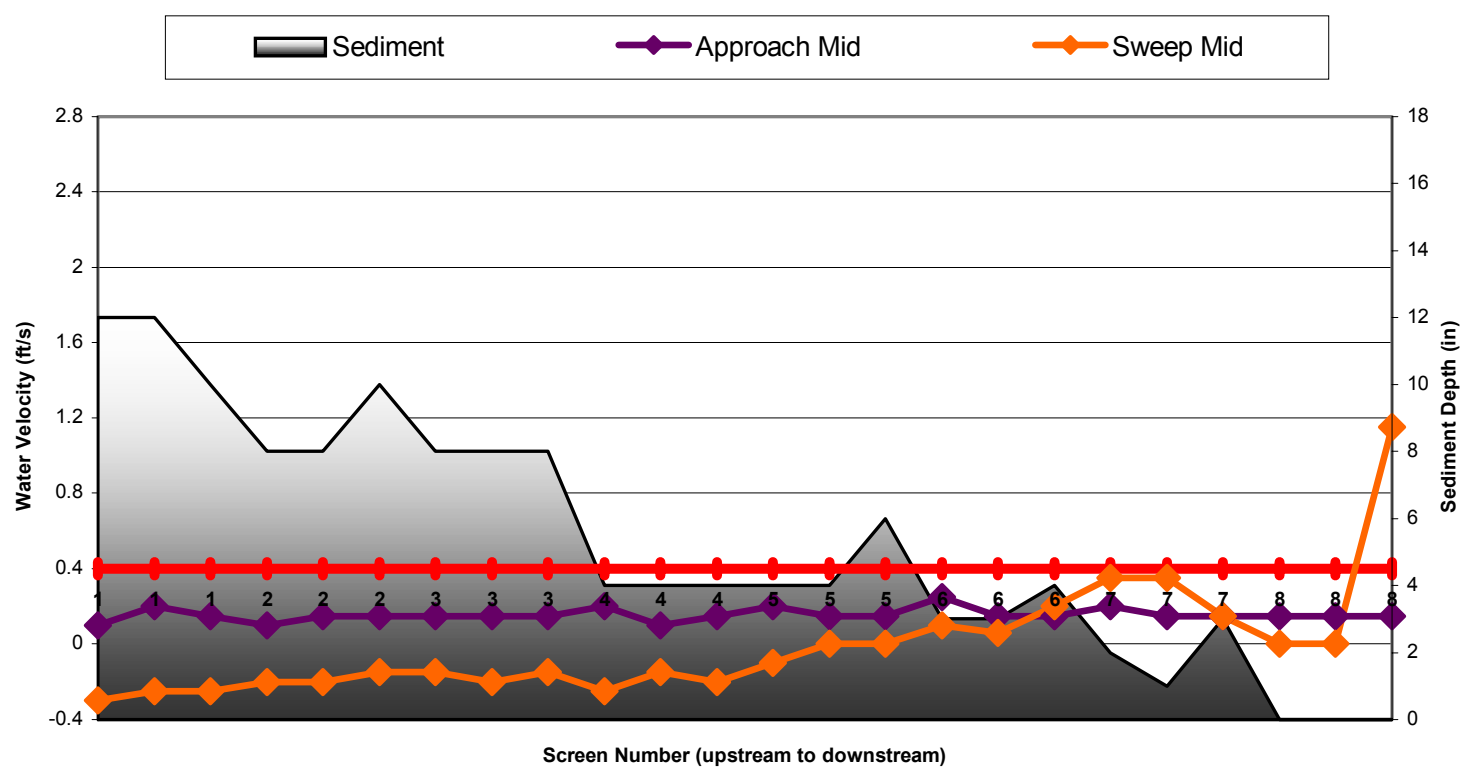

Figure 17. Water velocities and sediment depths at New Cascade, 7/22/99.

There appeared to be an inverse relationship between sediment depth and sweep velocity.

Sediment depth at the upstream end of the screens appeared to have been interfering with the operation of screen 1 . Screen 1 was not operating and was coated in algae and diatoms. Screen submergence was slightly high, $89 \%$ in May and $85 \%$ in July. Mean bypass velocities exceeded mean sweep velocities; however, many sweep velocities were negative. The screen material and seal condition looked generally good, with the exception of Screen 8, which had a worn-looking seal along the top. Water always flowed freely over the bypass weir and provided plenty of opportunity for fish passage. Outfall conditions for fish were always within NMFS criteria.

\section{$\underline{\text { Snipes-Allen }}$}

The Snipes-Allen site was evaluated 5/14/99 and 8/4/99. All approach velocities recorded at the Snipes-Allen site met NMFS criteria (Figure 18 and Figure 19). Sweep velocities were generally about the same as approach velocities until near the bypass where they increased. Mean bypass velocities exceeded mean sweep velocities at this site in 1999. Screen submergence was recorded at 81 and $86 \%$ (slightly above the criteria of $65-85 \%$ ). Silt was not a problem at this site in 1999. The screens were partially clogged with diatoms, and there was a small patch on screen 1. Although the screens were brown with algae, they rotated evenly, and the seals were in good condition. The cleaning system did not appear to be working when the site was evaluated in August. Water behind the bypass weir flowed smoothly, though slowly, in August. The outfall 
was submerged and appeared to be running smoothly. Other outfall conditions were acceptable for fish bypass.

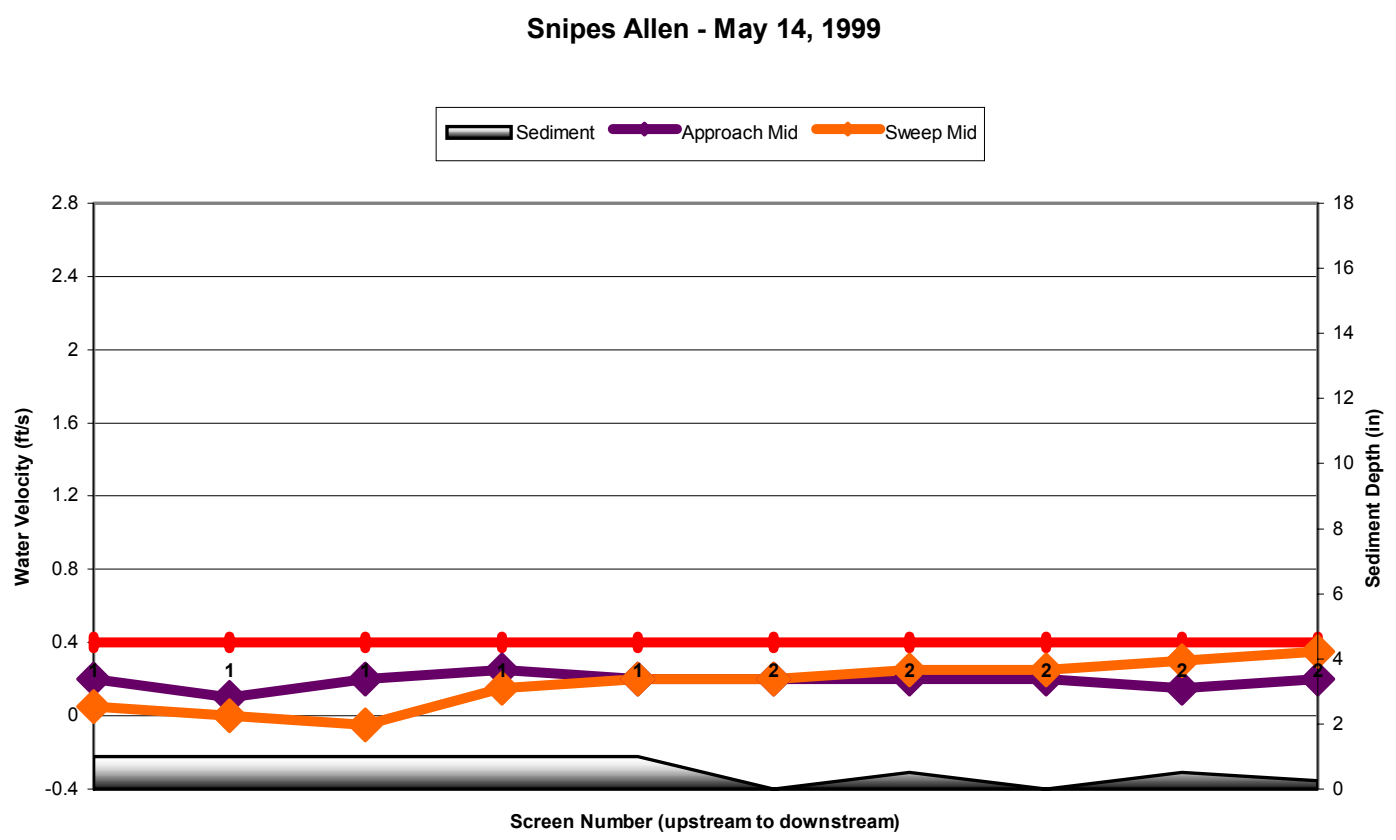

Figure 18. Water velocities and sediment depths at Snipes-Allen, 5/14/99. 


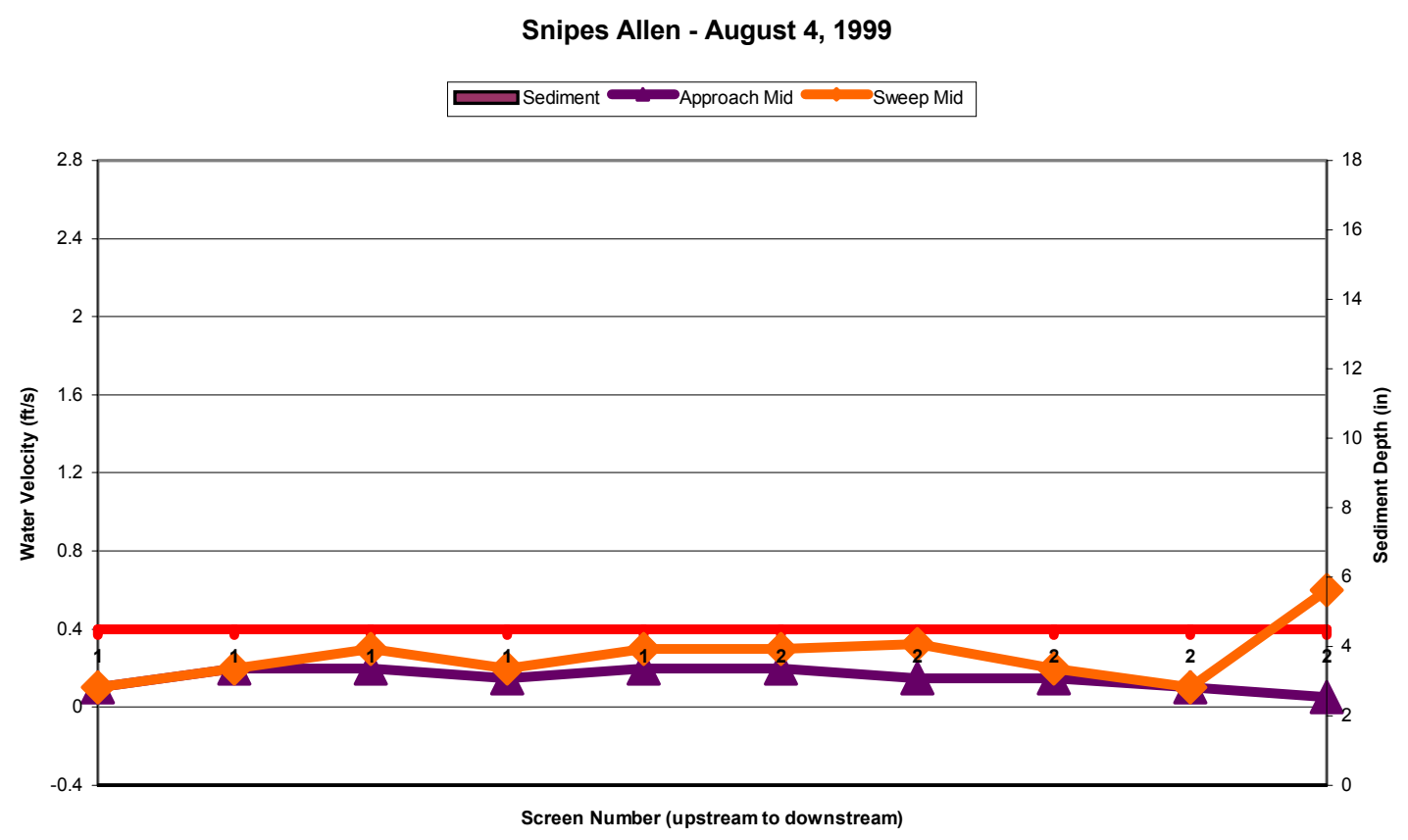

Figure 19. Water velocities and sediment depths at Snipes-Allen, 8/4/99.

Taylor

The Taylor site was evaluated 5/19/99 and 7/22/99. All approach velocities recorded met NMFS criteria. Sweep velocities were generally greater than the corresponding approach velocities and sweep velocities, increased toward the bypass in May (Figure 20), but not in July (Figure 21). Mean bypass velocities exceeded mean sweep velocities at his site in 1999. Screen submergence was 82 and $75 \%$.

Screens operated similarly to the way they did in September 1998; screen 2 exhibited a rough jerking motion. The screen seals, however, were in good condition. Debris was not much of a problem, and silt deposition was relatively low. Water flowed freely behind the bypass weir. The bypass outfall was running smoothly and it discharged into an area that was over $1 \mathrm{ft}$ deep. 


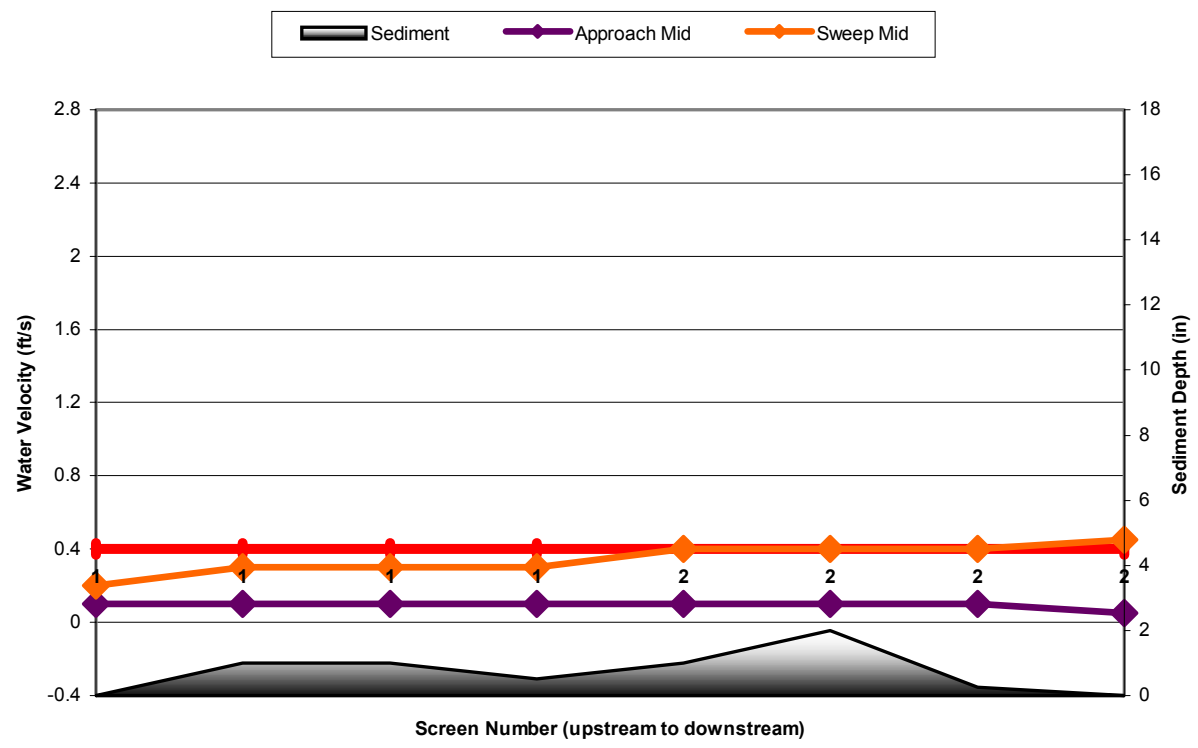

Figure 20. Water velocities and sediment depths at Taylor, 5/19/99.

Taylor - July 22, 1999

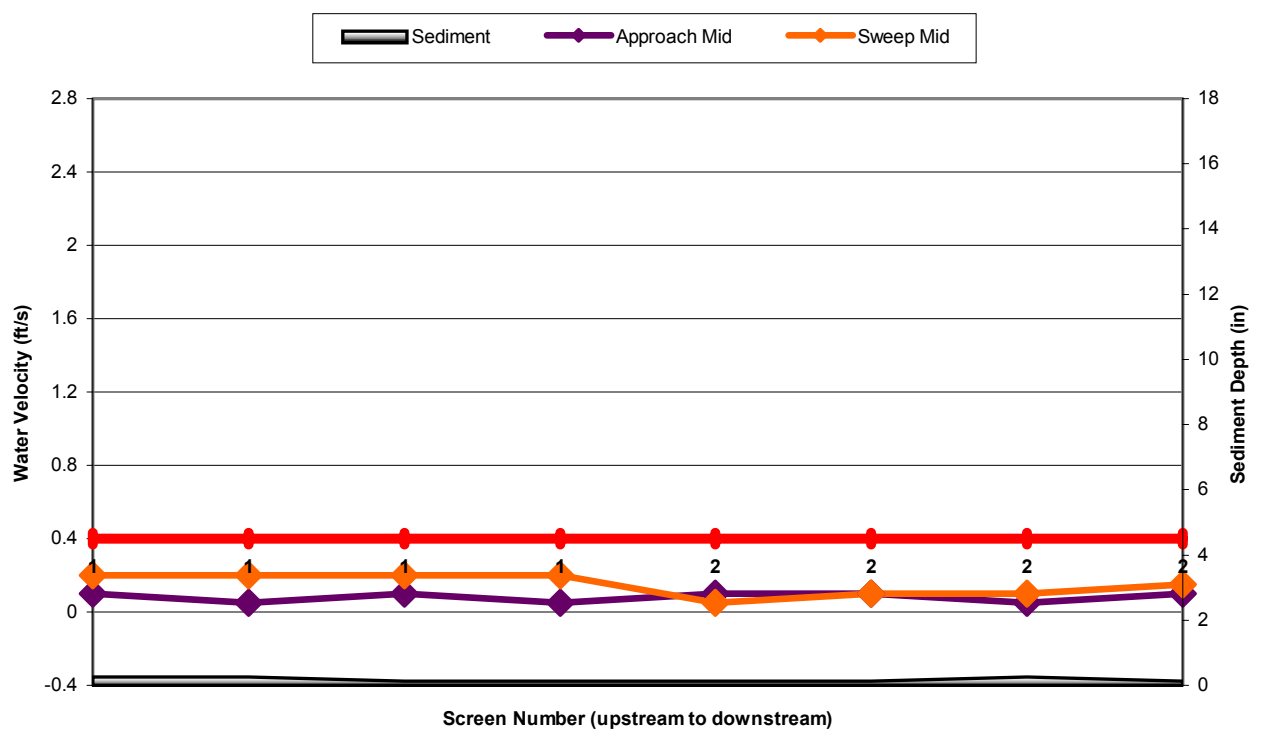

Figure 21. Water velocities and sediment depths at Taylor, 7/22/99. 


\section{Toppenish Pump}

This site was evaluated 5/19/99 and 7/22/99. About one-quarter of the approach velocities measured at this site in 1999 were higher than the NMFS allowed (Figure 22 and Figure 23). This was actually an 'improvement' from 1998, when $60 \%$ of approach velocities were $>0.4$ fps. Sweep velocities were generally greater than approach velocities and increased toward the bypass. Mean bypass velocities exceeded mean sweep velocities by a large margin. Screen submergence was approximately 81 and $80 \%$ on the May and July sample dates, respectively.

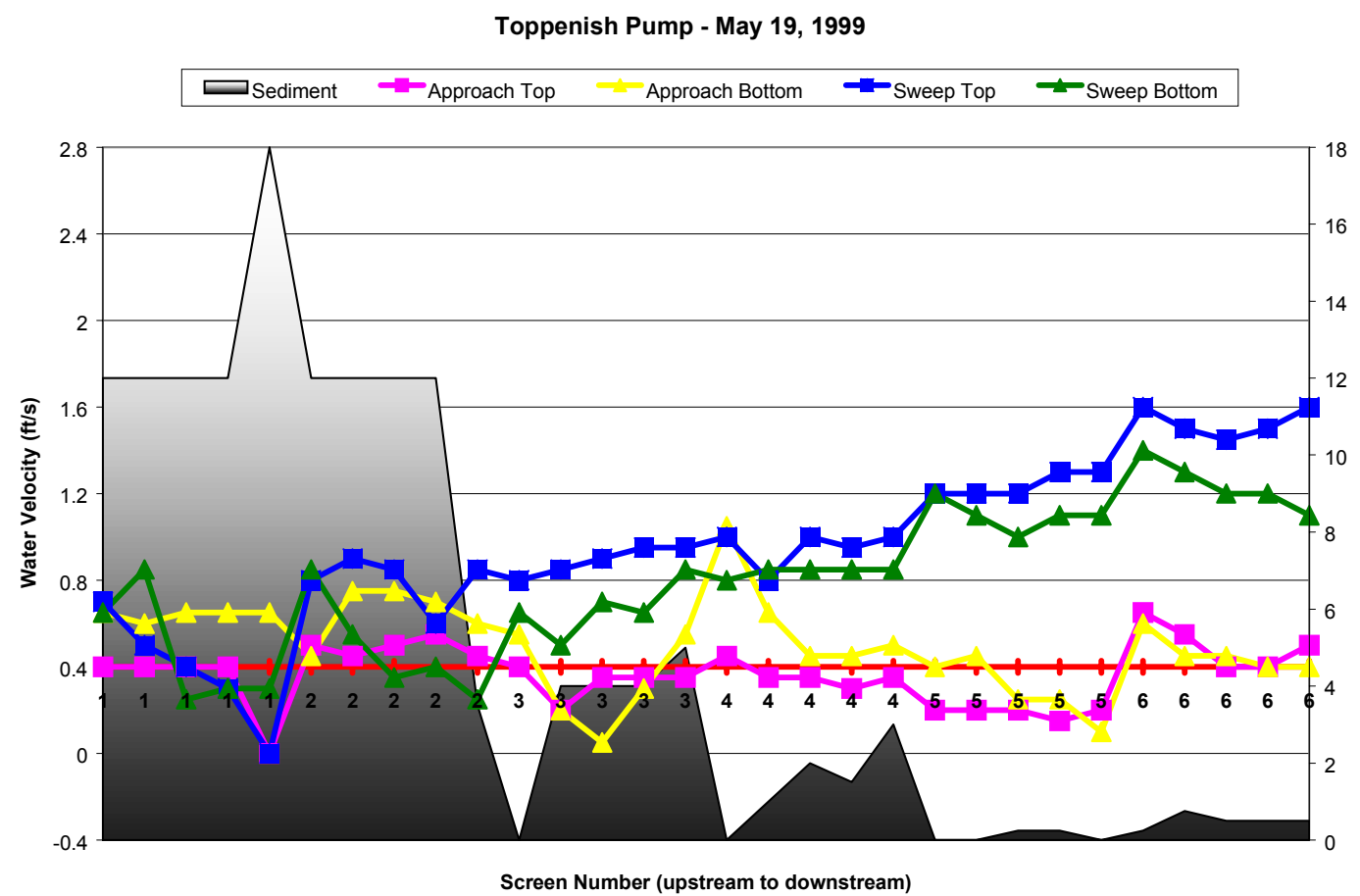

Figure 22. Water velocities and sediment depths at Toppenish Pump, 5/19/99. 


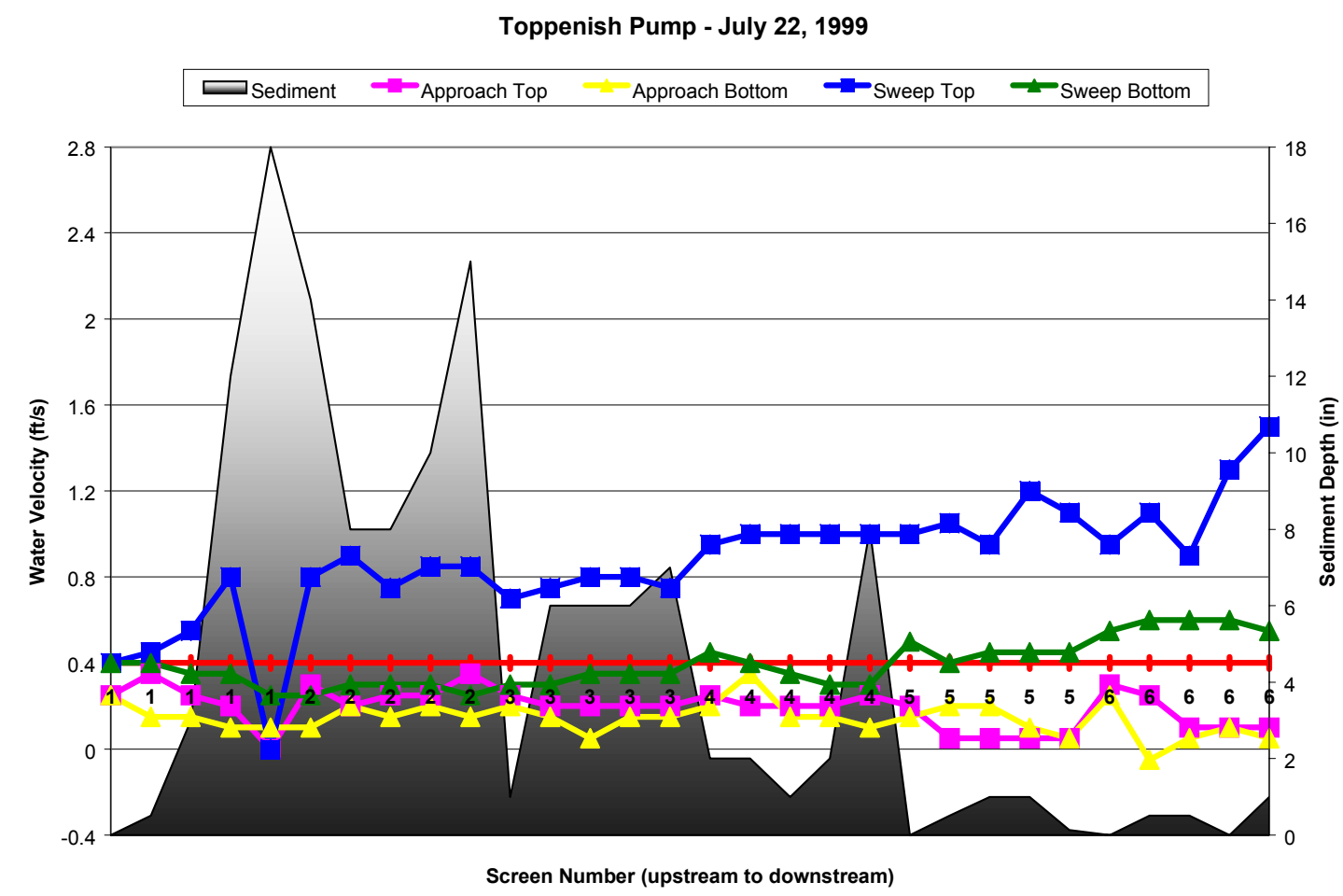

Figure 23. Water velocities and sediment depths at Toppenish Pump, 7/22/99.

Screens 3 and 4 were brown with diatoms and algae. All screens turned smoothly, and seals were generally in good condition, with the exception of the top seal on Screen 1, which was worn and had a possible gap in the side seal. Water flowed freely over the bypass weir, and all outfall conditions were acceptable for fish bypass. However, the area above the outfall pipe accumulates floating debris, and a mat of sticks was observed. There was up to $18 \mathrm{in}$. of silt in the forebay, with more noted upstream than downstream. Woody debris had accumulated in front of the screens, possibly due to the gap in the trash rack (Figure 24). Water in the canal was too turbid, and the silt was too deep to observe the bottom seal with the underwater video camera in May. Underwater video in July showed a possible gap in the side seal of screen 1. 


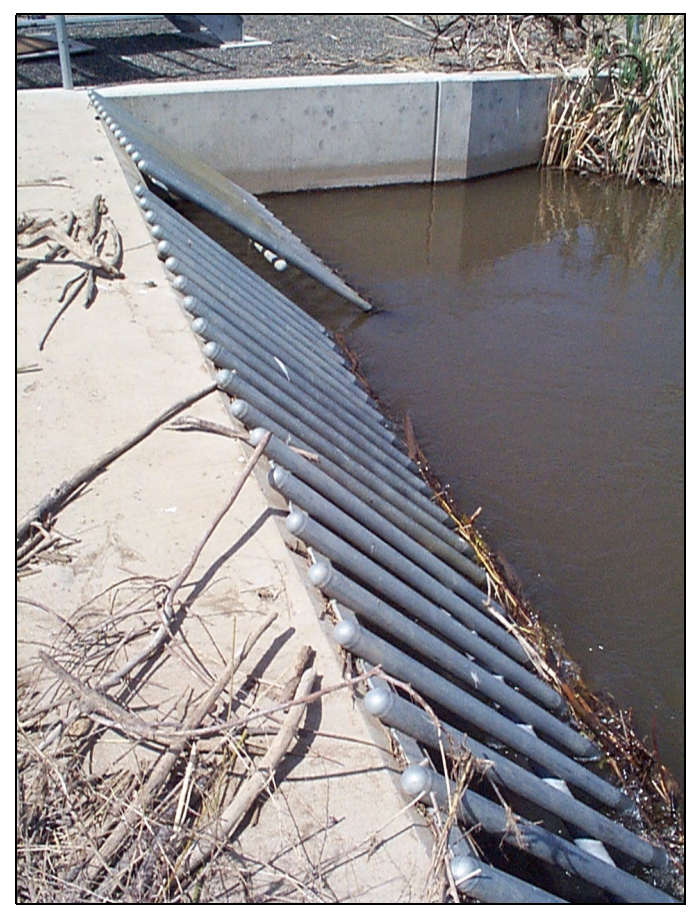

Figure 24. Trash rack at Toppenish Pump site, note separation of metal grate and concrete.

\section{WIP Upper}

The WIP upper site was visited 5/12/99 and 7/15/99. Almost all of the recorded approach velocities met NMFS criteria (97.5\%) (Figure 25 and Figure 26). Sweep velocities generally exceeded approach velocities; however, they did not typically increase toward the bypass. Mean bypass velocities were greater than mean sweep velocities at this site in 1999. Screen submergence levels were 79 and $81 \%$.

Uneven wear was noted by observing patterns of algal growth on the screens. Screens 1 and 4 had some clean (rubbed) sections while Screens 2 and 3 were clean. It looked like there were small gaps in the seal at screen 1 . There was too much silt in front of the seals at Screens 3 and 4 to examine the screen seals with the underwater video camera. Adequate water was bypassed, and water was running freely behind the bypass weir. Outfall conditions at the terminus of the bypass pipe were good for fish passage. 


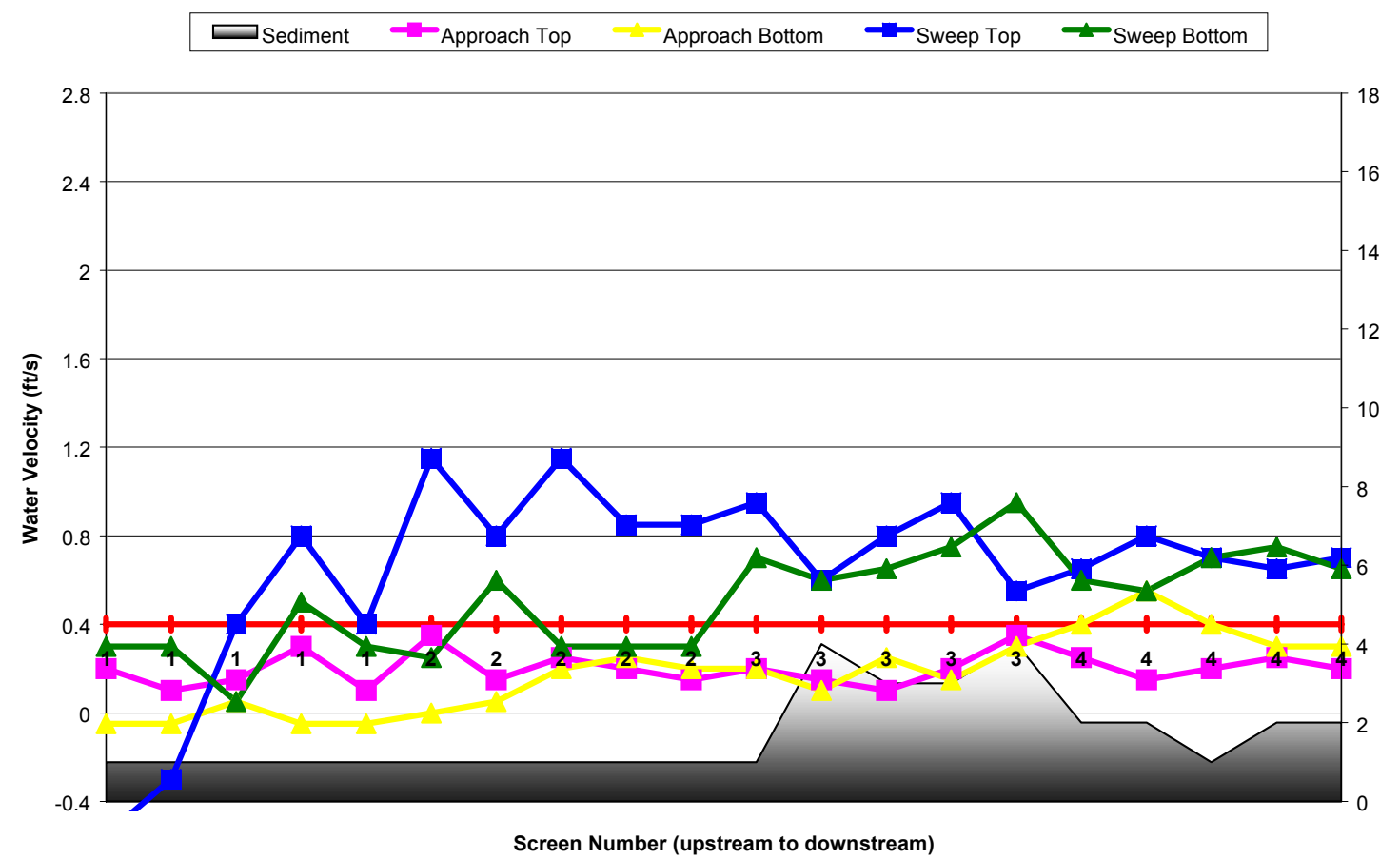

Figure 25. Water velocities and sediment depths at the WIP upper site, 5/12/99.

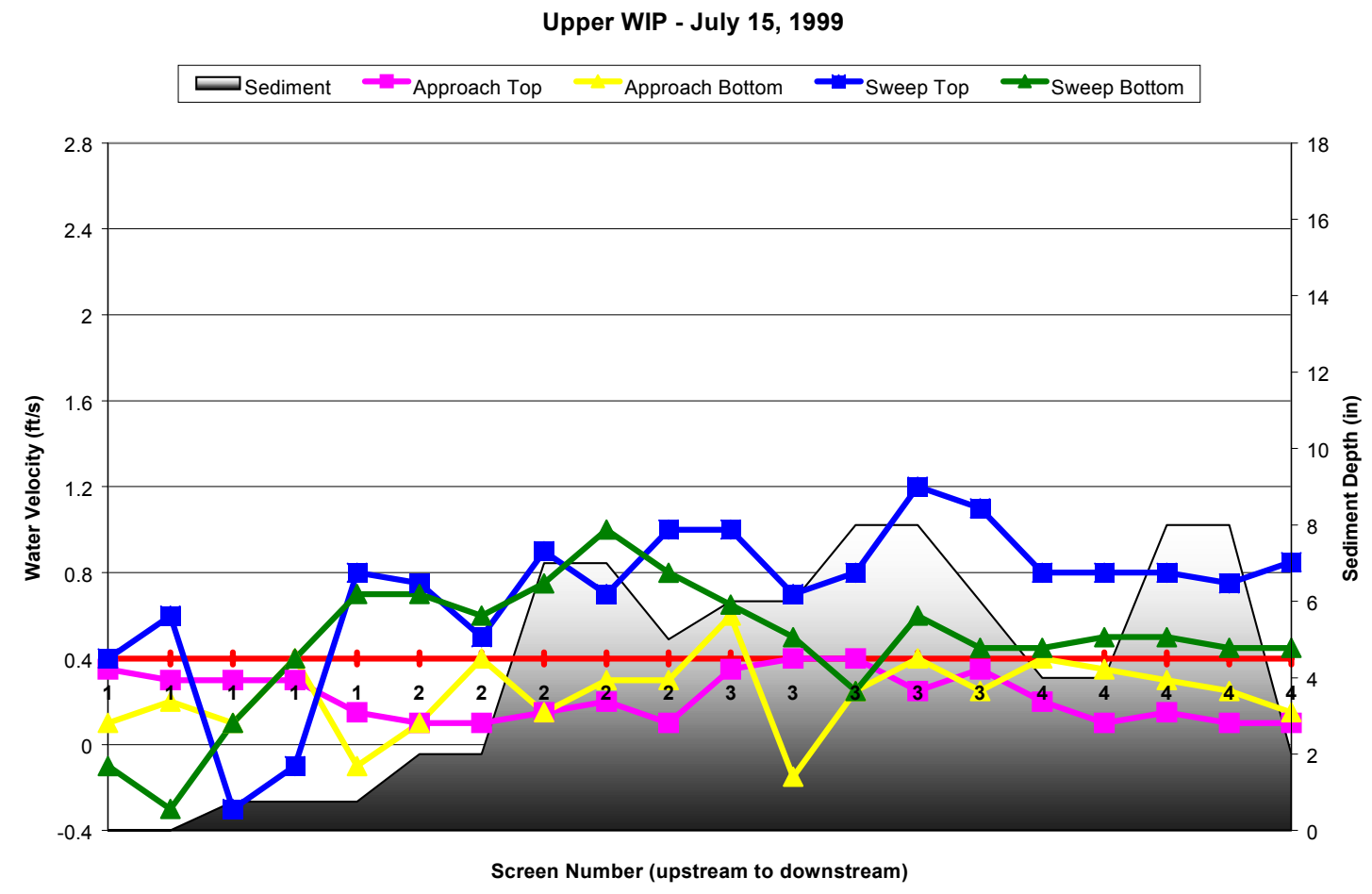

Figure 26. Water velocities and sediment depths at the WIP upper site, 7/15/99. 


\section{Flat Plate Screens}

$\underline{\text { Bull }}$

The Bull site was evaluated 5/20/99 and 7/23/99. About $15 \%$ of the recorded approach velocities exceeded 0.4 fps. Sweep velocities were not consistently higher than approach velocities, and there was often disparity between top and bottom sweep velocities (Figure 27 and Figure 28). Overall, sweep was slow, and bottom sweep values were often less than corresponding approach velocities. Water in front of the screens was always high, and submergence values for the flat plate screen was $94 \%$ on $5 / 20 / 99$.

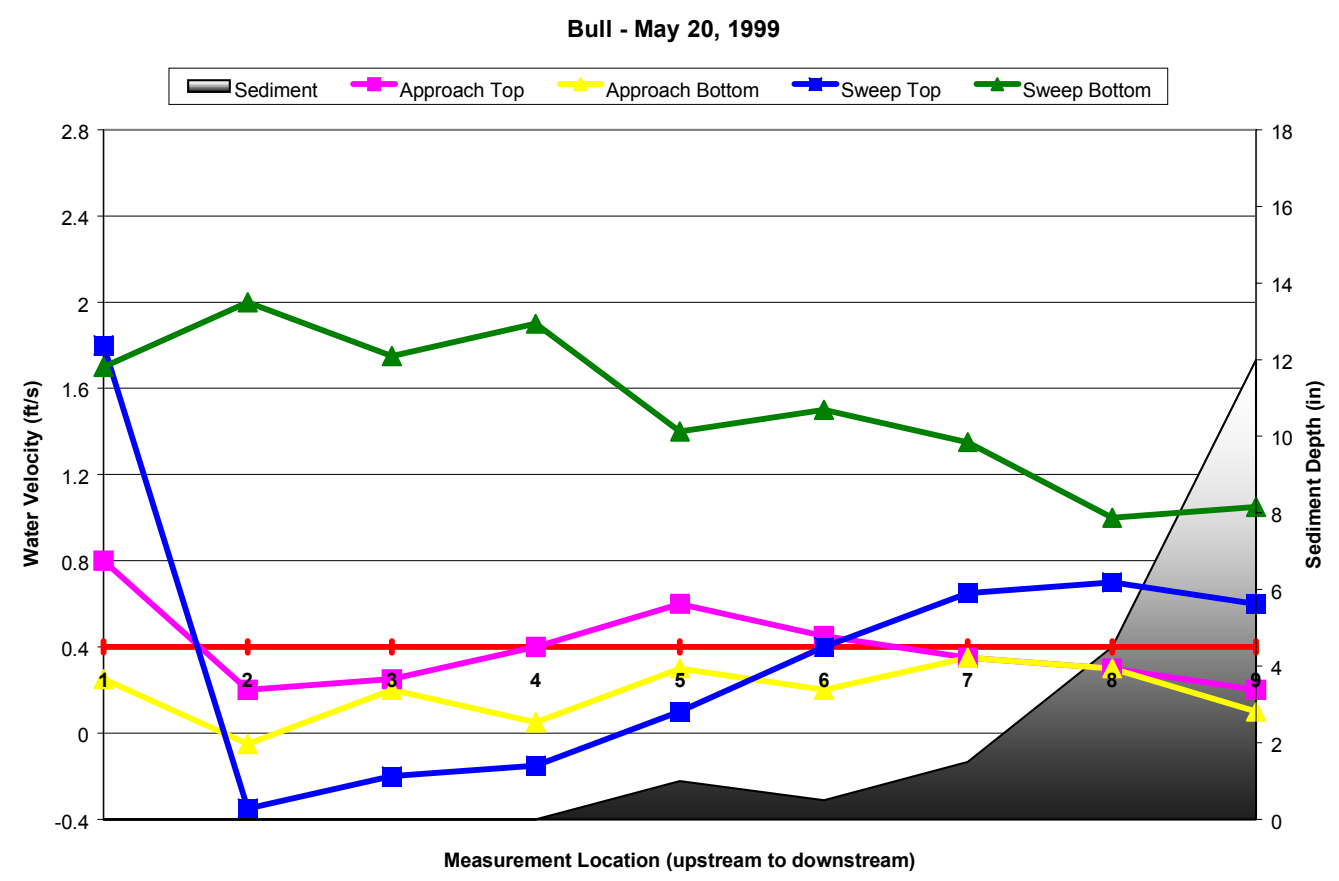

Figure 27. Water velocities and sediment depths at Bull, 5/20/99. 
Bull - July 23, 1999

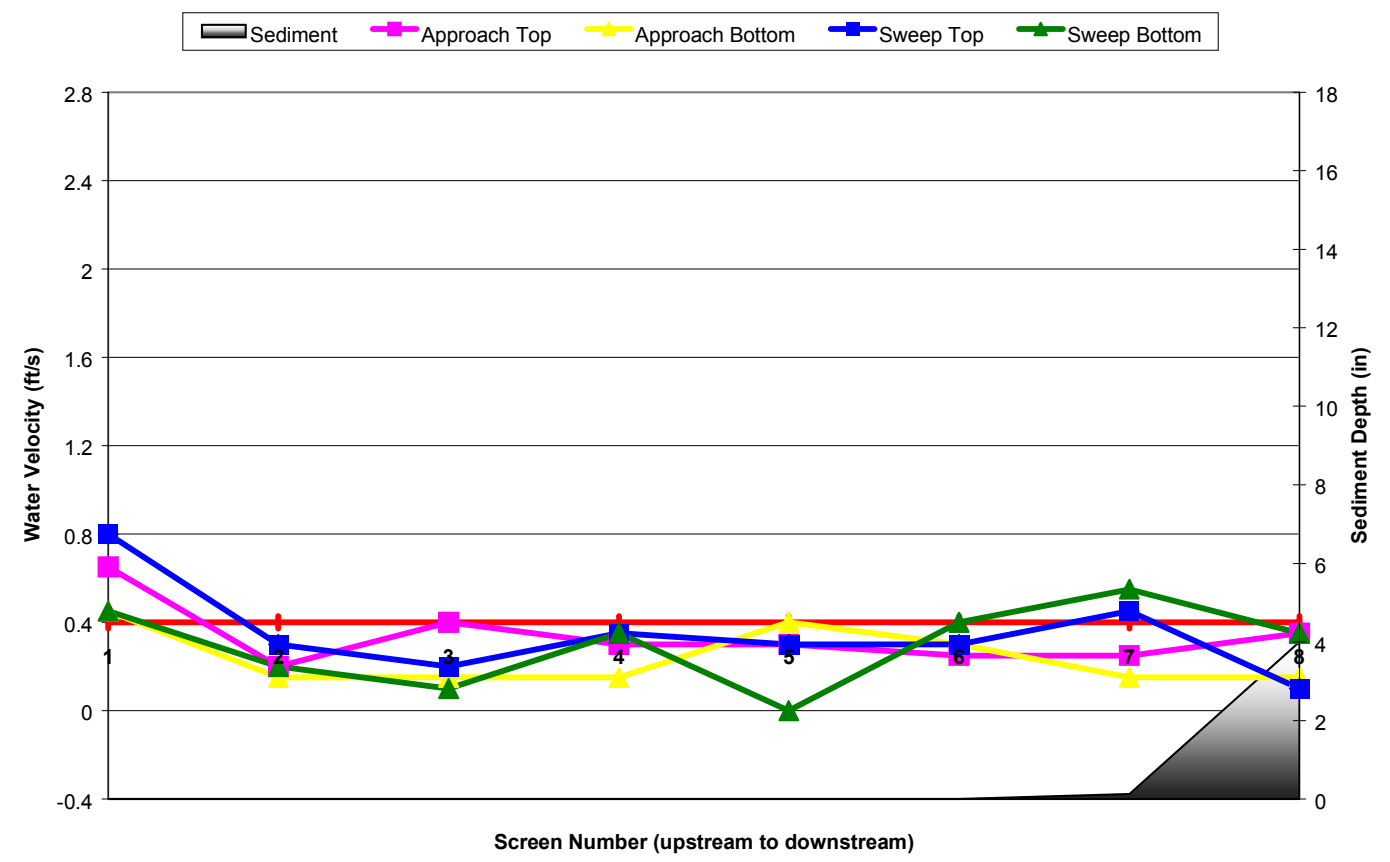

Figure 28. Water velocities and sediment depths at Bull, 7/23/99.

The screens and seals were generally in good condition, though it was difficult to assess screens and seals from the surface. Some leafy material and sticks/limbs were getting stuck in the trash rack and on the screen. The cleaning brushes were ineffective, especially on screen 4, where the brush was not touching the screen. During the May survey, no silt was observed along the upstream end of the screen and increased toward the downstream end of the screen where approximately $12 \mathrm{in.} \mathrm{of} \mathrm{sand} \mathrm{and} \mathrm{leaves} \mathrm{had} \mathrm{accumulated.} \mathrm{By} \mathrm{July,} \mathrm{the} \mathrm{amount} \mathrm{of} \mathrm{silt} \mathrm{near} \mathrm{the}$ downstream panel was about 4 in. deep.

\section{Ellensburg Mill}

The Ellensburg Mill site was evaluated 5/19/99 and 7/23/99. In May, approach velocities did not exceed sweep velocities (Figure 29). When we measured top and bottom velocities separately in July, we found that top velocities were much faster than bottom velocities (Figure 30 ). When all approach velocities are considered, $33 \%$ were greater than $0.4 \mathrm{fps}$. In most other cases, sweep velocities exceeded their corresponding approach velocities. However, sweep did not generally increase near the bypass, and mean bypass velocities were lower than mean sweep velocities. This flat plate screen does not appear to have any submergence problems as measured submergence values were only 25 and 34\% during the 1999 evaluations. 
Ellensburg Mill - May 19, 1999

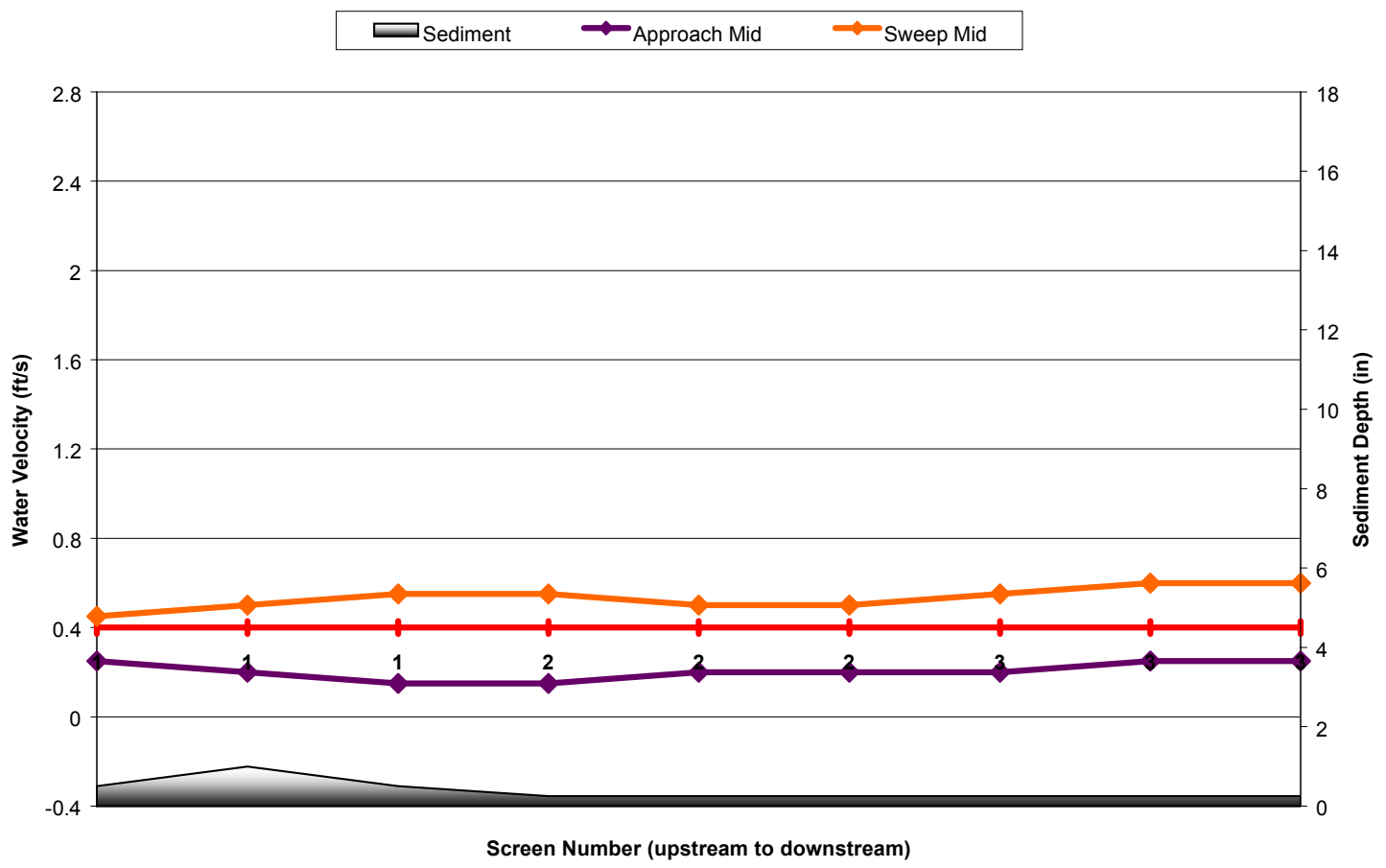

Figure 29. Water velocities and sediment depths at Ellensburg Mill, 5/19/99.

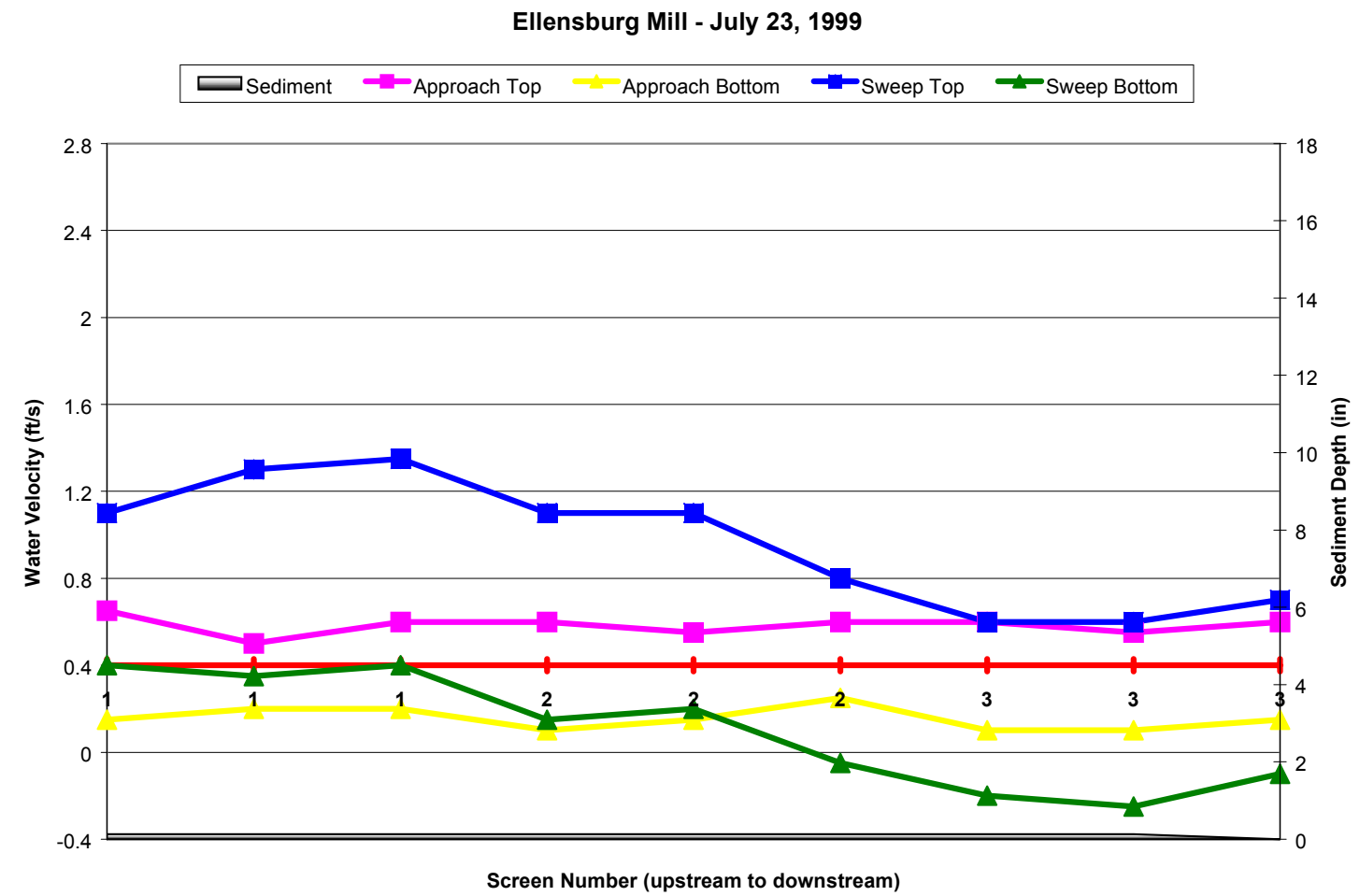

Figure 30. Water velocities and sediment depths at Ellensburg Mill, 7/23/99. 
The screens were in good condition, but the seal caulking at Screen 1 had come loose or was missing. Water flowed over the bypass weir and flowed freely behind the weir. Conditions within the bypass and at the outfall were also good for fish passage in 1999.

\section{$\underline{\text { Fruitvale }}$}

The Fruitvale site was evaluated 5/13/99 and 7/14/99. Electrical interference kept us from collecting any reliable water velocities. In addition, extremely turbid water made accurate documentation of screen and seal condition difficult during the May evaluation. Limited underwater video footage was collected during the July evaluation. Screen submergence levels were approximately 94 and 100\%. The log book contained no records of screen overtopping. Adequate water always flowed over the bypass weir, and outfall conditions were good for fish passage. No sediment was observed in front of the screen in May. In July, sediment was approximately $0.5 \mathrm{in}$. deep around panel 2. Water flowed freely behind the bypass weir, and the outfall was running smoothly, with the exception of some entrapped air in May.

\section{$\underline{\text { Naches-Selah }}$}

This site was evaluated 5/17/99 and 8/4/99. Almost $28 \%$ of the approach velocities at Naches-Selah were greater than 0.4 fps (Figure 31 and Figure 32). This was a significantly higher than during the previous two years (1997: 5.5\%; 1998: 2.8\%). The high approach velocities were most apparent in August. Sweep velocities were always much greater than their corresponding approach velocities. Bypass velocities were always higher than the average sweep velocities. Screen submergence values for this flat plate screen were 82 and $85 \%$.

The screen was in generally in fair condition. There were some rust areas showing, and a small patch was on screen 5 . Screen 3 had perf plate attached to the face of the profile bar screen. As a result, screen 3 accumulated more leaf matter than adjacent screens. The cleaning system was not touching the entire length of the screen, leaving grasses and leaves behind. Underwater video revealed some loose caulking between panels 2 and 3, 3 and 4, 4 and 5, and 5 and 6 . Adequate amounts of water flowed over the weir at all times, and outfall conditions were good for fish passage. Sedimentation was not excessive at Naches-Selah in 1999. Silt depths ranged from 0 to about 4 in. 
Naches Selah - May 17, 1999

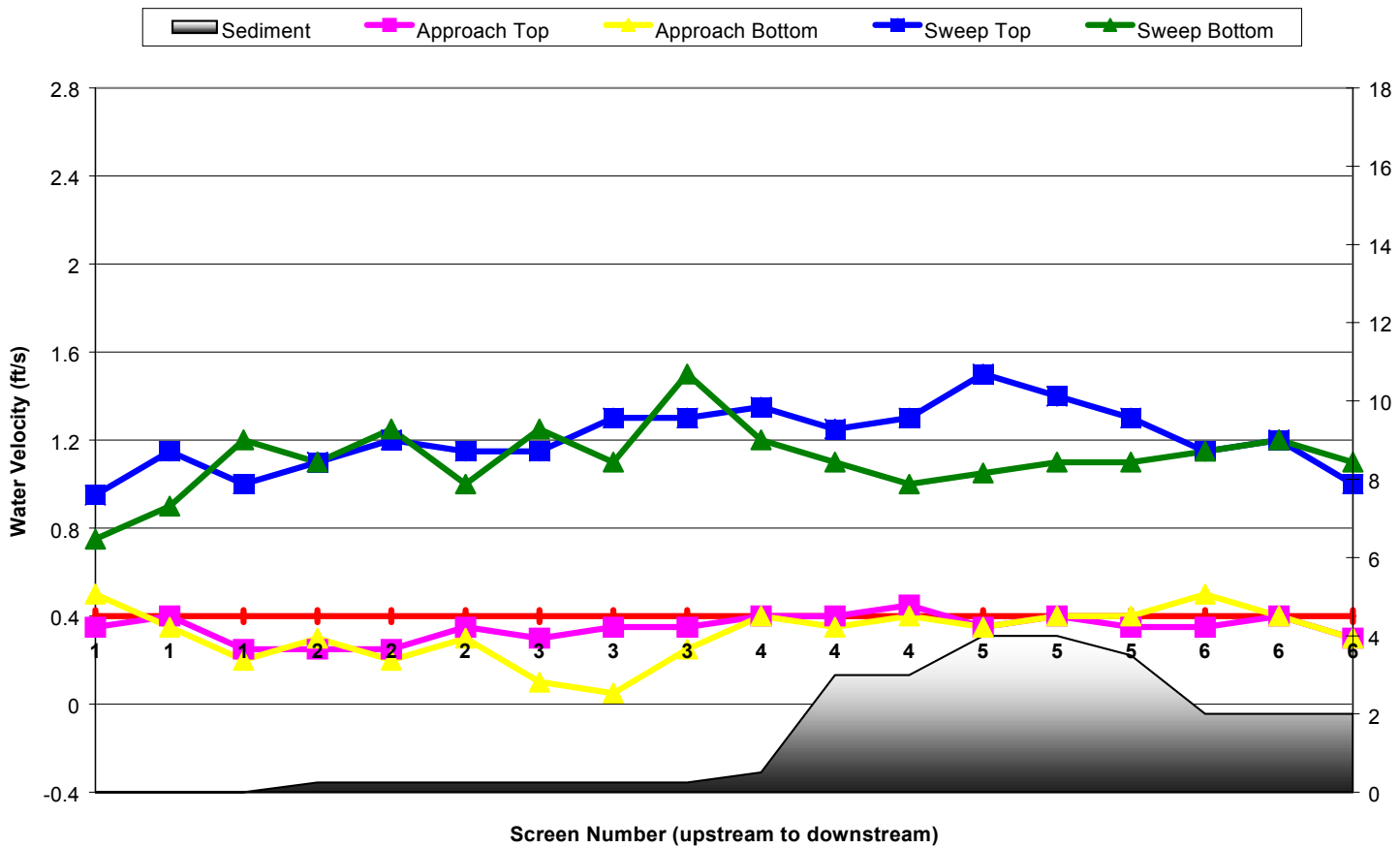

Figure 31. Water velocities and sediment depths at Naches-Selah, 5/17/99.

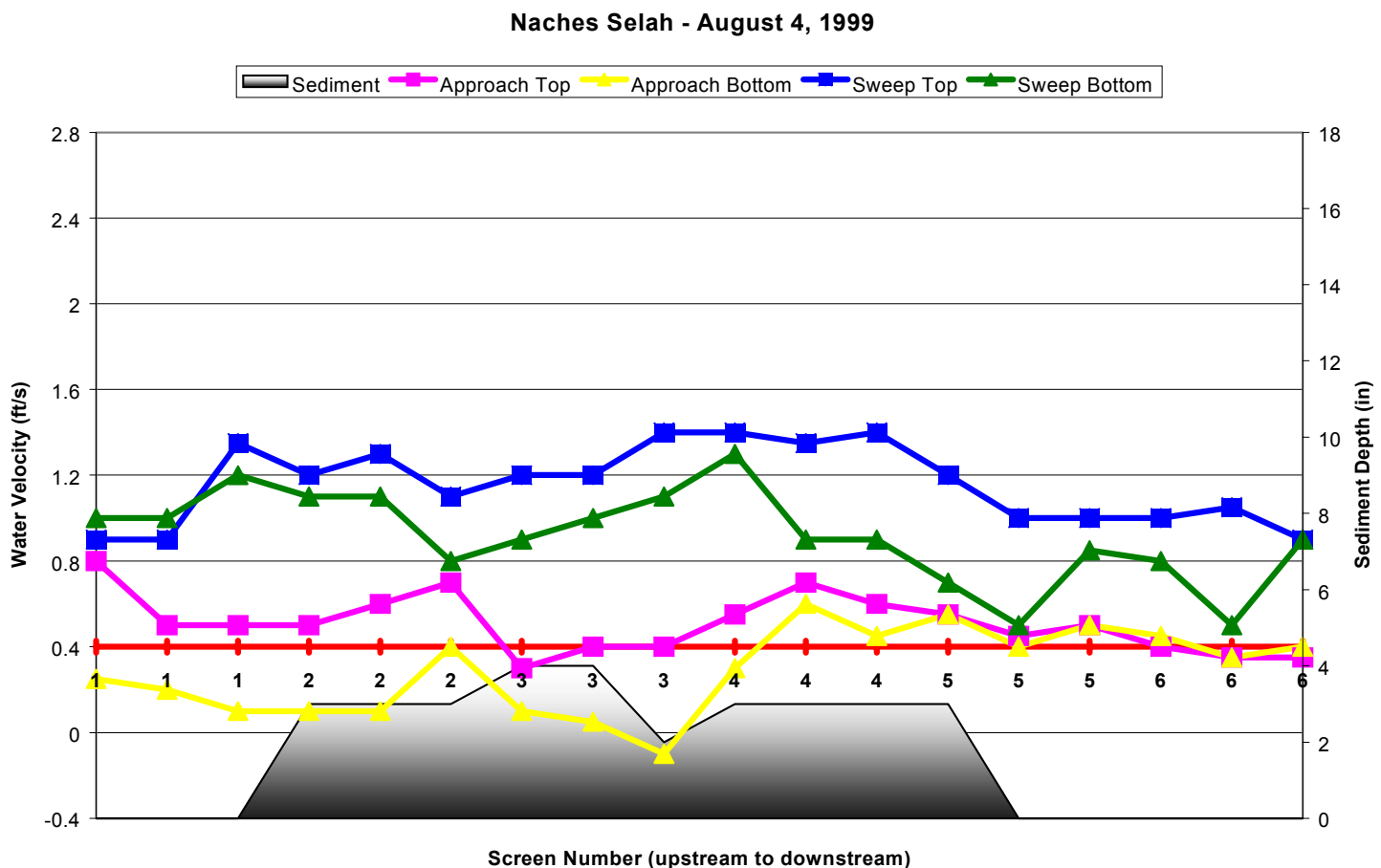

Figure 32. Water velocities and sediment depths at Naches-Selah, 8/4/99. 


\section{Union Gap}

The Union Gap site was evaluated 5/13/99 and 7/14/99. Approach velocities were much higher in 1999 than in previous years. Nearly 23\% of the approach velocities exceeded $0.4 \mathrm{fps}$ (Figure 33 and Figure 34). Sweep velocities, while always greater than corresponding approach velocities, generally decreased toward the bypass and were greater than the bypass velocities. Screen submergences at this flat plate site were 85 and $80 \%$. Screen submergence marks were present, but difficult to read because they were under the cleaning system when it was at rest.

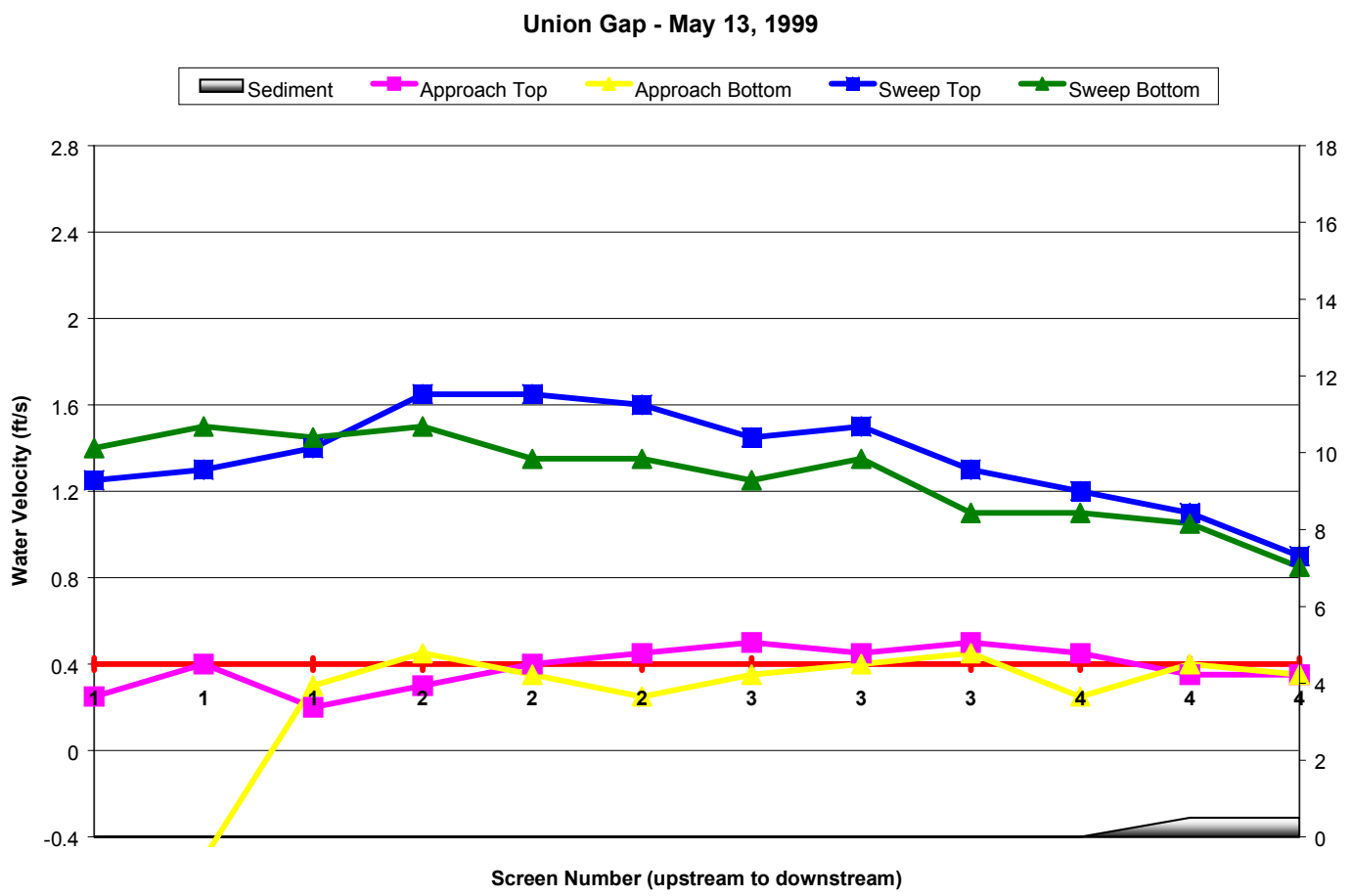

Figure 33. Water velocities and sediment depths at Union Gap, 5/13/99. 


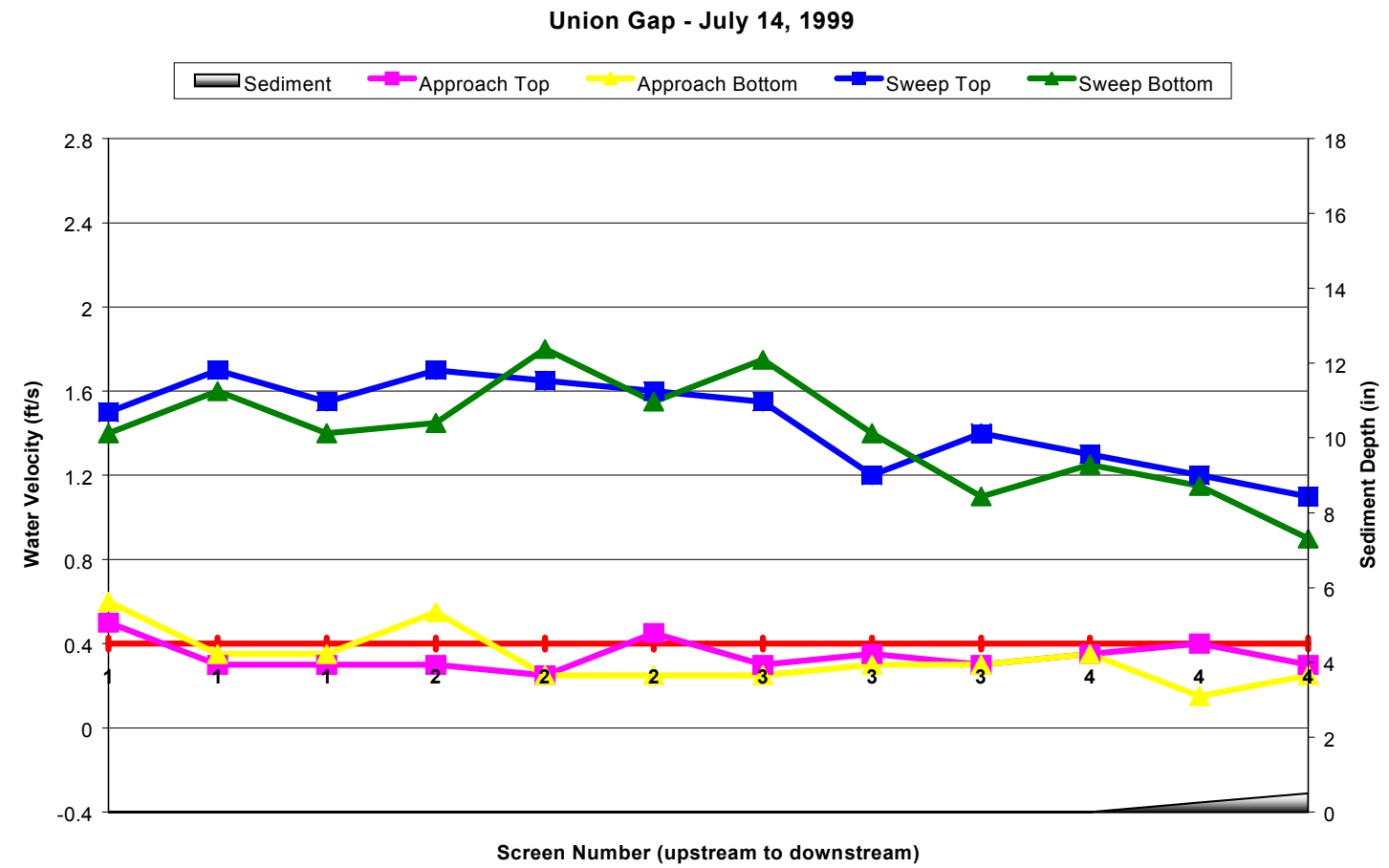

Figure 34. Water velocities and sediment depths at Union Gap, 7/14/99.

The screen and seals were in good condition; however, Screen 3 had a metal plate partially covering it. Screen seals were in poor condition, with missing caulking between screens 2 and 3 and 3 and 4. Adequate amounts of water always flowed over the bypass weir, and all other outfall conditions were good for fish passage. Sediment was not a problem at this site during the 1999 evaluations. The cleaning system failed to remove all leaves because the interval set for brush operation (approximately 1 hour) was too long.

\section{Yakima-Tieton}

The Yakima-Tieton site was evaluated 5/17/99 and 7/21/99. Eighty-eight percent of the recorded approach velocities were less than $0.4 \mathrm{fps}$ (Figure 35 and Figure 36). There is a fast flow at this site, and sweep velocities were always much higher than their corresponding approach velocities. However, sweep velocities did not increase toward the bypass, but sweep velocities were generally high enough to mitigate this condition. Sweep velocities were slightly higher than bypass velocities. Screen submergence at Yakima-Tieton was approximately 56 and $71 \%$. 


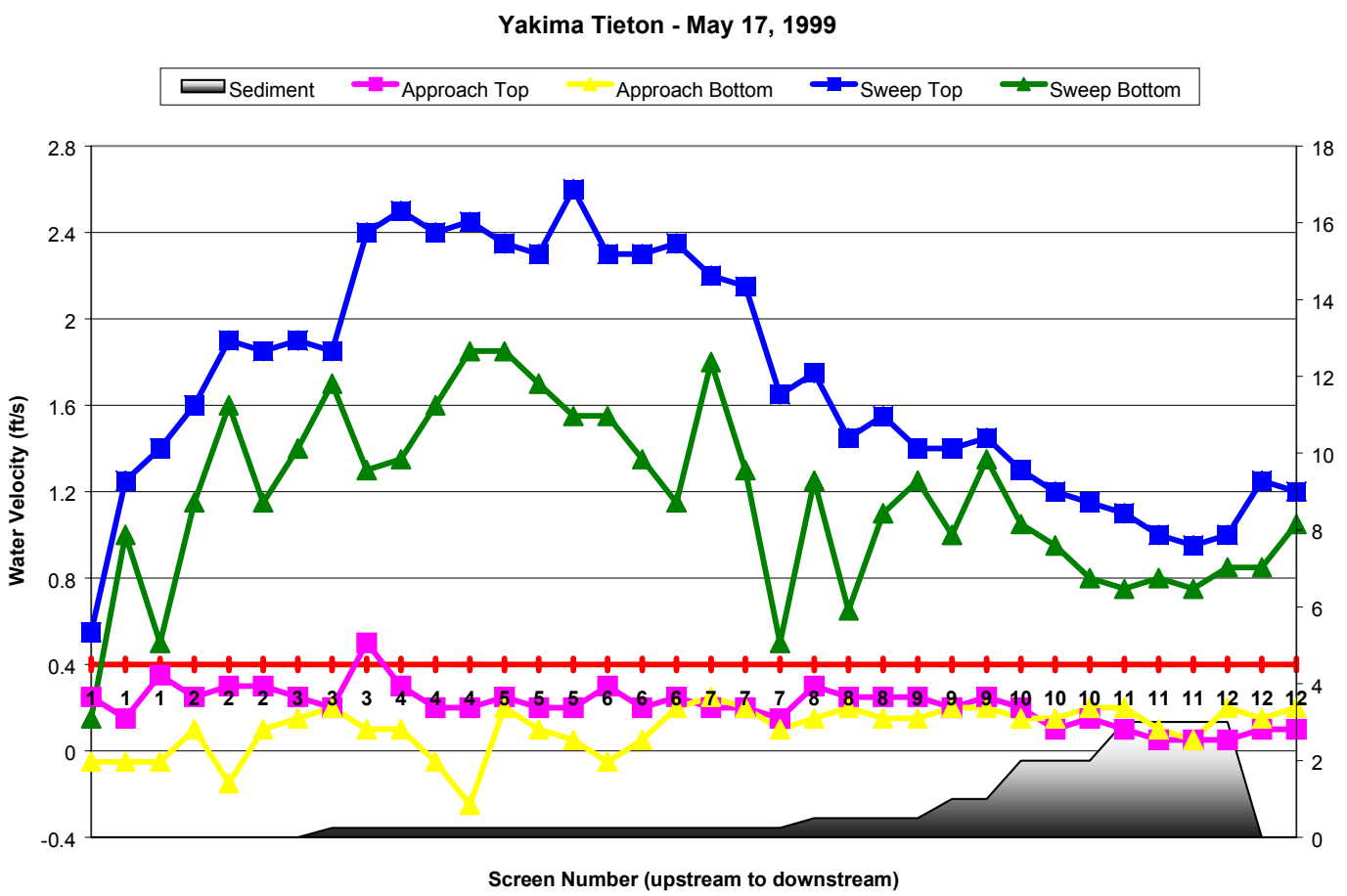

Figure 35. Water velocities and sediment depths at Yakima Tieton, 5/17/99.

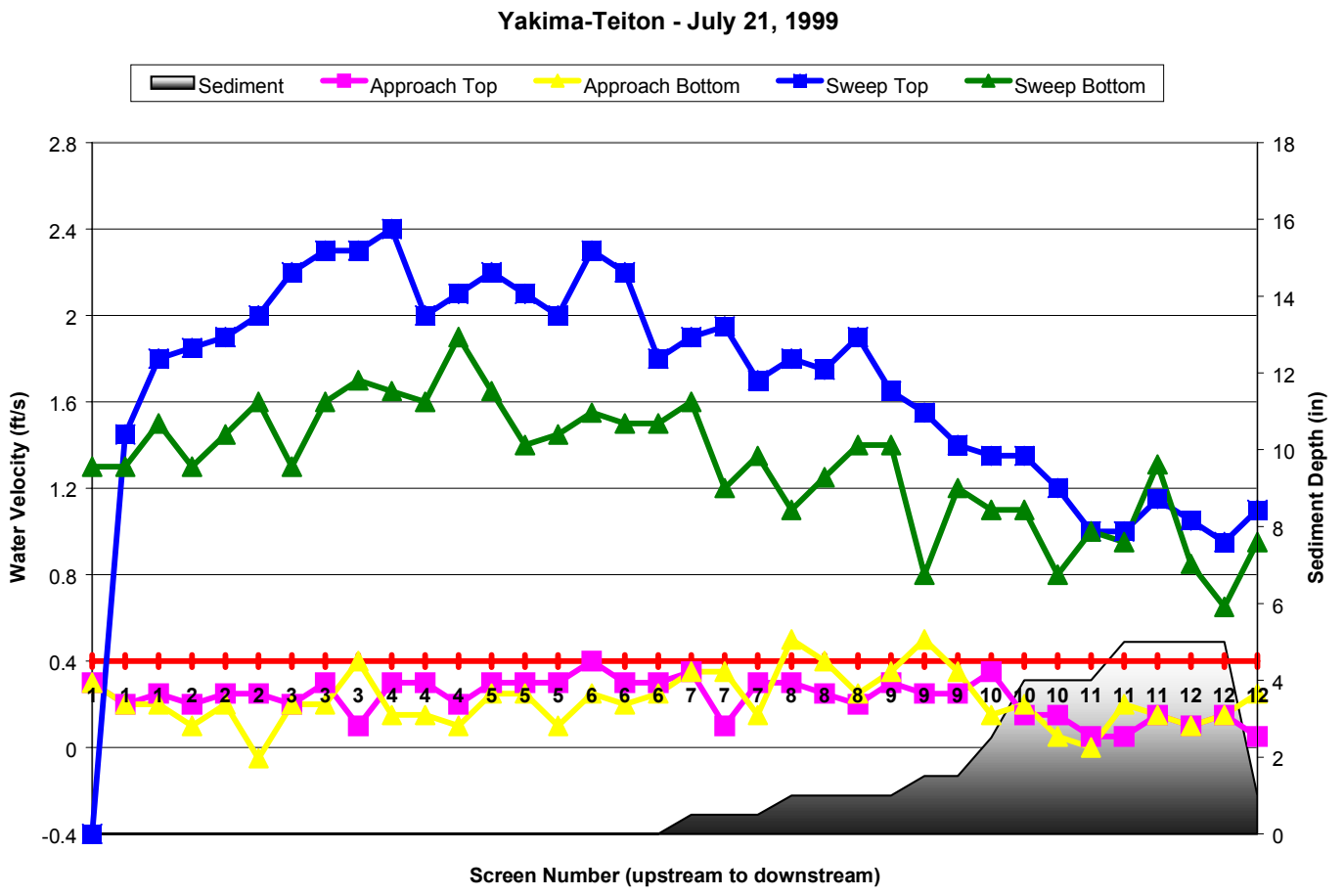

Figure 36. Water velocities and sediment depths at Yakima Tieton, 7/21/99. 
The screens were in good condition. Screen seals were in poor condition (Figure 37). On screen 3 the side seal caulking was cracking and the bottom corner was failing. On Screens 4 and 5 , the bottom seal was coming out, and the side seal was cracking. On Screen 6, 6 in. of the side caulking was missing, and 1 in. was cracked. On Screens 7, 8, and 10, the bottom seal was missing, and the sides were cracking. On screens 9,11 , and 12 , the bottom seals were missing or loose. Water was flowing over the bypass weir so fast in May that it hit the wall and rushed back towards the weir. Water flowed freely behind the weir in July. Outfall conditions were good for fish passage. Although there was never excessive sand, silt, or woody debris, there was a lot of leaf litter and small twigs that accumulated on the screens between brushings, especially in May. Generally, silt accumulated along the downstream half of the screen, though it was rarely greater than 4 in. deep.

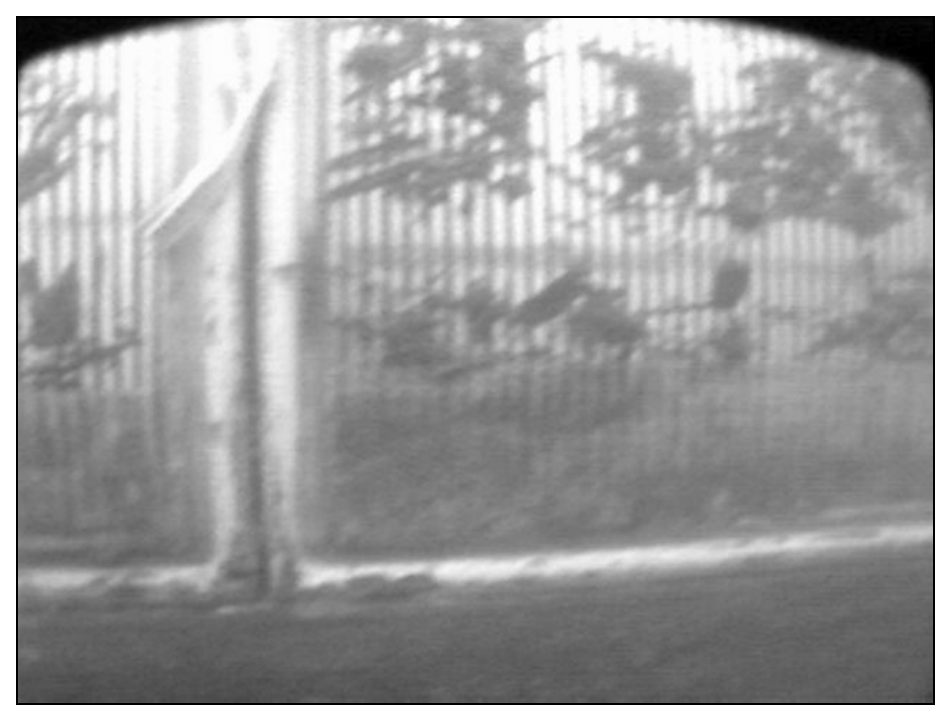

Figure 37. Loose/missing caulking on Yakima-Tieton screens, 7/21/99.

\section{Younger}

The Younger site, near Cle Elum, was evaluated for the first time on 5/20/99 and again on 7/23/99. All approach velocities were below NMFS criteria of $0.4 \mathrm{fps}$ (Figure 38 and Figure 39). Sweep velocities generally exceeded approach velocities. Screen and seal conditions were good. This site has no bypass. The cleaning brushes were running continuously, and seemed to affect water velocities. Debris was not a problem at Younger during the 1999 evaluations. 


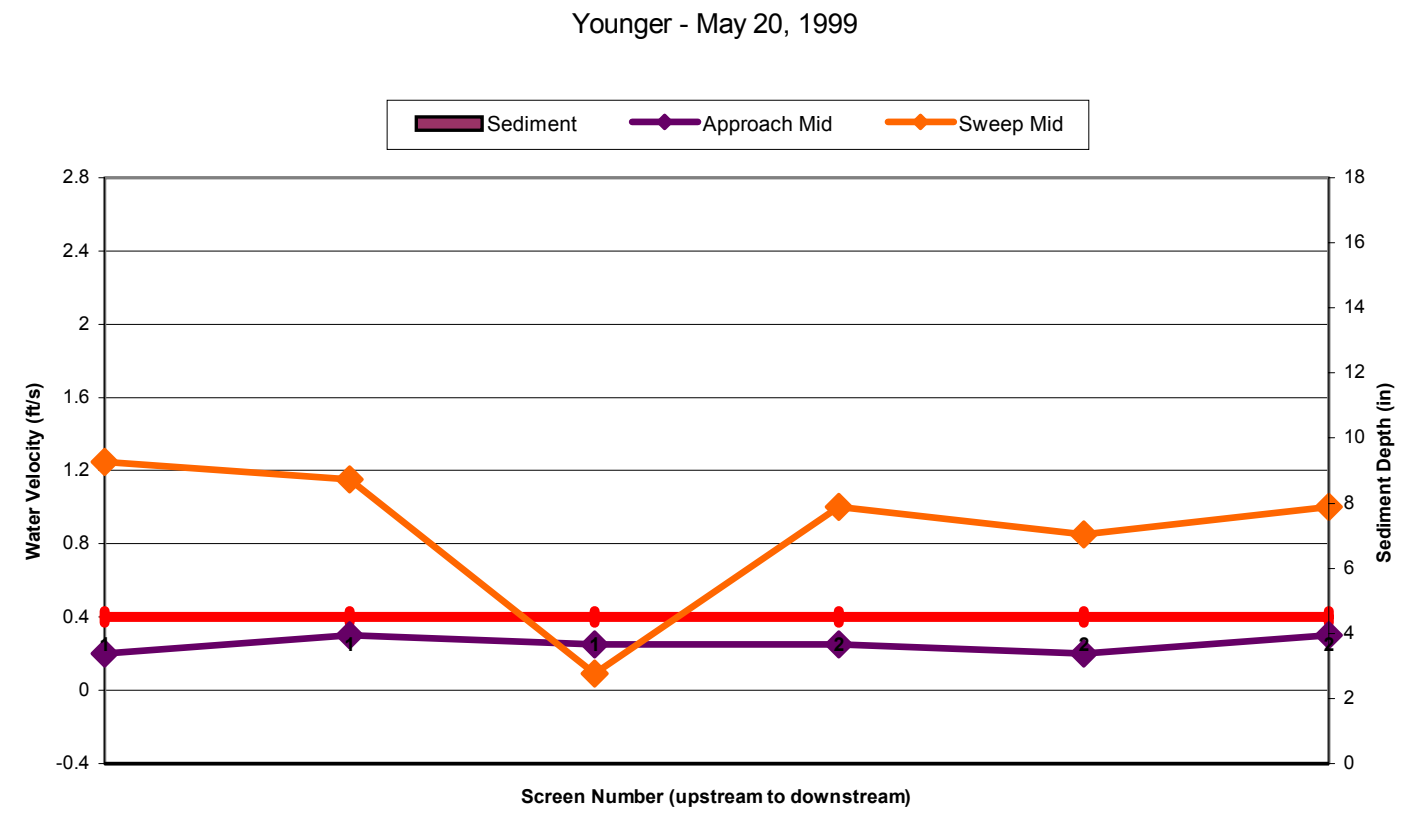

Figure 38. Water velocities and sediment depths at Younger, 5/20/99.

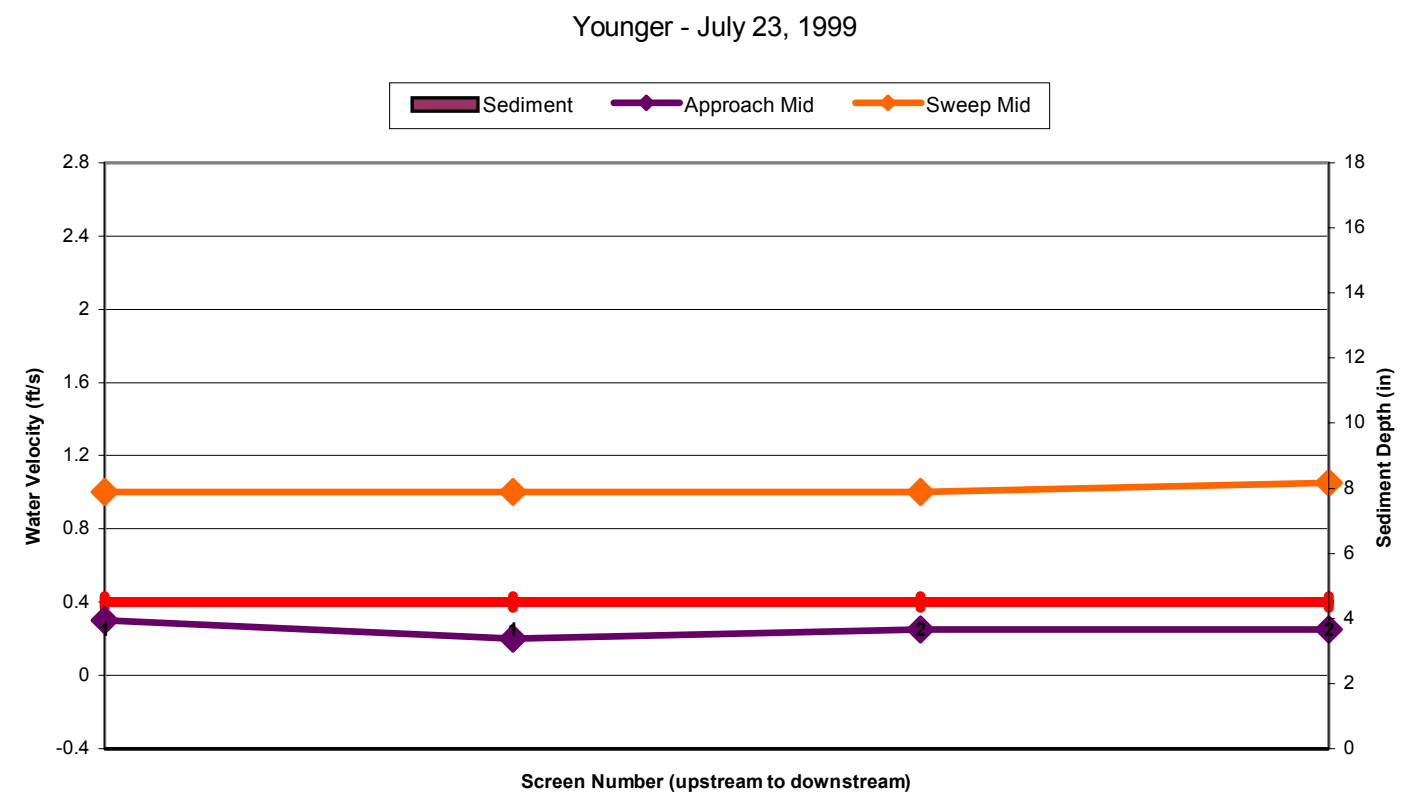

Figure 39. Water velocities and sediment depths at Younger, 7/23/99. 


\section{Vertical Traveling Screen}

\section{Gleed}

The Gleed site was evaluated 5/14/99 and 7/20/99. Electrical interference again prevented us from collecting much water velocity data. The velocity data we were able to collect (Figure 40) was limited, but showed some high approach velocities.

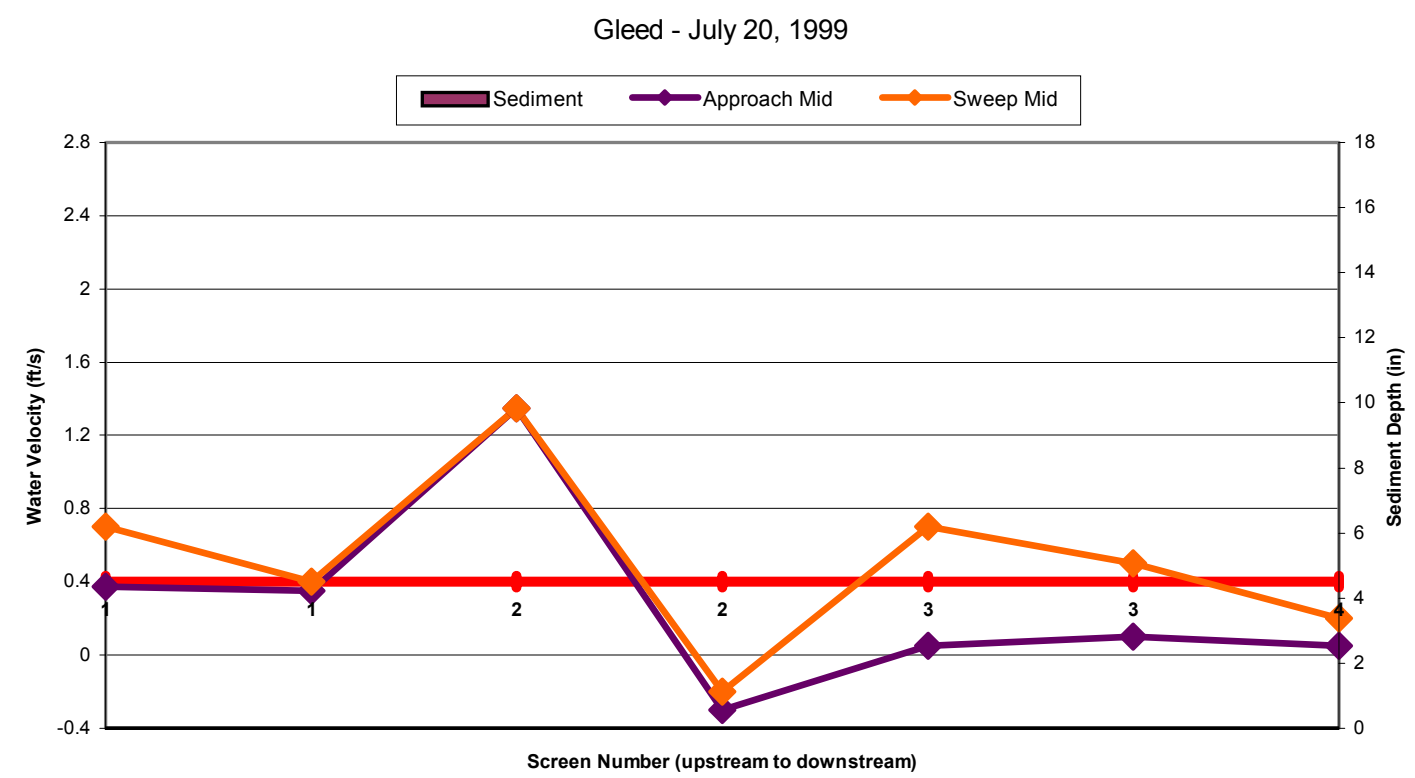

Figure 40. Water velocities and sediment depths at Gleed, 7/20/99.

About $14 \%$ of the approach velocities at Gleed exceeded $0.4 \mathrm{fps}$. Sweep velocities averaged higher than approach velocities, but not by too much. Debris was not a problem at the Gleed site in May, but there was an accumulation of sticks/leaves and a large log in front of Screens 1 and 2 in July. Screen submergence was 77\% on July 20 and was not measured on May 14, 1999. Screen condition was generally good. Screens 1 and 2 had patches and Screens 3 and 4 had been replaced with nylon material. Seals looked goo; however, there was debris along the seal on Screens 3 and 4. Silt did not accumulate at this site. 


\section{References}

Abernethy, C.S., D.A. Neitzel, and W.V. Mavros. 1996. Movement and Injury Rates for Three Life Stages of Spring Chinook Salmon Oncorhynchus tshawytscha: A Comparison of Submerged Orifices and an Overflow Weir for Fish Bypass in a Modular Rotary Drum Fish Screen. Prepared by the Pacific Northwest National Laboratory for the Division of Fish and Wildlife, Bonneville Power Administration, Portland, Oregon.

Abernethy, C.S., D.A. Neitzel, and E.W. Lusty. 1990. Velocity Measurements at Three Fish Screen Facilities in the Yakima River Basin, Washington, Summer 1989. Prepared by the Pacific Northwest Laboratory for the Division of Fish and Wildlife, Bonneville Power Administration, Portland, Oregon.

Blanton, S.L., D.A. Neitzel, and C.S. Abernethy. 1998. Washington Phase II Fish Diversion Screen Evaluations in the Yakima River Basin, 1997. Prepared by the Pacific Northwest National Laboratory for the Division of Fish and Wildlife, Bonneville Power Administration, Portland, Oregon.

Blanton, S.L., G.A. McMichael, and D.A. Neitzel. 1999. Washington Phase II Fish Diversion Screen Evaluations in the Yakima River Basin, 1998. Prepared by the Pacific Northwest National Laboratory for the Division of Fish and Wildlife, Bonneville Power Administration, Portland, Oregon.

Bryant, F.G., and Z.E. Parkhurst. 1950. Survey of the Columbia River and its tributaries; Part 4: Area III Washington streams from the Klickitat and Snake Rivers to Grand Coulee Dam, with notes on the Columbia and its tributaries above Grand Coulee Dam. U.S. Fish and Wildlife Service Special Scientific Report: Fisheries No. 37.

National Marine Fisheries Service (NMFS). 1995. Juvenile Fish Screen Criteria. National Marine Fisheries Service Environmental \& Technical Services Division, Portland, Oregon.

Neitzel, D.A., S.L. Blanton, C.S. Abernethy, and D.S. Daly. 1997. Movement of Fall Chinook Salmon Fry Oncorhynchus tshawytscha: A Comparison of Approach Angles for Fish Bypass in a Modular Rotary Drum Fish Screen. Prepared by the Pacific Northwest National 
Laboratory for the Environment, Fish and Wildlife Division, Bonneville Power Administration, Portland, Oregon.

Neitzel, D.A., C.S. Abernethy, and E.W. Lusty. 1990a. A Fisheries Evaluation of the Toppenish Creek, Wapato, and Sunnyside Fish Screening Facilities, Spring 1988. Prepared by the Pacific Northwest Laboratory for the Division of Fish and Wildlife, Bonneville Power Administration, Portland, Oregon.

Neitzel, D.A., C.S. Abernethy, and E.W. Lusty. 1990b. A Fisheries Evaluation of the Westside Ditch and Wapato Canal Fish Screening Facilities, Spring 1989. Prepared by the Pacific Northwest Laboratory for the Division of Fish and Wildlife, Bonneville Power Administration, Portland, Oregon.

Neitzel, D.A., C.S. Abernethy, E.W. Lusty, and S.J. Wampler. 1988. A Fisheries Evaluation of the Richland and Wapato Canal Fish Screening Facilities, Spring 1987. Prepared by the Pacific Northwest Laboratory for the Division of Fish and Wildlife, Bonneville Power Administration, Portland, Oregon.

Neitzel, D.A., C.S. Abernethy, and E.W. Lusty. 1986. A Fisheries Evaluation of the Richland and Toppenish/Satus Fish Screening Facilities, Spring 1986. Prepared by the Pacific Northwest Laboratory for the Division of Fish and Wildlife, Bonneville Power Administration, Portland, Oregon.

Neitzel, D.A., C.S. Abernethy, E.W. Lusty, and L.A. Prohammer. 1985. A Fisheries Evaluation of the Sunnyside Canal Fish Screening Facility, Spring 1985. Prepared by the Pacific Northwest Laboratory for the Division of Fish and Wildlife, Bonneville Power Administration, Portland, Oregon.

Northwest Power Planning Council (NPPC). 1994. Fish and Wildlife Program: Measure 7.10. Northwest Power Planning Council, Portland, Oregon.

Northwest Power Planning Council (NPPC). 1987. Fish and Wildlife Program: 1403.4. Northwest Power Planning Council, Portland, Oregon. 
Northwest Power Planning Council (NPPC). 1984. Fish and Wildlife Program: Measure 704(d). Northwest Power Planning Council, Portland, Oregon. 